\title{
RETAIL INNOVATIONS - THE USER ACCEPTANCE OF MOBILE SERVICE TECHNOLOGIES AND THE EFFECT ON RETAILER
}

\author{
Dissertation \\ zur Erlangung des Doktorgrades der Wirtschaftswissenschaftlichen Fakultät \\ der Georg-August-Universität Göttingen
}

vorgelegt von

Katrin Kallweit M.Sc.

geboren in Halle an der Saale 


\section{Betreuungsausschuss und Prüfungskommission}

Erstbetreuer:

Zweitbetreuer:

Drittbetreuer:

\author{
Prof. Dr. Waldemar Toporowski \\ Professur für Handelsbetriebslehre \\ Georg-August-Universität Göttingen \\ Platz der Göttinger Sieben 3 \\ 37073 Göttingen
}

Prof. Dr. Yasemin Boztuğ

Professur für Marketing und Konsumentenforschung

Georg-August-Universität Göttingen

Platz der Göttinger Sieben 3

37073 Göttingen

Prof. Dr. Lutz M. Kolbe

Professur für Informationsmanagement

Georg-August-Universität Göttingen

Platz der Göttinger Sieben 3

37073 Göttingen 


\section{Acknowledgements}

This doctoral thesis was written during my time as an external doctoral student at the Chair of Retailing at the Georg-August-Universität Göttingen. It has been a period of intense learning, definitely in the scientific arena but even more for myself on a personal level. I would like to reflect on the people who have been a tremendous help and showed incredible support throughout the entire time, which is something I am genuinely grateful for and always will be.

First and foremost I would like to express my sincere gratitude to my advisor, Prof. Dr. Waldemar Toporowski, for the continuous support of my research, for his patience and especially for his motivation to be an outstanding doctor father from the very beginning to the end. His guidance was crucial during all the time of research and writing of this thesis. Furthermore, I would like to thank my second examiner, Prof. Dr. Yasemin Boztug. She already supported during my master thesis and kindly agreed to write the second dissertation assessment about this doctoral thesis. I am also grateful that Professor Prof. Dr. Lutz M. Kolbe agreed to be my third examiner. Furthermore, I would like to send special thanks to my fellow "research mate" Dr. Philipp Spreer for the stimulating discussions, various overnight sessions during which we were working together towards deadlines, and above it all for the fun we have had during the last years of academic collaboration

A very special gratitude goes out to all down at the Rid Foundation (Munich), namely Michaela Pichlbauer and Peter Habit, for their valuable guidance I thoroughly appreciate. Moreover, I am also grateful to my employers over the last 6 years which have given me the freedom and support to follow through on my academic journey: 'elaboratum' (Munich), 'MaibornWolff (Munich)' and 'nexible' (Düsseldorf) including my current and former colleagues for the support I received and still receive to this very day. Also I would like to thank my friend and mentor over the last ten years, John-Paul Pieper, for his faith in my skills and for accepting nothing less than excellence from myself.

Getting through my dissertation required more than academic support, and I have many, many people who listened to my challenges with empathy, sharing a different viewpoint to put things into perspective or just an open ear when everthing simply seemed overwhelming in one of those moments. I am grateful for each minute all of you have spent and this acknowledgement section would not be enough, by far, 
to express my gratitude for deserving friendships like the ones we share. Therefore allow me to call out a special mention for each one of you:. Philipp Rauschanbel, Sandra Schatz, Johanna Auchtor, Christoph Kleine, Christina Stumpf, Michael Bauer, Lena Renke and Franziska Rödiger. Particular thanks goes to my best friend Tina, who is always on my side and prop me up during busy times with humor, wine and a lot of chocolate. I could never have done this without you! Last but not least, I would like to thank my family for their love and care throughout my life. 


\section{Table of Contents}

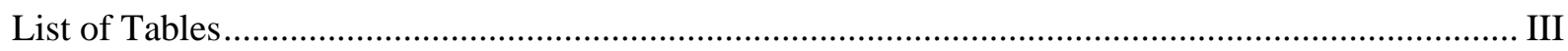

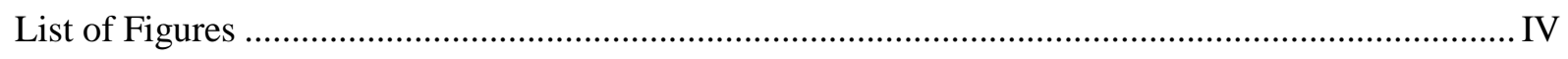

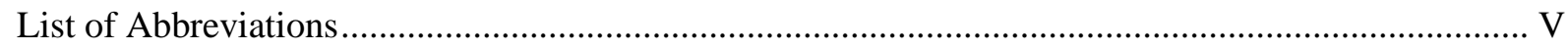

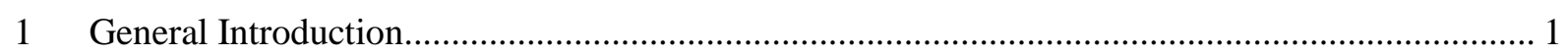

1.1 The relevance of Mobile Services in Retail Stores............................................................ 1

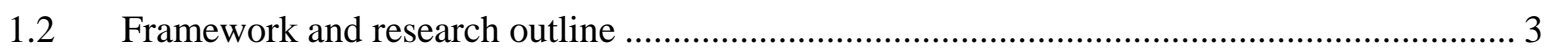

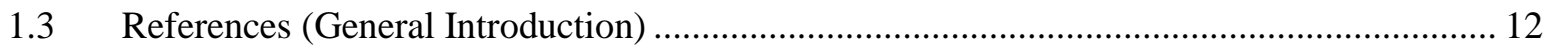

2 The relationship between mobile service acceptance and store patronage intention (Study 1) .... 16

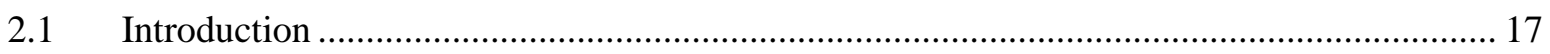

2.2 Conceptual Background and Hypothesis Development ................................................... 19

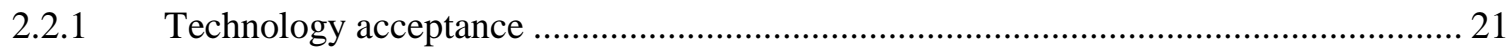

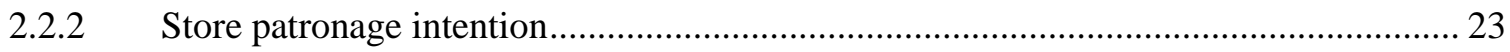

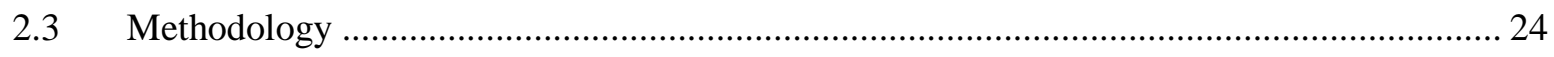

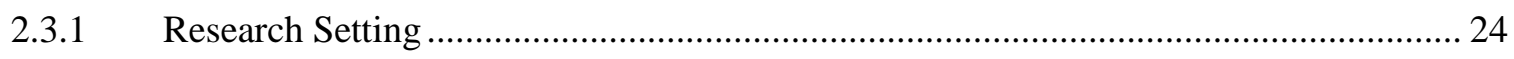

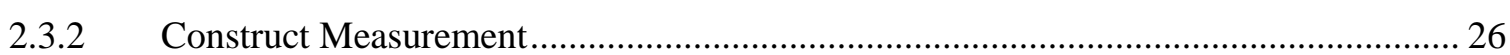

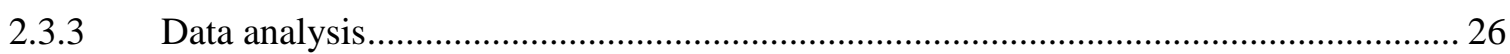

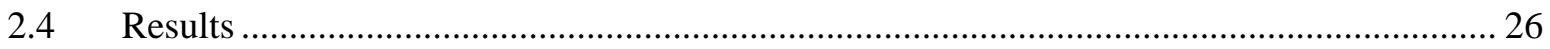

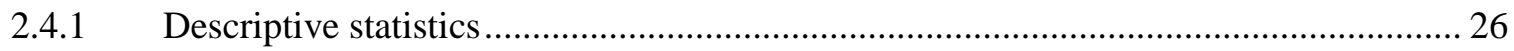

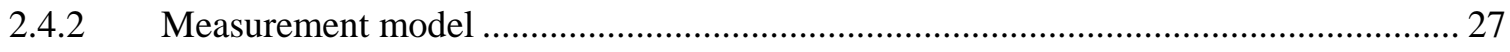

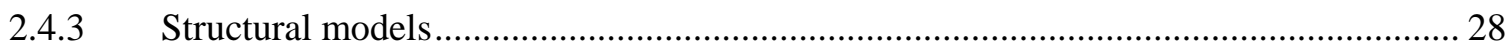

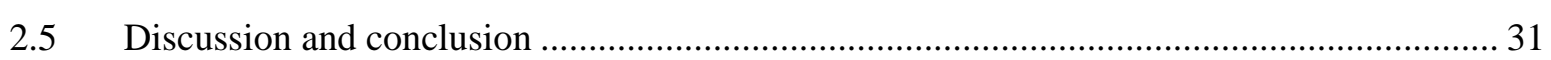

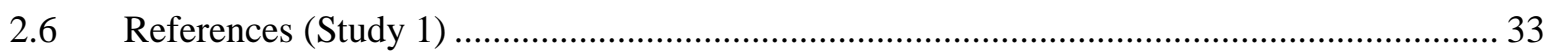

3 Why do Customers Use Self-Service Information Technologies in Retail? The Mediating Effect of

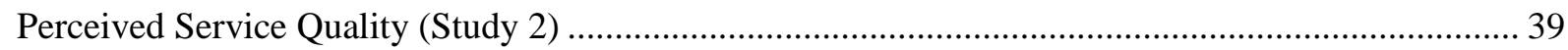

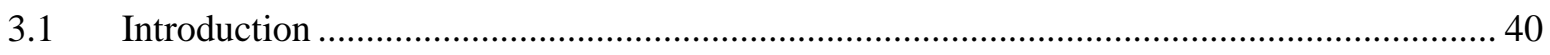

3.1.1 Self-service technologies with focus on information .............................................. 40

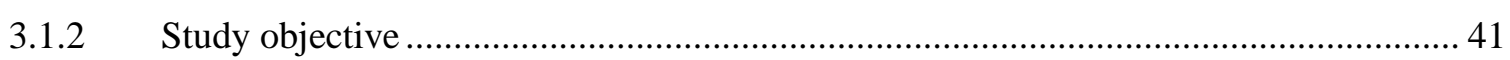

3.2 Conceptual Framework and Hypothesis Development ................................................... 42

3.2.1 Acceptance of Self-Service Technologies ..................................................................... 43

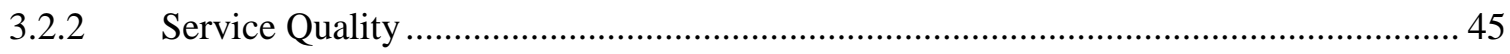

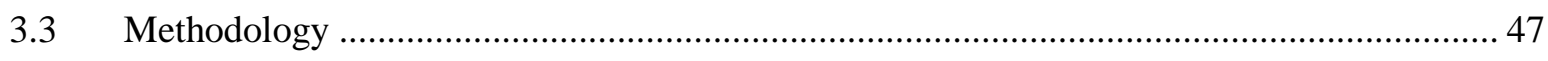

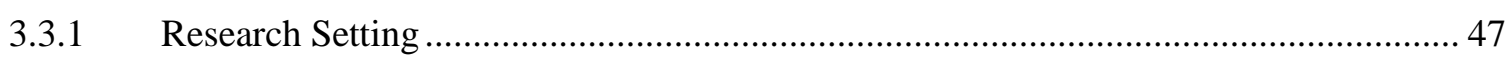

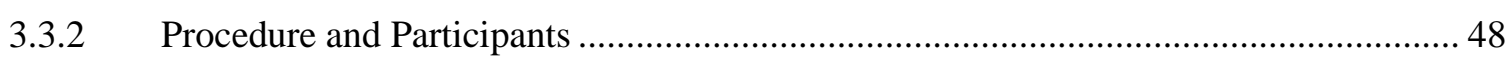

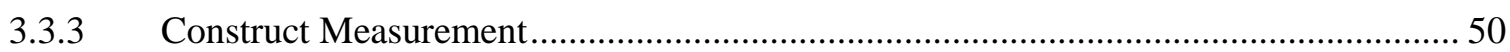

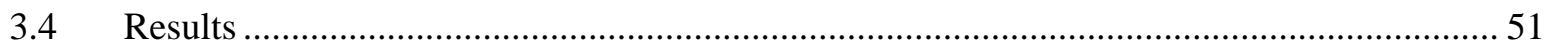




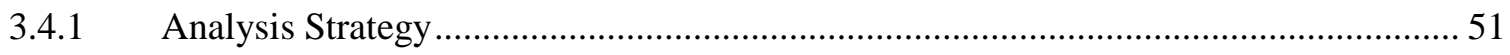

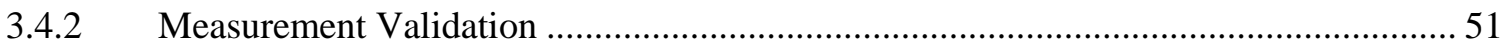

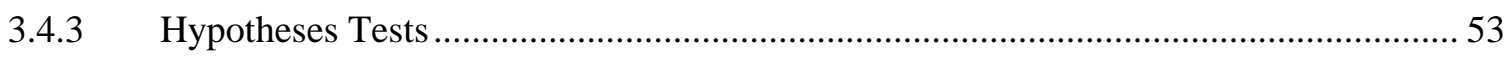

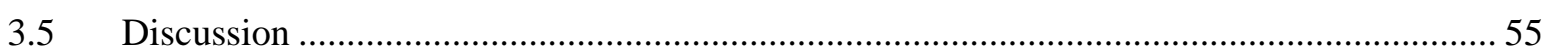

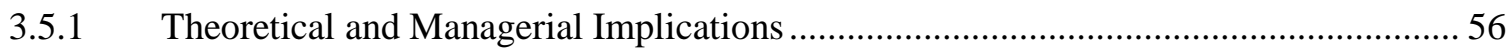

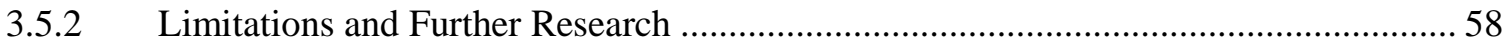

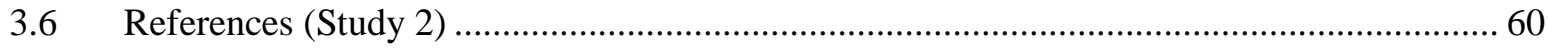

4 Exploring Customer Segments based on the Acceptance of Self-Service Technologies in Retailing

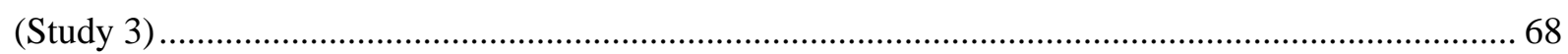

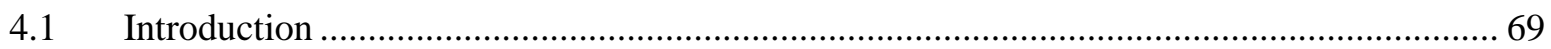

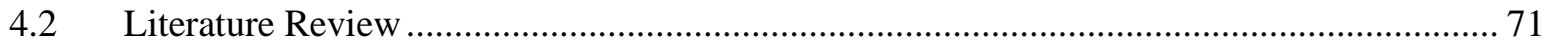

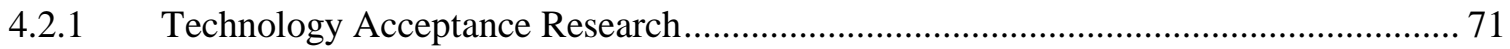

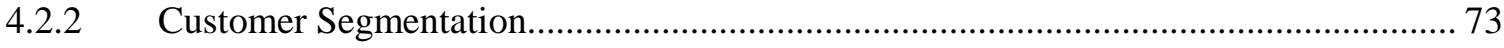

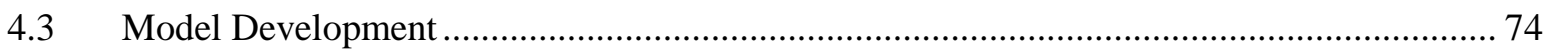

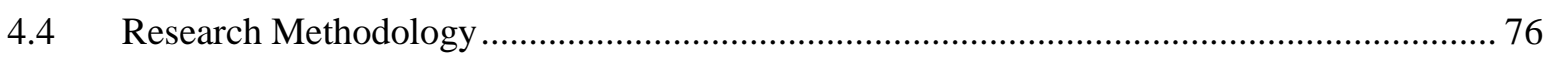

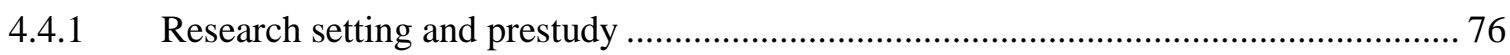

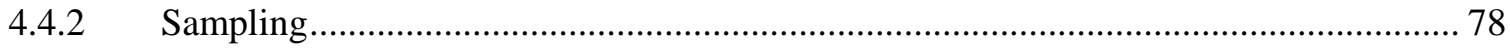

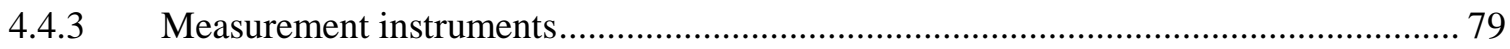

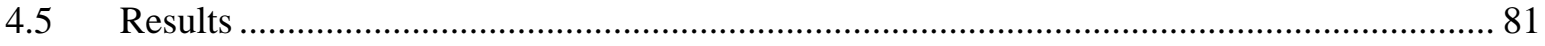

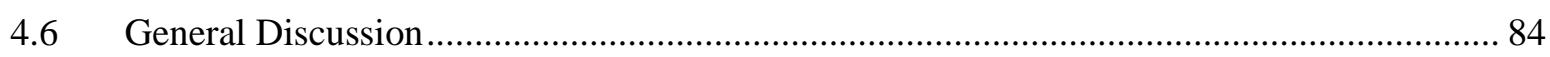

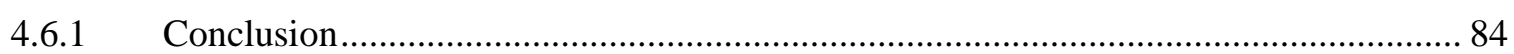

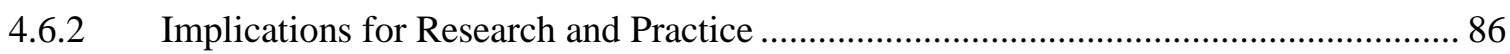

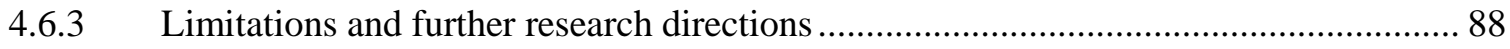

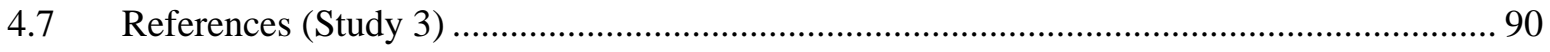

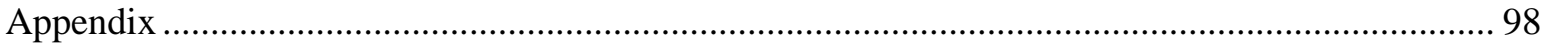

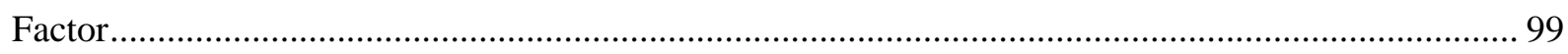

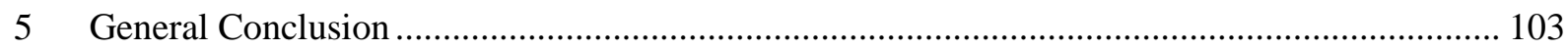

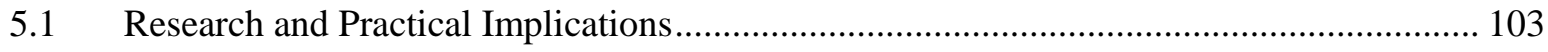

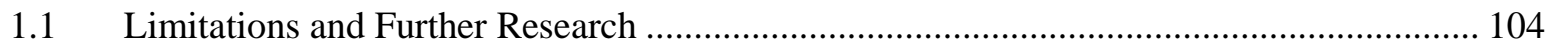

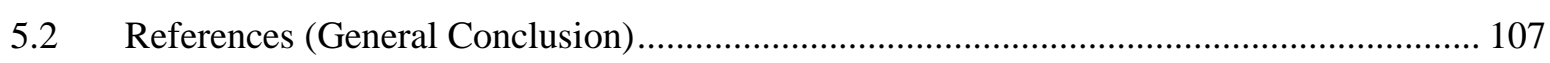

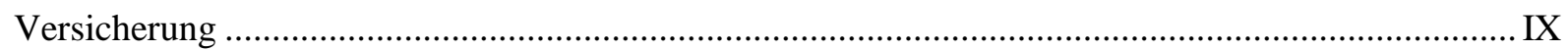

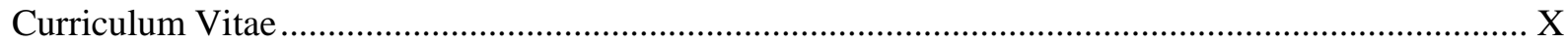




\section{List of Tables}

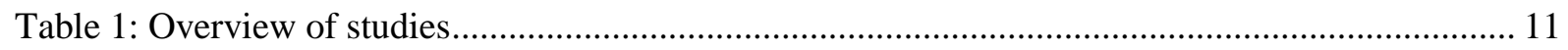

Table 2: Empirical research of retailing service technologies acceptance .......................................... 20

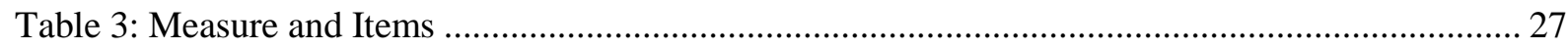

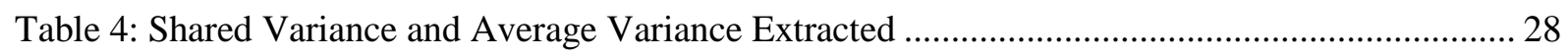

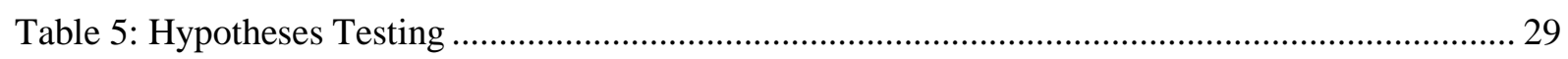

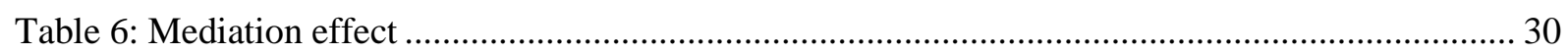

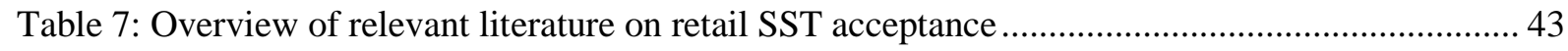

Table 8: Functionalities of the application used in the experiment ................................................... 50

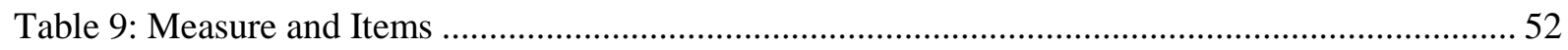

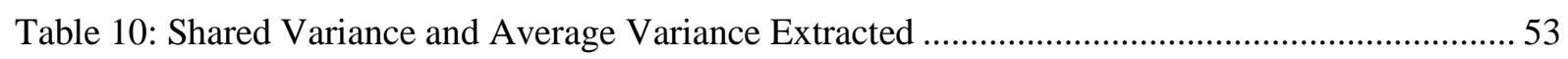

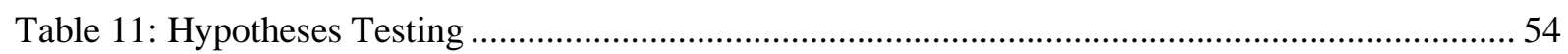

Table 12: Mediation effect of perceived service quality ...................................................................... 54

Table 13: Prior research overview on customer segmentation and technology acceptance .................. 73

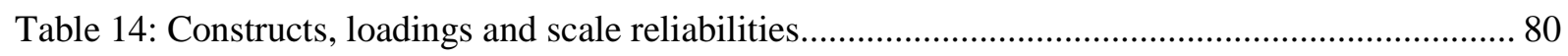

Table 15: Cluster centres and user characteristics of the end solution ................................................. 82

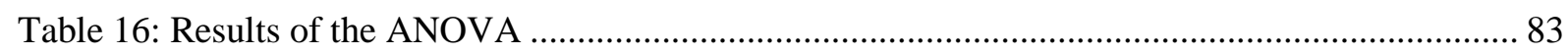

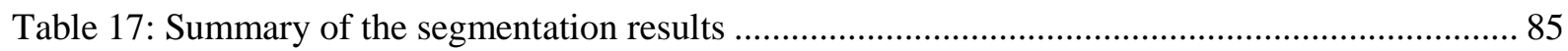




\section{List of Figures}

Figure 1: Mobile Service in the customer buying process (Puccinelli et al., 2009) ............................... 2

Figure 2: Innovations in retail (Sorescu, et al., 2011) ........................................................................ 4

Figure 3: Main literature pointing to retail innovations at the point of sale and research gap ................ 6

Figure 4: Overview of the conceptual framework (following Evanschitzky et al., 2015) ..................... 7

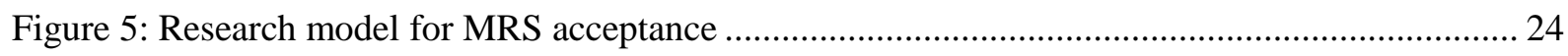

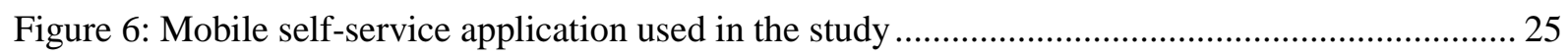

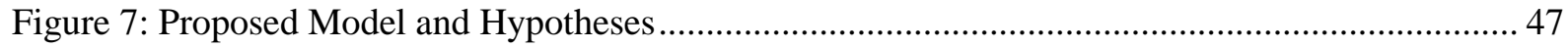

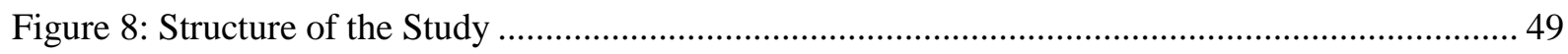

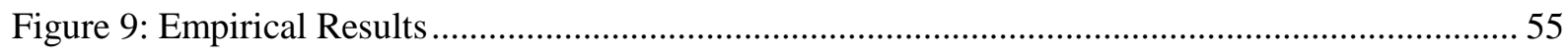

Figure 10: Underlying acceptance model for the segmentation ..................................................... 76

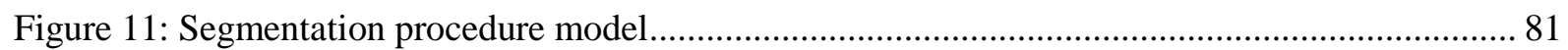




\section{List of Abbreviations}

AI

Adequacy of Information

ANOVA Analysis of Variance

ATU Attention to Use

AVE Average Variance Extracted

CFI Comparative Fit Index

C.R. Composite Reliability

d.f. $\quad$ Degrees of Freedom

DIY Do-It-Yourself

FPC Familiarity with the Product Category

$\mathrm{H} \quad$ Hypothesis

IR Intention to Reuse

IT Information Technology

MRS Mobile Retail Service

MSA Mobile Sales Assistant

n

Sample Size $n$.

pag. $\quad$ No Page Number

NFI Need for Interaction

NI Not investigated

No. Number

PC Personal Computer

PDA Personal Digital Assistant

PEOU Perceived Ease of Use

PIQ Perceived Information Quality

PLS Partial Least Squares 


\begin{tabular}{ll} 
PoS & Point of Sale \\
PSQ & Perceived Service Quality \\
PU & Perceived Usefulness \\
SD & Standard Deviation \\
SEM & Standardized Error \\
SL & Structural Equation Modeling \\
SPI & Standardized Loadings \\
SQ & Store Patronage Intention \\
SRMR & Service Quality \\
SSIT & Standardized Root Mean Square Residual \\
SST & Self-Service Information Technology \\
SV & Self-Service Technology \\
TAM & Shared Variance \\
TRA & Technology Acceptance Model \\
UTAUT & Unified Theory of Reasoned Action \\
\hline &
\end{tabular}




\section{General Introduction}

\subsection{The relevance of Mobile Services in Retail Stores}

Mobile internet devices like smartphones, wearables or Tablet PCs, have spread faster than most other technologies in human history (DeGusta, 2012). To put this into numbers: By 2017, 2.3 billion people are using smartphones. Therefore, the amount of people who have access to information, entertainment and social media everywhere is still growing (e.g. Blázquez, 2014). This has a considerable influence on the customer's shopping behavior in the physical retail store: Switching between channels in the buying process has become commonplace (Hudetz et al., 2011). Smartphone usage while shopping provides a high level of convenience as well as an improved service experience by offering additional product information such as reviews, product ratings or rich media content, especially in the prepurchase phase, where the access to information plays a decisive role.

Those changes in shopping behavior have generated a powerful environment to generate a new kind of customer experience (Spaid \& Flint, 2014). Physical stores are gaining a new significance since they are now the connection between traditional and digital channels (Cao, 2014). A study by McKinsey \& Company found that primary contact with a retailer is made via digital touchpoints, in most cases (Banfi et al., 2013). It is therefore unsurprising that most of the traditional retailers integrate all of their channels consistently and according to the digital needs of the customer. For this purpose, a successive extension of the point of sale $(\mathrm{PoS})$ digitalization using smart retail technologies is taking place (Lee \& Yang, 2013). Particularly, using the smartphone as a single point of contact to interact with the customer in the store seems very promising to get a comprehensive picture of the consumer and to improve the in-store experience in order to reduce the risk of losing the customer during their shopping trip (Peltola et al., 2015).

When speaking of mobile services in the retail environment, in the understanding of this thesis, we mean systematic use of mobile devices in a physical store to support the shopping process and to improve the customer experience. Mobile services are able to offer an interactive service as the customer evaluates different offers or considers possible solutions (Shankar et al., 2016). More specifically, it is a system 
for the consumers on mobile devices (Smartphone or Tablet PCs), providing interactive content and services in the context of indoor shopping (Panatnao \& Viassone, 2014). Additionally, it serves as a mediation technology between retailers and their customers, providing an added value to both of them by addressing the service related issues of a traditional store.

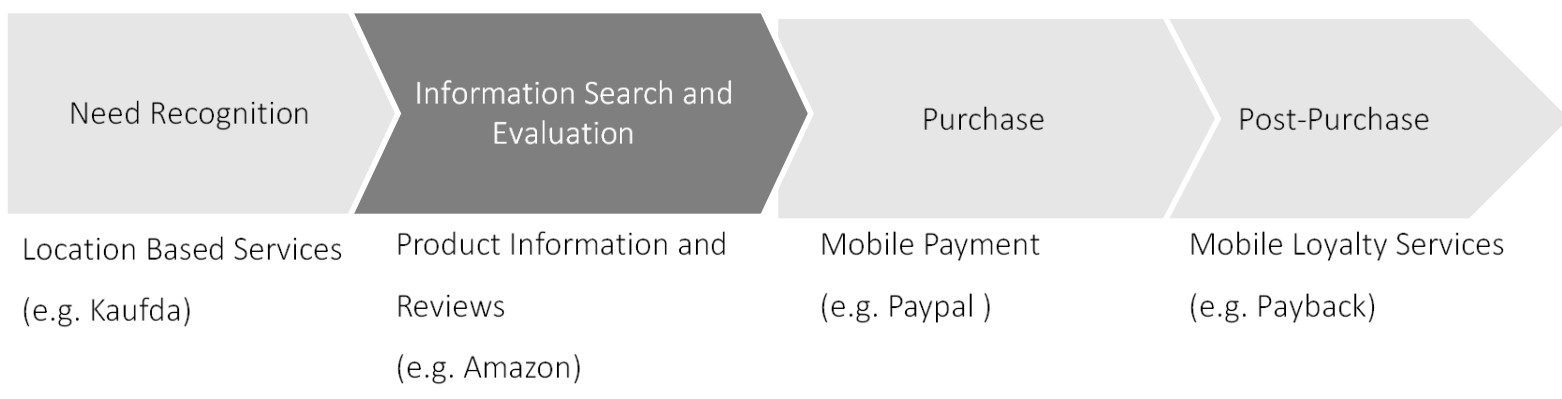

Figure 1: Mobile Service in the customer buying process (Puccinelli et al., 2009)

Retailers try to offer an additional service within their traditional business models in order to build up a customer-friendly service landscape. Figure 1 shows an overview of an exemplary mobile service, which supports the various purchase phases during the customer buying process at the PoS. For example, the retailer can use Location Based Services like Kaufda to increase the frequency of visits to the shop or mobile loyalty services like Payback to increase the number of visits. This makes the shopping easier, faster and more comfortable.

From a retailer's perspective, the information search phase is particularly critical because customers are increasingly using their smartphones to search for product reviews or ratings, price comparisons and videos or other content. Besides the convenience of mobile search as the main driver of usage, the sense of immediacy also makes it attractive for customers (Shankar et al., 2016). Such features are particularly interesting for people who are looking for a high level of individual control and want to avoid interpersonal interactions (Meuter, et al., 2003) or for those who have a low need for personal interaction (Gelderman, et al., 2011). Thus, it comes as no surprise that $82 \%$ of smartphone users turn to their devices while they are in a retail store (Mooney, 2015). Customers are using their smartphones as a new kind of shopping assistant, searching for prices and reviews, comparing products, scanning for coupons and promotions or staying in contact with friends via their preferred social network (e.g. Spaid \& Flint, 2014 or Verhoef et al., 2015). Moreover, the customer is quite independent of other determining factors, 
such as the availability of salespeople. For these reasons, the present work deals particularly with mobile service technologies supporting the customer during the information search and product comparison while shopping in-store.

\subsection{Framework and research outline}

As highlighted in the previous section, the usage of smartphones is on the brink of revolutionizing the way people shop and emphasizes the strategic importance of mobile services for retailers. Those innovations of business models beyond the borders of traditional retailing is indispensable and has to address the approach, which optimizes the direct interaction and enhances the customer experience (Grewal et al., 2009). This holds true especially for the customer interface design (e.g. in-store), as this is one of the most important responsibilities of a retailer within the value chain. The following section presents the theoretical classification of this thesis within the academic research of mobile services in the context of retailing.

Development in information and communication technologies especially for mobile devices has created new business models regarding point of sale technologies (Meuter et al., 2005). Sorescu et al. (2011) have developed a framework of innovations in retail (Figure 2) to provide a starting point for research and emphasize the need of empirical models to measure the effect on customer experience and retail performance (Sorescu et al., 2011).

Innovation approaches can be distinguished by their primary purpose (value creation and value appropriation) and identify three design themes for each of the two categories, as illustrated in Figure 2. Sorescu et al. (2011) stated that those innovations are mostly caused by two external drivers: the change in customer's values as well as technological developments. Looking at the technical trend in mobile technologies and the significant changes in the purchasing behavior of the customers as described in chapter 1.1, this is especially true for the role of mobile devices in the context of retailing at the point of sale. 


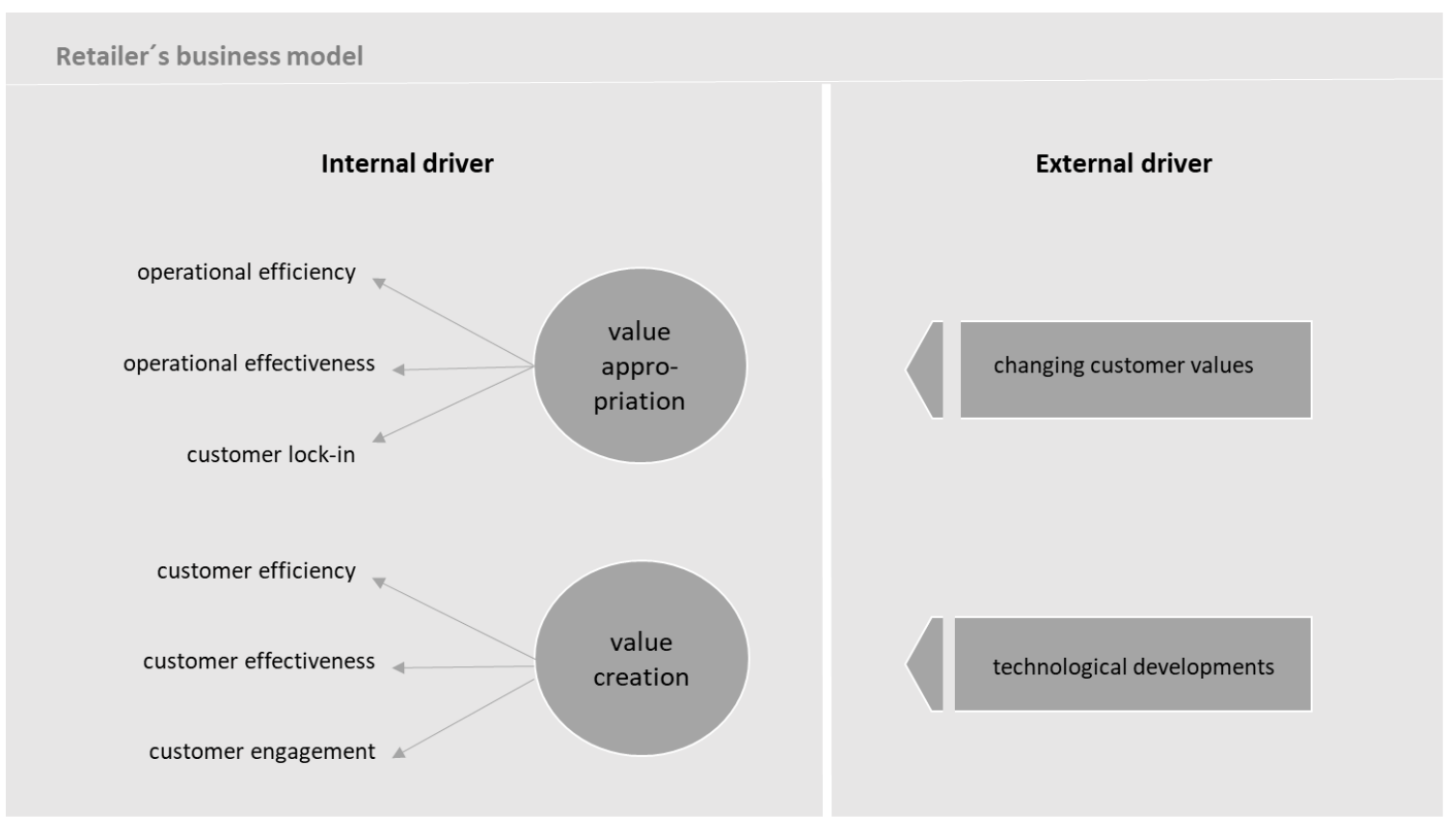

Figure 2: Innovations in retail (Sorescu, et al., 2011)

Concerning this matter, Shankar et al. (2016) has developed a framework specifically designed for mobile shopping in local stores and has identified several critical issues relating to mobile services across the different stages. The related research questions discussed in the paper deal with the reasonable application of mobile devices to best influence customers due to value creation on their path to purchase. Both emphasize the importance of further research on the potential of mobile services for users and retailers in an environment dominated by mobile devices (Hartfälder \& Winkelmann, 2016).

Many of the issues refer to the discovery and evaluation of products by the customer (Shankar et al., 2016). To increase the likelihood that a customer finds the product that truly meets his or her needs, mobile services can serve as a shopping assistant. Accordingly, this thesis deals with mobile services, which support the search and evaluation phase of the customer.

As already outlined in the previous section, the customers are taking on the role of enablers of innovation, as well as technology enabler (Larivière et al., 2017). Thus, the successful application of mobile service depends strongly on the evaluation and usage by the customers. For this reason, the acceptance of such a technology is a critical point for the selection of a suitable technology (Pantano, 2014). Avoiding the risk of failing by implementing such a system as the technology acceptance model 
by Davis (1989) is used to predict the acceptability of a given technology by the end user. Therefore, it also serves as a theoretical basis for the investigation of mobile service acceptance in this thesis.

Despite the increasing popularity of smartphones, the acceptance of mobile services in the context of a physical store environment is still a young field of research (Ström et al., 2014). Previous research on the acceptance has focused on fixed technologies such as self-service terminals (e.g. Weijters et al., 2007; Zielke et al., 2011; Wang, 2012; Lee \& Yang, 2013; Orel \& Kara, 2014; Kaushik \& Rahman, 2015). Whereas in-store systems have a limited mobility and are owned by the retailer (Pantano \& Viassone, 2014), mobile services are on the customer's smartphone and offer a service independent of time and place as well as a high potential for personalization (Ström et al., 2014) and can`t be equated.

Other research streams are focused on mobile systems owned by the retailer, like mobile recommendation agents (Kowatsch \& Maass, 2010) and mobile decision support systems (Heijden, 2006). These studies deal with mobile devices in the retail environment by focussing on "PDAs" and not state-of-the-art technologies like Smartphones or Tablet PCs and are hardly comparable to today's technical possibilities. Particularly, the usage of mobile services supporting the information search and evaluation in-store render customers independent of the availability and know-how of sales clerks and reduce the search cost by pooling all the relevant information available and providing it in a much more customized way (Pantano, 2013). As recommended by Hartfälder and Winkelmann (2016) all studies presented in this thesis are based on experiments with the latest technologies (Smartphone and Tablet PCs) and sophisticated software. Therefore, this thesis is going to contribute to the limited number of articles that relate to the acceptance of mobile services on the customer's device in-store regarding the research gap shown in Figure 3. 


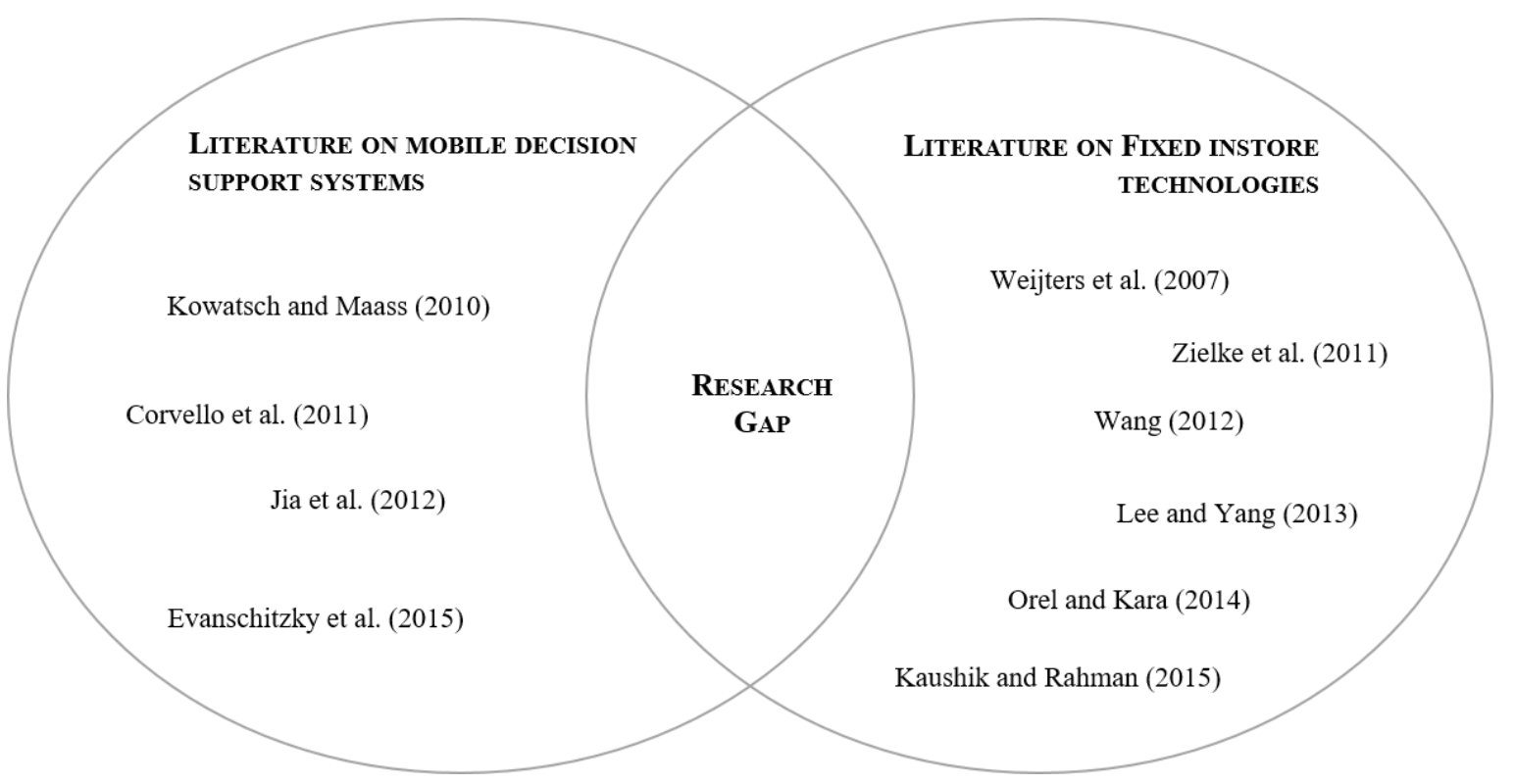

Figure 3: Main literature pointing to retail innovations at the point of sale and research gap

Furthermore, another part of the existing research in the context of mobile refers to the research stream of mobile commerce. However, this thesis focuses on shoppers' activities in-store regarding the search and discovery as well as the evaluation of products using a mobile device as a digital touchpoint, but does not deal with mobile advertising, mobile promotions or mobile gaming. Reference is made to Grewal et al. (2016) or Andrews et al. (2016) for a detailed discussion.

However, the advantages of mobile services are not limited to the customers' side. The Results of studies in the context of online shopping clearly show a strong relation between the technology acceptance and the behavioral intention toward the online retailer (Lee \& Yang, 2013). Therefore, it is even more surprising that the relationship between the attitude toward using a technology and the usage intention are rarely examined. Particularly, the impact of mobile service usage in-store on the perception of the retailer is of pivotal importance for both scholars and practitioners to understand how mobile services can be used to serve customers and extending the retailers' perspective to intensify their service orientation.

It is obvious that not all consumers will benefit immediately from innovations to the same degree. In reality, there are people who use their phone every five minutes and others who use it rarely. Additionally, the existing literature comes up with heterogeneous findings on the drivers of customer 
acceptance and the relationship among each other (e.g. Dabholkar \& Bagozzi, 2002; Simon \& Usunier, 2007). One suitable approach to address this criticism is to focus more intensely on different groups of users, following the assumption that a technology will not provide the same benefit to all users.

To address the presented challenges of mobile services in the retail environment, the following pages of this thesis cover:

(1) the analysis of the drivers of mobile service acceptance at the point of sale

(2) the relationship between acceptance and behavioral intention and

(3) the exploration of different segments based on their acceptance of mobile services.

The presented research in this thesis focuses on mobile services as a retailer initiative for value creation innovation (Sorescu et al., 2011) which support the customer information search and product evaluation in-store. The usage is driven by consumers evaluation of the technology, which has a crucial influence on retailer benefits (Evanschitzky et al., 2015). Therefore, the conceptual framework links mobile services to the consumer response as well as to the retailer benefit (Figure 4).
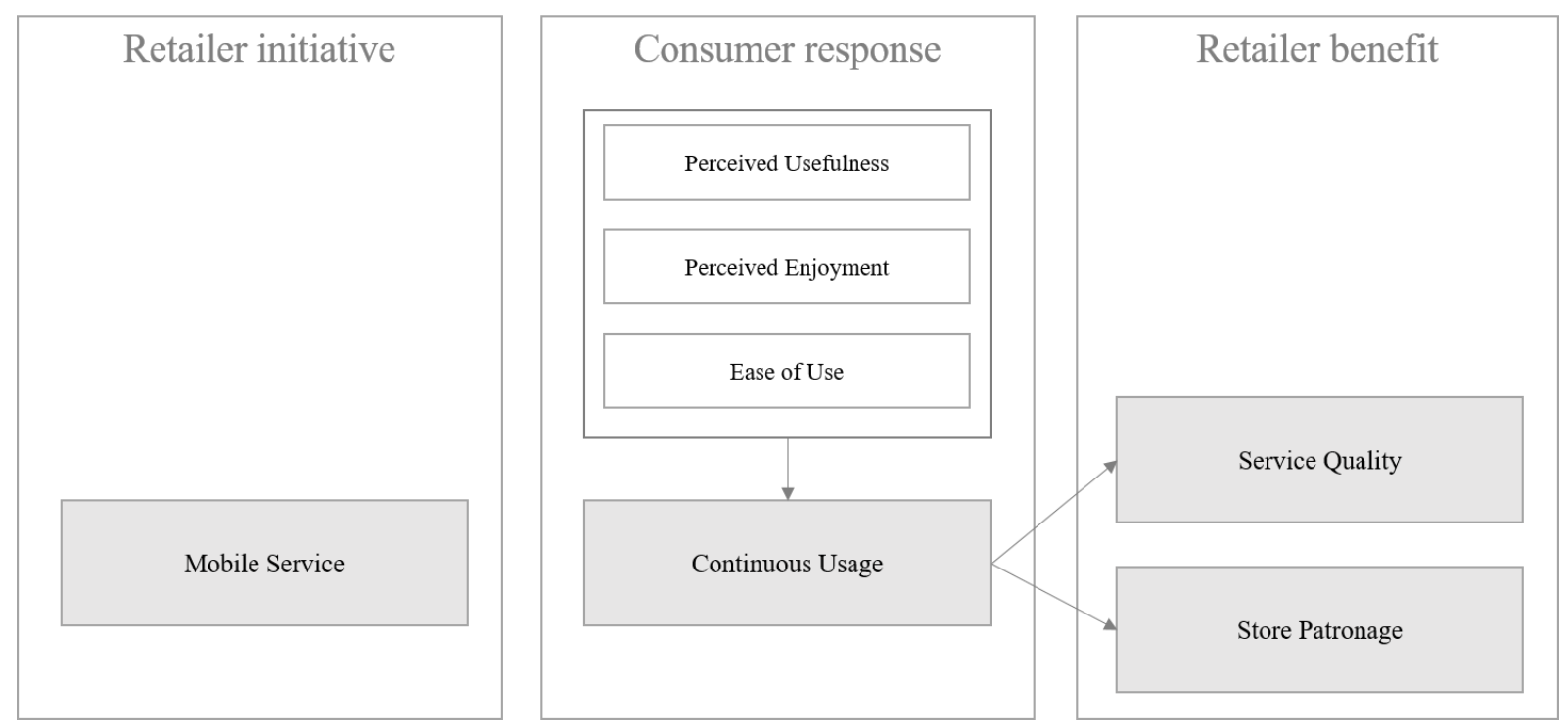

Figure 4: Overview of the conceptual framework (following Evanschitzky et al., 2015)

The investigated retail segments are characterized by a poor availability of sales clerks, with a large sales area and substantial need for information. More precisely, study 2 and study 3 consider the DIY branch and study 1 focuses on the consumer electronics. 
Study 1 draws attention to the main driver of acceptance of a mobile service using the technology acceptance model by Davis (1989). In particular, study 1 assesses the driver of continuous usage: perceived usefulness, perceived enjoyment and ease of use (Evanschitzky et al., 2015) including the hedonistic as well as the utilitarian aspects of the technology. Moreover, the study links the technology acceptance and the behavioral intention and shows the effect of interactive elements on retail patronage intentions.

\title{
Study 1: The relationship between mobile service acceptance and store patronage intention
}

\begin{abstract}
Services offered in a physical store is a major way of differentiation for companies and an important factor for customers to patronize a certain store. Among many other industries, this holds especially true for the retail environment, where access to digital information at the point of sale is already about to become a key success factor. The present study examines the mediation effect of store patronage within the technology acceptance model of mobile retail services (MRS). Building on data from a laboratory experiment using a fully functional application for smartphones, the partial least squares approach is applied. The acceptance of a MRS is influenced by utilitarian factors as well as by hedonic factors. Moreover, the findings reveal that the intention to use the technology fully mediates the effect of the attitude towards using on the retailer patronage. The results emphasize the strategic significance of mobile services for retailer.
\end{abstract}

Since the first study could prove that the proposed model is suitable to analyze the acceptance of mobile services as defined in this thesis, study 2 deepens the understanding of the utilitarian aspect of the technology as an important driver of usage. The results emphasize the value of information for the customer and the influence on the acceptance of mobile services. Besides, the paper sheds light on the role of service quality within the technology acceptance model. 
Study 2: Why do Customers Use Self-Service Information Technologies in Retail? The Mediating Effect of Perceived Service Quality

\begin{abstract}
To ensure a high level of service quality (SQ), retailers think about offering self-service information technologies (SSIT) at the point of sale. However, the explanatory value of the SQ for SSIT adoption is barely researched. Thus, the present study examines the mediation effect of SQ within the technology acceptance model. Building on data from a laboratory experiment using a fully functional application for Tablet PCs, the partial least squares approach is applied. The findings reveal that the perceived SQ partially mediates the effect of the attitude towards using on the intention to reuse. Therefore, retailers have to emphasize the service-related value of SSITs.
\end{abstract}

With these findings in mind, we assume that all consumers respond in the same way to innovations in retail. Study 3 identifies different segments based on the customer acceptance of mobile services. Based on the description of distinctive user clusters, the study also deduces important management implications for the implementation of mobile service technologies. 


\title{
Study 3: Exploring Customer Segments based on the Acceptance of Self-Service Technologies in Retailing
}

\begin{abstract}
Technology acceptance is one of the key factors in the successful implementation and usage of service technologies. However, technologies will neither provide the same benefit nor be used by all users and therefore need to address the specific needs of the target group. While previous studies on technology acceptance barely differentiated between users, this paper explores user segments based on technology acceptance constructs - a novel approach. Building on data from a laboratory study using a retail self-service technology prototype, a cluster analysis is employed, the results of which are two distinct segments which provide the basis for a meaningful customer approach.
\end{abstract}

Table 1 below summarizes the research goals and contains an overview of the samples, variables and methods of the three studies in this thesis. 


\begin{tabular}{|c|c|c|c|}
\hline 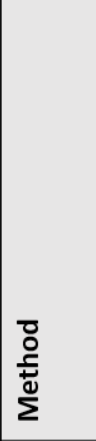 & 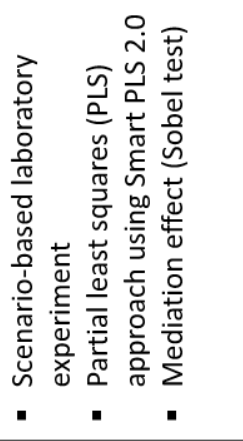 & 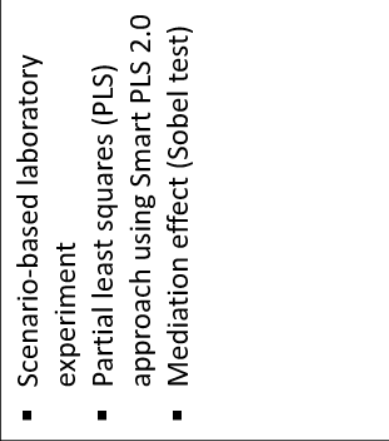 & 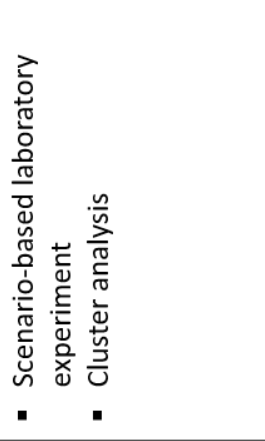 \\
\hline 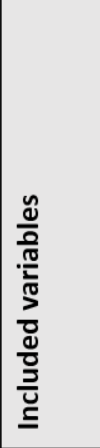 & 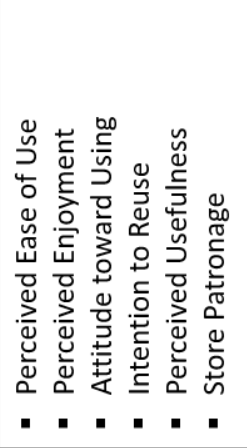 & 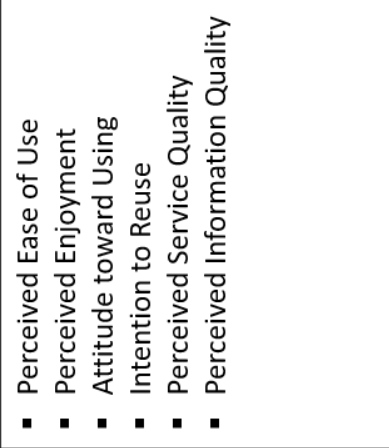 & 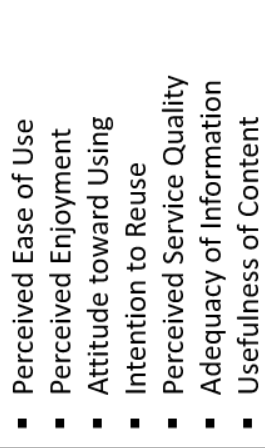 \\
\hline 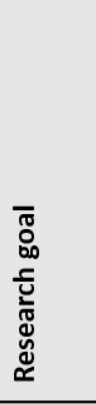 & 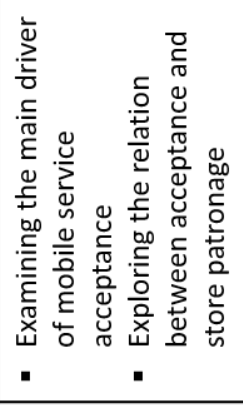 & 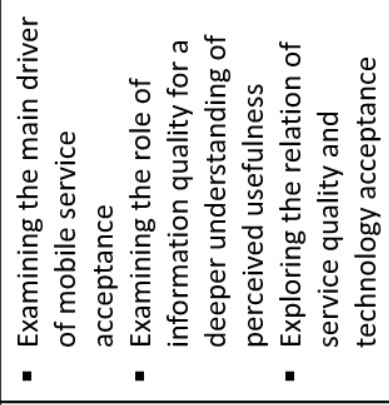 & 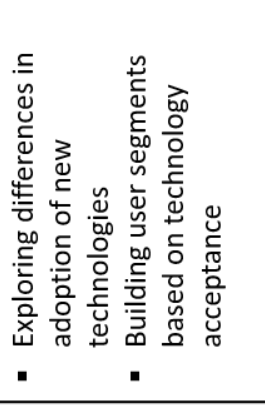 \\
\hline 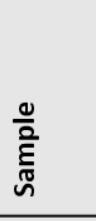 & 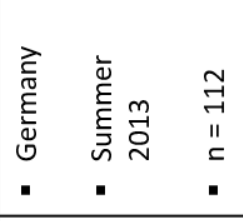 & 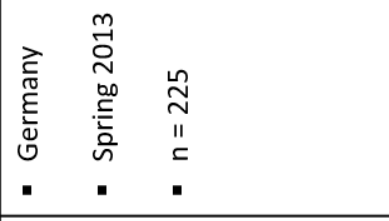 & \\
\hline 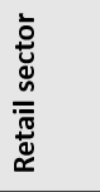 & 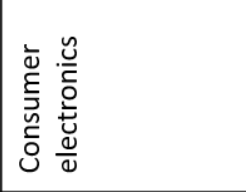 & 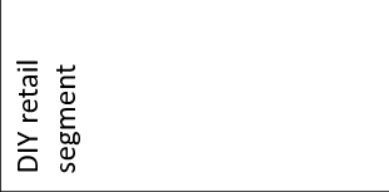 & \\
\hline 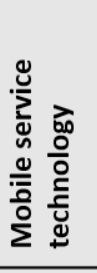 & 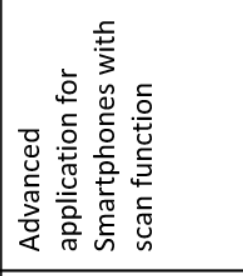 & 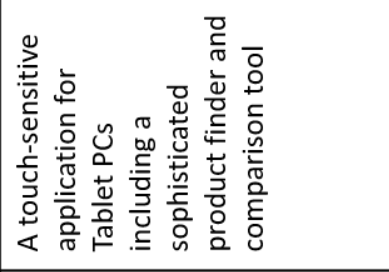 & \\
\hline $\begin{array}{l}\text { 를 } \\
\text { in }\end{array}$ & $\begin{array}{l}\overrightarrow{1} \\
\stackrel{2}{0} \\
\dot{\vec{z}} \\
\dot{n}\end{array}$ & 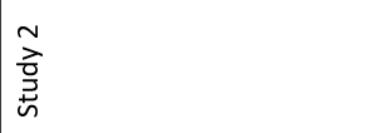 & 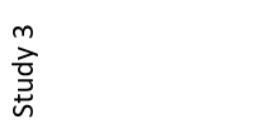 \\
\hline
\end{tabular}

Table 1: Overview of studies 


\subsection{References (General Introduction)}

Baker, J., Parasuraman, A., Grewal, D., \& Voss, G. B. (2002). The influence of multiple store environment cues on perceived merchandise value and patronage intentions. Journal of Marketing, 66(2), 120-141.

Blázquez, M. (2014). Fashion shopping in multichannel retail: The role of technology in enhancing the customer experience. International Journal of Electronic Commerce, 18(4), 97-116.

Cao, L. (2014). Business model transformation in moving to a cross-channel retail strategy: A case study. International Journal of Electronic Commerce, 18(4), 69-96.

Dabholkar, P. A., \& Bagozzi, R. P. (2002). An attitudinal model of technology-based self-service: moderating effects of consumer traits and situational factors. Journal of the Academy of Marketing Science, 30(3), 184-201.

Davis, F.D. (1989). Perceived usefulness, perceived ease of use, and user acceptance of information technology. MIS Quarterly, 13(3), 319-340.

DeGusta M (2012). Are Smart Phones Spreading Faster than Any Technology in Human History? http://www.technologyreview.com/news/427787/are-smart-phones-spreading-faster-thananytechnology-in-human-history. Last request 21.08.2017.

Evanschitzky, H., Iyer, G. R., Pillai, K. G., Kenning, P., \& Schütte, R. (2015). Consumer trial, continuous use, and economic benefits of a retail service innovation: the case of the personal shopping assistant. Journal of Product Innovation Management, 32(3), 459-475.

Gelderman, C. J., Paul, W. T., \& Van Diemen, R. (2011). Choosing self-service technologies or interpersonal services - The impact of situational factors and technology-related attitudes. Journal of Retailing and Consumer Services, 18(5), 414-421.

Grewal, D., Levy, M., \& Kumar, V. (2009). Customer experience management in retailing: an organizing framework. Journal of Retailing, 85(1), 1-14. 
Härtfelder, J., \& Winkelmann, A. (2016). Opportunities and challenges for local retailing in an environment dominated by mobile internet devices - literature review and gap analysis. Multikonferenz Wirtschaftsinformatik (MKWI).

Heijden, H.v.d. (2006). Mobile decision support for in-store purchase decisions. Decision Support Systems, 42(2), 656-663.

Hudetz, K., Hotz, A., \& Strothmann, S. (2011). Von Multi-Channel zu Cross-Channel: Konsumentenverhalten im Wandel; eine Studie des E-Commerce-Center-Handel (EEC-Handel) über das sich verändernde Informations - und Kaufverhalten der Konsumenten in Zusammenarbeit mit der hybris-GmbH. Inst. f. Handelsforschung.

Kaushik, A. K., \& Rahman, Z. (2015). An alternative model of self-service retail technology adoption. Journal of Services Marketing, 29(5), 406-420.

Larivière, B., Bowen, D., Andreassen, T.W., Kunz, W., Sirianni, N.J., Voss, C., Wünderlich, N.V., \& De Keyser, A. (2017). “Service Encounter 2.0”: An investigation into the roles of technology, employees and customers. Journal of Business Research, 79, 238-246.

Lee, H.J., \& Yang, K. (2013). Interpersonal service quality, self-service technology (SST) service quality, and retail patronage. Journal of Retailing and Consumer Services, 20(1), 51-57.

Meuter, M.L., Ostrom, A.L., Bitner, M.J., \& Roundtree, R. (2003). The influence of technology anxiety on consumer use and experiences with self-service technologies. Journal of Business Research, 56 (11), 899-906.

Meuter, M. L., Bitner, M. J., Ostrom, A. L., \& Brown, S. W. (2005). Choosing among alternative service delivery modes: An investigation of customer trial of self-service technologies. Journal of Marketing, 69(2), 61-83.

Mooney, A., \& Johnsmeyer, B. (2015). I-Want-to-Buy Moments: How Mobile Has Reshaped the Purchase Journey, https://www.thinkwithgoogle.com/marketing-resources/micro-moments/i-want-tobuy-moments/, Last request 21.08.2017. 
Orel, F. D., \& Kara, A. (2014). Supermarket self-checkout service quality, customer satisfaction, and loyalty: Empirical evidence from an emerging market. Journal of Retailing and Consumer Services, 21(2), 118-129.

Pantano, E., \& Viassone, M. (2014). Demand pull and technology push perspective in technology-based innovations for the points of sale: The retailers evaluation. Journal of Retailing and Consumer Services, 21(1), 43-47.

Pantano, E. (2013). Ubiquitous retailing Innovative Scenario: from the fixed point of sale to the flexible ubiquitous store. Journal of Technology Management \& Innovation, 8(2), 84-92.

Saarijärvi, H., Mitronen, L., \& Yrjölä, M. (2014). From selling to supporting-Leveraging mobile services in the context of food retailing. Journal of Retailing and Consumer Services, 21(1), 26-36.

Shankar, V., Kleijnen, M., Ramanathan, S., Rizley, R., Holland, S., \& Morrissey, S. (2016). Mobile shopper marketing: Key issues, current insights, and future research avenues. Journal of Interactive Marketing, 34(C), 37-48.

Simon, F., \& Usunier, J. C. (2007). Cognitive, demographic, and situational determinants of service customer preference for personnel-in-contact over self-service technology. International Journal of Research in Marketing, 24(2), 163-173.

Sorescu, A., Frambach, R. T., Singh, J., Rangaswamy, A., \& Bridges, C. (2011). Innovations in retail business models. Journal of Retailing, 87, S3-S16.

Spaid, B. I., \& Flint, D J (2014). The meaning of shopping experiences augmented by mobile internet devices. Journal of Marketing Theory \& Practice, 22(1), 73-90.

Ström, R., Vendel, M., \& Bredican, J. (2014). Mobile marketing: A literature review on its value for consumers and retailers. Journal of Retailing and Consumer Services, 21(6), 1001-1012.

Peltola, S., Vainio, H., \& Nieminen, M. (2015). Key factors in developing omnichannel customer experience with finnish retailers. In HCI in Business, volume 9191 of Lecture Notes in Computer Science, 335-346. 
Puccinelli, N. M., Goodstein, R. C., Grewal, D., Price, R., Raghubir, P., \& Stewart, D. (2009). Customer experience management in retailing: understanding the buying process. Journal of Retailing, 85(1), 1530.

Wang, M. C. H. (2012). Determinants and consequences of consumer satisfaction with self-service technology in a retail setting. Managing Service Quality, 22(2), 128-144.

Weijters, B., Rangarajan, D., Falk, T., \& Schillewaert, N. (2007). Determinants and outcomes of customers' use of self-service technology in a retail setting. Journal of Service Research, 10(1), 3-21.

Verhoef, P. C., Kannan, P., \& Inman, J. J. (2015). From multi-channel retailing to omnichannel retailing: Introduction to the special issue on multi-channel retailing. Journal of Retailing, 91(2), 174-181.

Zielke, S., Toporowski, W., \& Kniza, B. (2011). Customer acceptance of a new interactive information terminal in grocery retailing. In Pantano, E. \& Timmermans, H. (Eds.). Advanced Technologies Management for Retailing, 289-305. 


\title{
2 The relationship between mobile service acceptance and store patronage intention (Study 1)
}

\begin{abstract}
Services offered in a physical store is a major way of differentiation for companies and an important factor for customers to patronize a certain store. Among many other industries, this holds especially true for the retail environment, where access to digital information at the point of sale is already about to become a key success factor. The present study examines the mediation effect of store patronage within the technology acceptance model of mobile retail services (MRS). Building on data from a laboratory experiment using a fully functional application for smartphones, the partial least squares approach is applied. The acceptance of a MRS is influenced by utilitarian factors as well as by hedonic factors. Moreover, the findings reveal that the intention to use the technology fully mediates the effect of the attitude towards using on the retailer patronage. The results emphasize the strategic significance of mobile services for retailer.
\end{abstract}




\subsection{Introduction}

The choice of a preferred retailer results from the evaluation of certain perceived retail store characteristics and the customer's own expectations (Engel et al., 1968). Research on the context of traditional stores has shown a strong relationship between store environment and the customers' intentions to patronize a store (e.g. Baker et al., 2002). Particularly, the findings of Lee et al. (2009) show evidence for the high relevance of service provided by sales person as a key to achieving retail patronage. Hence, services offered in a physical store are a major way of differentiation for retailers to turn visitors into returning customers and remain successful in competition (Sivadas \& Baker-Prewitt, 2000). As physical retail stores are usually limited in terms of their product information due to spatial restrictions as well as waiting time for service (Baker et al., 2002), customers show an increasing demand for technologies and the access to digital content supporting the shopping trip by saving time and offering more service and convenience (Pantano \& Viassone, 2014).

As a response of the reatiler, a successive extension of the point of sale (PoS) digitalization using instore retail technologies has already taken place (Lee \& Yang, 2013). Such technologies are for example fixed in-store systems with automated interfaces like digital signage, self-service encounter or interactive terminals (Weijters et al., 2007; Pantano, 2014). In the long term this is aiming at improvement in service quality (Lin \& Hsieh, 2011) as well as a higher customer satisfaction (Wang, 2012). The success is, however, limited by the restrictions on the amount of investment for hard- and software and the number of adopters (Pantano, 2014).

Therefore, retailers have recognized the potential of mobile technologies as a promising complement to traditional service channels. This is mainly expedited by the strong spread of mobile technologies. The smartphone penetration rate in Germany has already reached about 71.7 percent by 2016 (Statista, 2016) and continues to rise. Using the smartphone in a physical store everyone can obtain digital content and access to information at any time and at any place (Ström et al., 2014). As a recent study shows, by now $42 \%$ of the consumers already use their smartphone for information search while being in a store (Samir, 2014). Regarding this, especially mobile systems supporting the buying process for example through product search, additional information or product comparison are of particular interest (Pantano \& 
Viassone, 2014). By providing a mobile system (e.g. applications) for smartphones, retailers are able to offer digital services in the context of in-store shopping to afford an additional service option as a supplement to the traditional sales assistance (Maas \& Varshney, 2008; Pantano \& Viassone, 2014). Such a technology is named hereafter as mobile retail services (MRS) and mainly consists of a software application available for customers to use it on their own smartphones. Given that the investment is relatively low compared to other in-store technologies like terminals or big screens, the uncertainty about the user acceptance presents the highest risk for the retailer (Pantano, 2014). This is particularly true for implementing a MRS as customers became a part of the service delivery process in-store (Roggeveen et al., 2012) independent of any sales clerk (Meuter et al., 2000).

Although there are several studies dealing with the drivers of in-store technology usage little is known about the acceptance of a MRS relating to the store patronage. This is particularly surprising, as MRS differ considerably from other in-store technologies because they are running on the customers' personal mobile device and offer services independent of time and place as well as a high ability of personalization (Saarijärvi et al., 2014). Hence, unlike comparable technologies the customers know how to operate the MRS, because they are already familiar with the usage of other applications on their smartphones. Moreover, based on the portability of the technology, customers are able to use the MRS in a concrete purchase situation or probably in front of the product of interest and exactly at the time when they have a high need for information and digital content (Kowatsch \& Maass, 2010). Taking this into account, the MRS may also differ in terms of technology acceptance. Accordingly, the first purpose of this study is to provide a deeper understanding of the MRS acceptance in a traditional store environment.

The author examines the drivers of acceptance on the basis of the technology acceptance model from Davis (1989). This will help researchers and actioners to gain a deeper understanding of the mobile retail service adoption and reducing the risk for retailers.

Moreover, costumers using a MRS in a store receive a service option in addition to the traditional providing digital information and media content. Previous research has already drawn the positive relationship between content offered by an online-shop and the customer's intention to visit the store 
again (Kim et al., 2007; Ahmed \& Forsythe, 2015). Also in the context of physical stores the access to digital services seems to be of high relevance for customers. So for example, the work of Lee (2015) reveals a positive relation between the usage of self-service technologies and the store patronage within a retail setting. It is therefore considered that also the MRS as an additional service option will lead customers' to patronize a particular store. However, it can be considered that the customer's positive attitude toward the MRS usage alone is not sufficient to affect the store choice substantially. Rather it can be assumed that the behaviour intention to use the technology has a mediation role between the attitude toward using the MRS and the intention to patronize a particular store. In this case, the offer and design of the mobile service is a key differentiator in particular for retailer with physical stores. Thus, the second approach of the study used to examine the relationship between the MRS acceptance and the customer's preference for a MRS enabled retailer.

Considering the research objectives mentioned above the remainder of this study is organized as follows: Deduced from the relevant literature, the research model is proposed and specific research propositions are made. Following a description of the methodology, the results are provided. Subsequently, the most relevant findings as well as the theoretical and managerial implications are discussed.

\subsection{Conceptual Background and Hypothesis Development}

The TAM (Davis, 1989) is one of the most widely used models regarding the acceptance of new technologies and has been applied to a broad range of research objectives and support the stability and robustness of TAM.

Also in the retail environment different technologies were already examined. Previous research has focused on the acceptance of fixed technologies such as terminals (Weijters, 2007) as well as mobile systems owned by the retailer like mobile recommendation agents (Kowatsch \& Maass, 2010) and mobile decision support systems (Heijden, 2006) as shown in Table 2. Despite the increasing popularity of smartphones, mobile services are still a young field of research. Whereas in-store systems have a limited mobility and are owned by the retailer (Pantano \& Viassone, 2014), mobile services are installed on the customer's smartphone which offer a service independent of time and place as well as a high 
ability of personalization (Saarijärvi et al., 2014). In contrast, MRS examined in this study for consumers' own device are rarely considered in the context of technology acceptance (Stroem et al., 2014).

\begin{tabular}{|c|c|c|c|c|}
\hline Study & $\begin{array}{l}\text { Owner of } \\
\text { technology }\end{array}$ & $\begin{array}{l}\text { Technology } \\
\text { acceptance }\end{array}$ & Research design & $\begin{array}{c}\text { Store } \\
\text { patronage }\end{array}$ \\
\hline Heijden, (2006) & retailer & $\checkmark$ & $\begin{array}{l}\text { laboratory experiment } \\
(\mathrm{N}=86)\end{array}$ & $x$ \\
\hline Weijters et al. (2007) & retailer & $\checkmark$ & field study (497) & $x$ \\
\hline Kowatsch \& Maass (2010) & retailer & $\checkmark$ & $\begin{array}{l}\text { laboratory experiment } \\
(\mathrm{N}=50)\end{array}$ & $\checkmark$ \\
\hline Müller-Seitz et al. (2009) & retailer & $\checkmark$ & Survey $(\mathrm{N}=206)$ & $x$ \\
\hline Karaatli \& Suntornpithug (2010) & consumer & $\checkmark$ & $\begin{array}{l}\text { Online survey } \\
(\mathrm{N}=120)\end{array}$ & $x$ \\
\hline Kallweit et al. (2014) & retailer & $\checkmark$ & $\begin{array}{l}\text { laboratory experiment } \\
(\mathrm{N}=225)\end{array}$ & $x$ \\
\hline Saarijärvi et al. (2014) & consumer & $x$ & Case studies & $x$ \\
\hline
\end{tabular}

Table 2: Empirical research of retailing service technologies acceptance

The customers' acceptance of a new technology is one important aspect of a successful implementation, while another one is the impact on the store patronage. To date only a few studies exist that examine the link between technology acceptance and the impact on the customers intention to revisit a MRS enabled store (Kowatsch \& Maass, 2010). Therefore, this paper aims at filling this gap by examining the acceptance of a MRS and the effect on the store patronage intention. It indicates the importance of both scholars and practitioners to understand how mobile services can be used to serve customers and extending the retailers' perspective to intensify their service orientation. Therefore, in the present study the TAM serves as the theoretical basis to analyze the MRS acceptance. 


\subsubsection{Technology acceptance}

The TAM (Davis, 1989) is one of the most widely used models regarding the acceptance of new technologies. The acceptance of a technology is reflected in the strength of attitude towards using (ATU) which is understood as the evaluation of the technology and the following behavioral intention to use (IU) (Davis et al., 1989). ATU in turn is influenced by the perceived usefulness (PU) and the perceived ease of use (PEOU). PU refers to the utility value of a technology and is defined as the degree to which a person believes that using a particular system would enhance his or her performance (Davis, 1989). By using a MRS, customers have an additional service option as an alternative to the traditional sales assistant (Pantano \& Viassone, 2014). Thus, the customer became part of the service delivery process (Rogggeven et al., 2012). As previous studies conducted the perceived value of a technology is increasing with the participation of the user (Ström et al., 2014). Moreover, the value for the customer using the MRS in this study results from an advanced offer of digital information available while shopping in a physical store. Due to the mobility of smartphones compared to other in-store technologies the service is appropriable at any place and directly in front of the product of interest. The additional information may lead to well-founded buying decision and to a higher attitude to use the technology, which is in line with prior research (Pihlström \& Brush, 2008). Considering this it can be assumed that the additional service option of the MRS may lead to a higher perceived usefulness.

\section{H1. The perceived usefulness has a positive impact on the attitude towards using the MRS.}

According to TAM the PEOU represents the second important acceptance predictor (Davis, 1989). The PEOU describes the belief that the technology can be used easily and without great cognitive efforts (Davis, 1989). In the context of other technologies like for example self-service technologies or recommendation agents, the PEOU was identified as a critical factor influencing the attitude towards using the system (Wang et al., 2012). Moreover, if customers find the MRS easy to use, the effort as well as the risk involved using the service can be reduced (Shamdasani, et al., 2008) and they consider the technology as an attractive alternative to a traditional sales assistant. Regarding the growing popularity of mobile devices and given that the smartphone usage has become already part of the 
everyday life, there should not be any difficulty in using the MRS. Thus, PEOU is supposed to positively influence the attitude towards using the MRS.

\section{H2. The perceived ease of use has a positive impact on the attitude towards using the MRS.}

While PU consider the utilitarian aspect of technology use, perceived enjoyment (PE) was added to the model due to the need of reflecting the hedonic part (Davis et al., 1992; Dabholkar \& Bagozzi, 2002). PE can be defined as the extent to which the activity of using a technology "is perceived to be enjoyable in its own right" (Davis et al., 1992). In spite of the fact that obtaining information via the MRS is more utilitarian than hedonic, previous studies have shown an important contribution of adding the PE to the TAM (Venkatesh et al. 2003). Particularly, research on internet technologies reveals a strong positive effect on the attitude toward online retailers (e.g. O'Brien, 2010). In the context of online shopping, Koufaris et al. (2001) found that customers enjoyed using the product search function are more likely to return to the site. Moreover, customers who find the shopping experience using an MRS pleasurable are willing to visit the store more frequently. As the MRS provide in depth information as well as rich media content customer may find it enjoyable to use the technology while they are shopping. Therefore, it can be assumed that the PE is positively related to the attitude towards using the MRS.

\section{H3. The perceived enjoyment has a positive impact on the attitude towards using the MRS.}

Attitude is seen as the user's evaluation towards a technology, whereas the intention to use is related to a certain behavior (Davis, 1989). A number of studies have found a link between the customer attitude toward the use of novel technologies and the behavioral intention to use a system (Venkatesh et al., 2003). Also in the case of retailing the attitude toward the technology leads to a greater likelihood of using the system implemented in a store while shopping (Saarijärvi et al., 2014). Thus, it can be assumed:

\section{H4. The attitude toward usage has a positive impact on the intention to use the MRS.}




\subsubsection{Store patronage intention}

Research on retail patronage tries to explain the consumers' store choice behavior (Lee et al., 2009). This patronage behavior is influenced by several aspects whereby market relevant attributes like service quality and convenience were the key factors which influence the consumers' store choice (Pan \& Zinkhan, 2006). So for example some studies showed that the waiting time for service from a sales assistant could result in dissatisfaction (Katz et al., 1991) and therefore has a negative influence on store patronage behavior (Grewal et al., 2003). As mentioned earlier, MRS enabled retail stores offer an additional service independent of any sales person to create a more convenient (e.g. reduce waiting time for service) an sophisticated shopping experience. Taking this into account, the attitude toward using the MRS is a decisive reason for the retailers' decision to implement such a system (Grewal et al., 2003). Results of previous studies in the context of online shopping clearly showed a strong relation among the technology acceptance and the behavioral intention toward the online retailer (Lee et al., 2006). Using an online decision support system the research of Kamis et al. (2008) showed the relation between the TAM based constructs perceived usefulness, perceived ease of use, perceived enjoyment and the behavioral intention. Regarding retail technologies in a physical store environment Lee et al. (2009) examined the importance of self-service kiosks for developing consumers' retail patronage intentions and found that service quality delivered by self-service kiosks is a direct and an indirect determinant of consumers' retail patronage intention. As some studies reveal, the service quality is an overall evaluation similar to the attitude (Parasuraman et al., 1985). It can be assumed that a positive attitude toward using the MRS leads to a higher store patronage intention:

\section{H5. The attitude toward using the MRS has a positive impact on the store patronage intention.}

Some studies examined several mediation effects of external variables within the TAM (BurtonJones \& Hubona, 2006). However, there is little agreement about the concrete way the TAM constructs are related to behavioral intentions (Brady et al., 2005). A positive attitude toward using a MRS in a retailer's store is only one prerequisite for the customer's decision to patronize a store, but rather influenced by the willingness to use it. As the IU is defined as the "degree to which the subject is willing to use a certain system" (Venkatesh et al., 2003) it is also necessary that the customer will use the MRS. 
To gain a deeper understanding it might be reasonable to analyze the possibility that IU intervenes between ATU and SPI (Mediation Hypothesis).

MH: The effect of attitude toward using the MRS on the retailer patronage of a MRS enabled store is mediated by the intention to use it.

Figure 5 gives an overview of all postulated hypotheses.

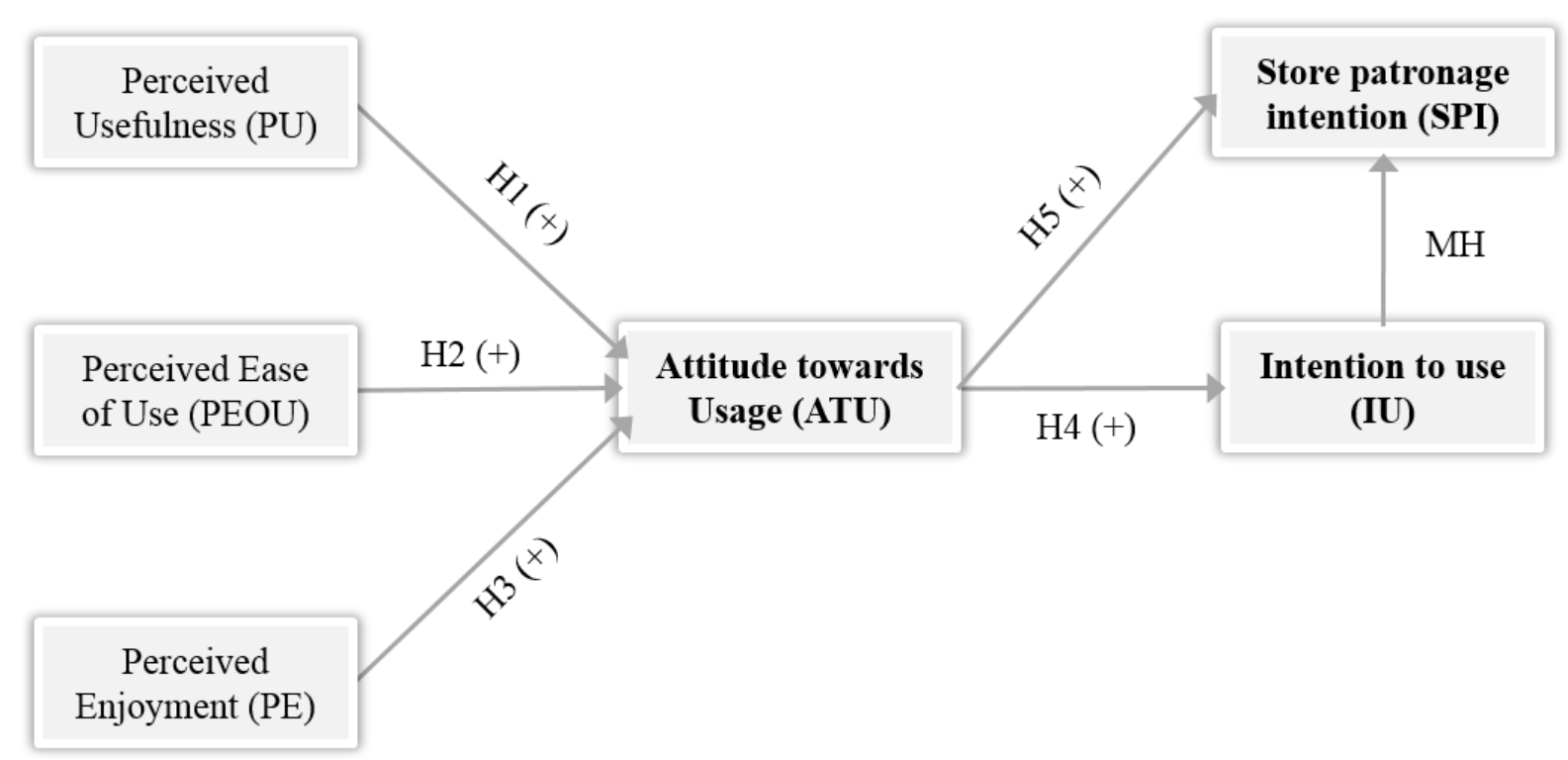

Figure 5: Research model for MRS acceptance

\subsection{Methodology}

\subsubsection{Research Setting}

The study was conducted using the context of consumer electronics, more precisely the product segment of navigation systems. Consumer electronics are among the complex product categories that require indepth information and explanation and therefore seem to be well-suited to analyze a MRS providing digital information. The participants were recruited in the urban center of a medium-sized city in Germany. The MRS used in this study as a stimulus for the subsequent experiment is a real mobile application provided by one of the leading multi-channel consumer electronics retailer in Europe. The application, which is available for the android operating system (Google) or iOS (Apple), has to be downloaded and installed by the user on their own mobile device. Customers are able to use the MRS 
simply by pointing a smartphone on the product. The MRS provide customers with access to detailed product information, images and customer reviews. Moreover, the application was able to find the best fitting product based on a structured needs assessment, considering criteria such as reviews, price range as well as brand (Figure 6).
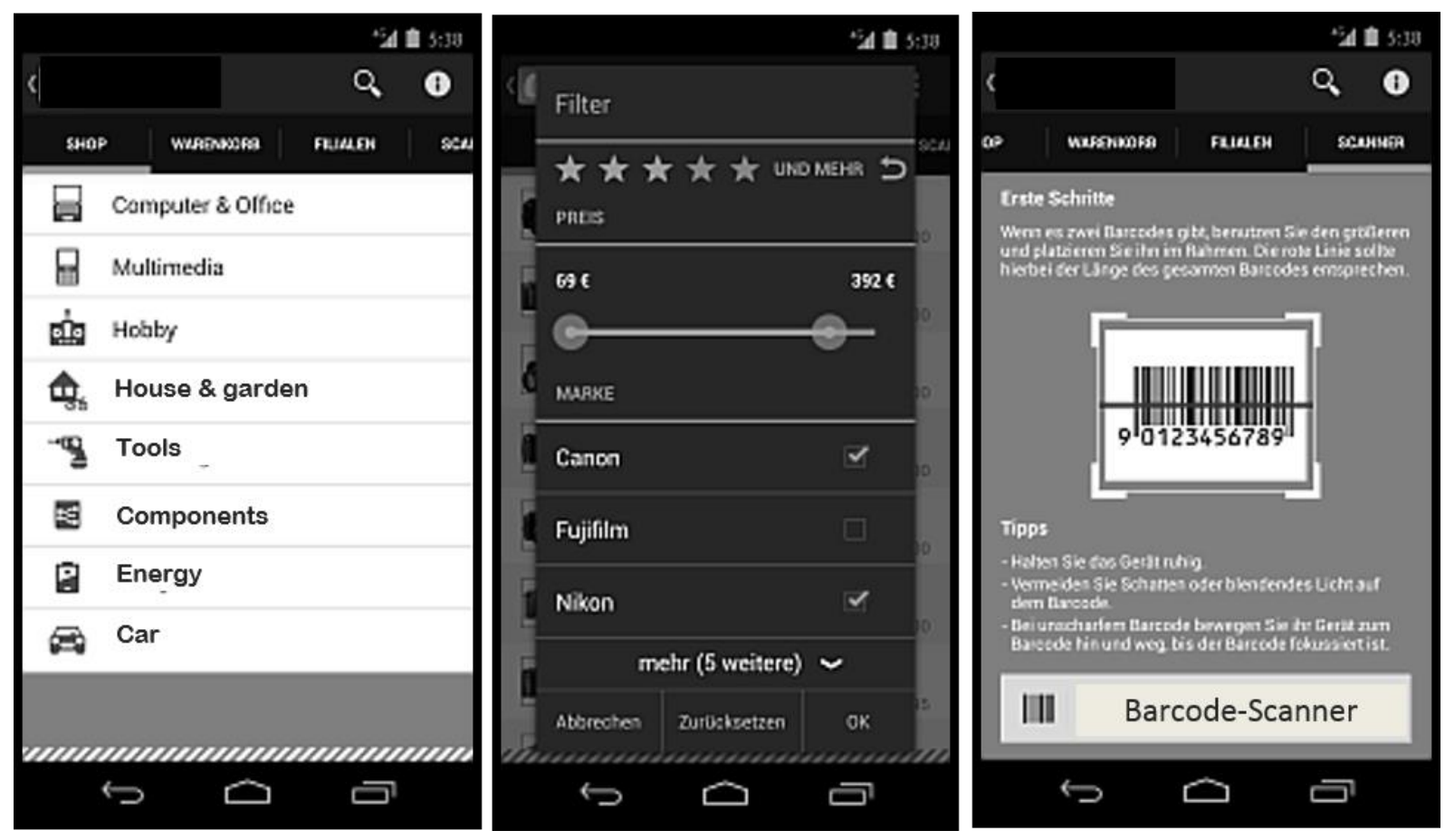

Figure 6: Mobile self-service application used in the study

This MRS differ in some characteristics from other in-store technologies: the customer uses the application in his own device and thus is more experienced than with other in-store technologies. Moreover, the smartphone is always with the customer an can be used at any time, at any location.

A scenario-based laboratory experiment was conducted. The experiment started with a brief introduction to a concrete buying scenario and an orientation phase before the participants used the application. The products were furnished with EAN codes to provide further product information to the user by scanning the code with the smartphone. Afterwards the product information is displayed on the device screen. Finally, the test subjects answered a structured questionnaire on their assessments of the use of the MRS, their general smartphone usage for information search as well as individual traits and demographic characteristics. A total of 112 users tested the application and answered the questionnaire. 


\subsubsection{Construct Measurement}

The measures for each construct are based on the existing literature and adjusted for the MRS. Items were translated and formulated to measure the relevant constructs. PU and PEOU were measured using a three and four-item scale based on the work of Davis (1989). For PE a scale consisting of four and five items borrowed from the work of Dabholkar (1996) was used. To measure ATU and IR, scales consisting of four items adapted from Venkatesh et al. (2003) and Dabholkar (1994) were used. Finally, SPI was measured with one item borrowed from Kowatsch and Maass (2010). All the items were measured using a seven-point Likert scale ranging from 1 (meaning "strongly disagree") to 7 (meaning "strongly agree"). Demographic variables such as age, gender, income and profession were also included, as well as individual predispositions such as product experience or need for interaction.

\subsubsection{Data analysis}

To analyze the acceptance of the mobile retail service the partial least squares (PLS) approach and the software SmartPLS 2.0 (Henseler et al., 2009) was used to estimate the measurement and structural parameters in the structural equation model (SEM). In this way the prediction quality of endogenous constructs should be maximized (Yi et al., 2013). Because PLS is a variance-based approach of SEM, it does not require a multivariate normal dataset (Jain et al., 2012) and it is suggested for small sample sizes. The standard boot-strapping procedure in the SmartPLS software was used and a robust standard error and t-statistic was generated. As recommended by Baron and Kenny (1986), the mediation path from ATU via IU to SPI was also estimated by SEM to avoid unreliability. For proofing the significance of the postulated mediation effect, a specialized t-test, the Sobel test was conducted (Sobel, 1982). Therefore, the "Sobel Test Calculator for the Significance of Mediation" was used (Soper, 2013).

\subsection{Results}

\subsubsection{Descriptive statistics}

The participants were between 20 and 63 years of age and $43 \%$ of them were male whereas $57 \%$ were female. Moreover, $80 \%$ already owned a smartphone and are familiar with mobile devices. Not 
surprisingly, $60 \%$ of the participants have already searched information using their smartphone while shopping consumer electronics, followed by books and fashion.

\subsubsection{Measurement model}

To ensure the internal reliability of the scale items the Cronbach's coefficient alpha was calculated. All constructs were proved to have a good level of reliability with all loadings clearly greater than 0.7 (Nunally, 1978). The results of all remaining items are presented in Table 3. Furthermore, the composite reliability which is supposed to yield better estimates of true reliability than Cronbach's coefficient alpha including the number of indicators was assessed (Chin, 1998). All constructs achieved values much greater than 0.7 (Hulland, 1999).

\begin{tabular}{|c|c|c|c|c|c|c|}
\hline Construct & Item & $\begin{array}{l}\text { Standard } \\
\text { loadings }\end{array}$ & t-value & $\begin{array}{l}\text { Cronbach's } \\
\text { coefficient } \\
\text { alpha }\end{array}$ & $\begin{array}{l}\text { Composite } \\
\text { reliability }\end{array}$ & $\begin{array}{l}\text { Average } \\
\text { variance } \\
\text { extracted }\end{array}$ \\
\hline \multirow[t]{3}{*}{ Perceived Usefulness } & PU1 & 0.9430 & 70.9706 & \multirow{3}{*}{0.8739} & \multirow{3}{*}{0.9232} & \multirow{3}{*}{0.8008} \\
\hline & PU2 & 0.9173 & 37.2202 & & & \\
\hline & PU3 & 0.8195 & 14.2035 & & & \\
\hline \multirow[t]{4}{*}{ Perceived Ease of Use } & PEOU1 & 0.9031 & 22.0696 & \multirow{4}{*}{0.9079} & \multirow{4}{*}{0.9354} & \multirow{4}{*}{0.7838} \\
\hline & PEOU2 & 0.9248 & 35.1031 & & & \\
\hline & PEOU3 & 0.8542 & 18.3358 & & & \\
\hline & PEOU4 & 0.8572 & 16.9570 & & & \\
\hline \multirow[t]{4}{*}{ Perceived Enjoyment } & PE1 & 0.8492 & 7.4713 & \multirow{4}{*}{0.8163} & \multirow{4}{*}{0.8832} & \multirow{4}{*}{0.6597} \\
\hline & PE2 & 0.8702 & 7.3368 & & & \\
\hline & PE3 & 0.9045 & 10.0245 & & & \\
\hline & PE4 & 0.5851 & 4.1667 & & & \\
\hline \multirow[t]{3}{*}{ Attitude towards Usage } & ATU1 & 0.9524 & 73.1542 & \multirow{3}{*}{0.9172} & \multirow{3}{*}{0.9483} & \multirow{3}{*}{0.8599} \\
\hline & ATU2 & 0.9692 & 144.0561 & & & \\
\hline & ATU3 & 0.8563 & 20.4984 & & & \\
\hline \multirow[t]{3}{*}{ Intention to Reuse } & IR1 & 0.8839 & 30.5824 & \multirow{3}{*}{0.9018} & \multirow{3}{*}{0.9387} & \multirow{3}{*}{0.8362} \\
\hline & IR2 & 0.915 & 28.9451 & & & \\
\hline & IR3 & 0.9435 & 67.3605 & & & \\
\hline \multicolumn{2}{|c|}{ Store patronage intention SPI } & 1 & 1 & 1 & 1 & 1 \\
\hline
\end{tabular}

Table 3: Measure and Items 
To evaluate the set of indicators also the average variance extracted (AVE) was calculated. The AVE determines how much of the total variance of all indicators can be explained by the construct (Fornell \& Larcker, 1981). The AVE should be higher than 0.5 so that at least $50 \%$ of the total variance of all indicators is explained. In this study, each construct fulfils this criterion as shown in Table 4. Additionally, to ensure that the outer loadings were greater than the cross-loadings on all other constructs the discriminant validity was tested (Chin, 1998). Moreover, the Fornell and Larcker criterion (1981) was used to make sure that a construct shares more variance with its measures than with other model constructs (Chin, 1998). Table 4 provides a detailed summary of all the results regarding the shared variance $(\mathrm{SV})$ and the AVE.

\begin{tabular}{|c|c|c|c|c|c|c|}
\hline SV/AVE & $\overline{\text { ATU }}$ & PE & PEOU & $\mathbf{P U}$ & IU & SPI \\
\hline 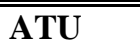 & $\overline{0,860}$ & 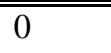 & 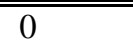 & $\bar{~} 0$ & 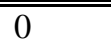 & " 0 \\
\hline PE & 0,147 & 0,660 & 0 & 0 & 0 & 0 \\
\hline PEO & 0,142 & 0,000 & $\mathbf{0 , 7 8 4}$ & 0 & 0 & 0 \\
\hline PU & 0,234 & 0,104 & 0,196 & $\mathbf{0 , 8 0 1}$ & 0 & 0 \\
\hline IU & 0,125 & 0,129 & 0,003 & 0,009 & $\mathbf{0 , 8 3 6}$ & 0 \\
\hline SPI & 0,330 & 0,109 & 0,027 & 0,045 & 0,377 & 1 \\
\hline
\end{tabular}

Table 4: Shared Variance and Average Variance Extracted

\subsubsection{Structural models}

The hypotheses postulate that the PU, PEO and PE should increase the ATU (H1, H2, and H3). Also, the ATU has a positive influence on the IU (H4) as well as on the SPI (H5). To test the proposed model and establish the significance of parameter estimates, t-values using 1,000 bootstrap samples were calculated (Henseler et al., 2009). Table 5 shows the path coefficients $\beta$ and t-values for the model along 
with the R2 for ATU, IU and SPI and indicates the results of the hypothesis test for a level of significance of $5 \%$

\begin{tabular}{|c|c|c|c|c|c|}
\hline Hypothesis & Relationship & Direction & $\begin{array}{l}\text { Standardized } \\
\text { Coefficient }(\beta)\end{array}$ & $t$-value & Result \\
\hline$\overline{\mathrm{H} 1}$ & "PU $\rightarrow$ ATU & Positive & 0.272 & 2.527 & Supported \\
\hline $\mathrm{H} 2$ & $\mathrm{PEOU} \rightarrow \mathrm{ATU}$ & Positive & 0.260 & 2.820 & Supported \\
\hline $\mathrm{H} 3$ & $\mathrm{PE} \rightarrow \mathrm{ATU}$ & Positive & 0.299 & 3.403 & Supported \\
\hline $\mathrm{H} 4$ & $\mathrm{ATU} \rightarrow \mathrm{IU}$ & Positive & 0.574 & 6.361 & Supported \\
\hline H5 & $\mathrm{ATU} \rightarrow \mathrm{SPI}$ & Positive & 0.613 & 7.266 & Supported \\
\hline Fit Measures & Endogenous Construct & Model & & & \\
\hline \multirow[t]{3}{*}{$\overline{\mathrm{R}^{2}}$} & ATU & "0.34 & & & \\
\hline & $\mathrm{IU}$ & 0.33 & & & \\
\hline & SPI & 0.37 & & & \\
\hline
\end{tabular}

\section{Table 5: Hypotheses Testing}

All postulated hypotheses are confirmed. The results show that the PU $(B 1=0.272 ; p<0.01)$, the PEOU $(\beta 2=0.260 ; \mathrm{p}<0.01)$ and the PE $(\beta 3=0.299 ; \mathrm{p}<0.01)$ have a significant effect on the ATU, supporting $\mathrm{H} 1, \mathrm{H} 2$ and $\mathrm{H} 3$. As $\mathrm{H} 4$ predicted, the effect of the ATU $(B 4=0.574 ; \mathrm{p}<0.001)$ on the IU is also significant and positive. In addition, the influence of IU on SPI ( $(35=0.613 ; \mathrm{p}<0.001)$ supports H5. Most of the variance of the dependent variables can be explained: As shown in Table 5, almost $40 \%$ of the variance of the SPI is explained by the exogenous factors. Also, the explanatory power for the ATU with $34 \%$ and for the IU with more than $33 \%$ is high, suggesting that PU, PEOU and PE are predictors of the ATU. As mentioned above, all suggested relationships were confirmed including the mediation effect of IU on the relation between ATU and the SPI. Most of them were shown to be significant on a level of $1 \%$. 


\begin{tabular}{|ll|}
\hline Direct Effect with no mediator & $\mathbf{0 . 3 5 6}$ \\
Direct Effect with mediator & $\mathbf{0 . 0 0 4}$ \\
\hline \hline ATU --> IU (Beta) & 0.575 \\
IU --> SPI (Beta) & 0.614 \\
ATU --> IU (SE) & 0.067 \\
IU --> SPI (SE) & 0.085 \\
& \\
\hline \hline Sobel test statistic: & $\mathbf{4 . 9 0 1}>\mathbf{1 . 9 6}$ \\
One-tailed probability: & $0.000<0.05$ \\
& \\
Two-tailed probability: & $0.000<0.05$ \\
& \\
\hline
\end{tabular}

NOTE: SE = Standardized Error

\section{Table 6: Mediation effect}

The relationship between the ATU and the SPI is assumed to be mediated through the IU, in addition to the direct effect. The results shown in Table 6 establish the mediation effect of IU. Precisely, by including the IU as a mediator, the effect of the ATU on SPI no longer exists, which is the case of a complete mediation (Warner, 2012). The Sobel test examines a significant effect $(\mathrm{z}=4.901, \mathrm{p}<0.001)$ of the postulated mediation (Sobel, 1982). Several control variables (i.e. customer age and gender, customer education, product experience and need for interaction) were included in the structural model to avoid the problem of a possible omitted variable bias, which can occur when a model incorrectly leaves out one or more important causal factors. The results show no significant effect of the control variables on the dependent variable. 


\subsection{Discussion and conclusion}

As one of the study objectives was to deepen the understanding of MRS acceptance based on the TAM the relation between PU, PEOU, PE as well as the ATU as well as IU was examined. The empirical results of this study yield strong evidence to support the proposed model as all of the postulated relations were shown to be highly significant. In particular, the results of the structural equation modelling reveals that the highest predictive power for the ATU the mobile service belonged to PE, followed by PU and PEOU. The relevance of PEOU seems quite comprehensible because the majority (80\%) of the consumers are already familiar with smartphones and it is not an obstacle using a mobile device to obtain services in a retail store. Regarding this result, the PEOU is likely to be the major advantage for retailers, particularly compared to other (fixed) retailer owned technologies. In this context it is important to ensure that the MRS will work faultlessly. Therefore, retailers have to ensure a sufficient infrastructure and accessibility for example by providing a free internet access via WIFI. The results also reveal that the PU of the mobile service examined in this study, which refers to the access to digital content in a store as an additional service option to the assistance of a sales clerk, has a significant impact on the ATU. The participants of this study stated that the detailed product information (48\%) and the customer reviews $(45 \%)$ were most helpful while shopping in-store. Furthermore, the integrated filter function provide a valuable assistance to the customer. However, it is important for the PEOU as well as the PU that the MRS is designed with regards to commonly used mobile usability standards (Lee et al., 2013). $\mathrm{PE}$, in contrast to the other factors, refers to the hedonic part of the technology without taking the result delivered by the technology into account (Davis et al., 1992). Although the focus of the MRS in this study is utilitarian, the PE seems almost more important for the attitude toward the MRS as the original constructs of the TAM, the PU and the PEOU. This can be explained as follows: Using a smartphone is perceived to be enjoyable in its own right (Ström et al., 2014). The MRS provides access to digital media content (e.g. images, videos or 3D animations) and is therefore not only a source of information but entertaining as well. Moreover, the technology is highly interactive and therefore more exciting than traditional in-store communication. This reveals that PE not only has a positive effect on the attitude toward online retailers (e.g. O'Brien, 2010) but also holds true for a MRS. Thus, the acceptance of a 
MRS is influenced by utilitarian factors as well as by hedonic factors. Overall, these results as well as the strong relationship between ATU and UI are in line with findings from previous research (e.g. Davis, 1989; Lee et al., 2006).

As another concern of this study, the relation between the acceptance of the MRS as an additional service option within traditional stores and the customer's intention to patronize a MRS enabled retailer was examined. The results clarify how the behavioral intention to use a MRS matters in the contribution of attitude toward the technology to retail patronage by showing its mediation role. The findings reveal that a positive attitude toward the MRS leads to a higher store patronage intention ( $B 5=0.613$; $\mathrm{p}$ < 0.001). To clarify the nature of this relationship the mediation effect of IU was determined using the Sobel test (Sobel, 1982). The results show that the ATU affects retail patronage through the intention to use the MRS. The mediation testing shows that the influence of the ATU the MRS on the store patronage intention is fully mediated by IU which implies a strong and dominant mediator (Sun \& Zhang, 2008). Therefore, it can be assumed that customer who have the intention to use a MRS would patronize a MRS enabled retail store. While this study provides a precious contribution to the literature of mobile services in retailing, it also has some limitation that need to be discussed. The results afford interesting insights into the use of mobile services for retailer with complex product categories that require in-depth information. Although no trade-segment specific constructs were used, the evidence provided in this study is limited to consumer electronics. Nevertheless, the findings may vary in different sectors for example in terms of the information type. Therefore, further research should also address the issue and broaden the investigation in order to prove if different results will be achieved. The attitude of an individual toward an object and the repeat patronage are both linked to a loyal behavior of a customer (Dick \& Basu, 1994). Regarding this, it is important to ascertain not only the behavioral intention of a repeat visit but the actual behavior over a longer period.

Overall, the results emphasize the strategic significance of mobile services for a retailer. Moreover, the usage of MRS has the advantage of being already familiar to the customer, require no hardware investments and can be used in the immediate vicinity of the product of interest. Regarding this and the 
fact that customers already use their smartphone while shopping, the question should not be whether, but rather how retailers use mobile services to enhance the in-store experience in their stores.

\subsection{References (Study 1)}

Ahmed S. H., \& Forsythe S. (2015). Adapting a Comprehensive Physical Store Environment and Patronage Model to Examine Online Store Environment and Patronge Intentions. In: Spotts H. (eds) Marketing, Technology and Customer Commitment in the New Economy. Developments in Marketing Science: Proceedings of the Academy of Marketing Science. Springer, Cham.

Baker, J., Parasuraman, A., Grewal, D., \& Voss, G. B. (2002). The influence of multiple store environment cues on perceived merchandise value and patronage intentions. Journal of Marketing, 66(2), 120-141.

Baron, R.M., \& Kenny, D.A. (1986). The moderator-mediator variable distinction in social psychological research: Conceptual, strategic, and statistical considerations. Journal of Personality and Social Psychology, 51(6), 1173-1182.

Brady, M. K., Knight, G. A., Cronin Jr, J. J., Tomas, G., Hult, M., \& Keillor, B. D. (2005). Removing the contextual lens: a multinational, multi-setting comparison of service evaluation models. Journal of Retailing, 81(3), 215-230.

Burton-Jones, A., \& Hubona, G. S. (2006). The mediation of external variables in the technology acceptance model. Information \& Management, 43(6), 706-717.

Chin, W. W. (1998). The partial least squares approach to structural equation modeling. Modern Methods for Business Research, 295(2), 295-336.

Dabholkar, P. A. (1994). Incorporating choice into an attitudinal framework: analyzing models of mental comparison processes. Journal of Consumer Research, 21(1), 100-118.

Dabholkar, P. A. (1996). Consumer evaluations of new technology-based self-service options: an investigation of alternative models of service quality. International Journal of Research in Marketing, 13(1), 29-51. 
Dabholkar, P. A., \& Bagozzi, R. P. (2002). An attitudinal model of technology-based self-service: moderating effects of consumer traits and situational factors. Journal of the Academy of Marketing Science, 30(3), 184-201.

Davis, F.D. (1989). Perceived usefulness, perceived ease of use, and user acceptance of information technology. MIS Quarterly, 13(3), 319-340.

Davis, F. D., Bagozzi, R. P., \& Warshaw, P. R. (1989). User acceptance of computer technology: a comparison of two theoretical models. Management Science, 35(8), 982-1003.

Davis, F. D., Bagozzi, R. P., \& Warshaw, P. R. (1992). Extrinsic and intrinsic motivation to use computers in the workplace1. Journal of Applied Social Psychology, 22(14), 1111-1132.

Dick, A. S., \& Basu, K. (1994). Customer loyalty: toward an integrated conceptual framework. Journal of the Academy of Marketing Science, 22(2), 99-113.

Engel, J. F., Kollat, D. T., \& Blackwell, R. D. (1968) Consumer Behavior. New York: Holt, Rinehart, and Winston, Inc., 1968.

Fornell, C., \& Larcker, D.F. (1981). Evaluating structural equation models with unobservable variables and measurement errors. Journal of Marketing Research, 18 (1), 39-50.

Grewal, D., Baker, J., Levy, M., \& Voss, G. (2003). The Effects of Wait Expectations, Store Atmosphere and Merchandise Value Perceptions on Store Patronage Intentions. Journal of Retailing, 79(4), 259268.

Heijden, H. (2006). Mobile decision support for in-store purchase decisions. Decision Support Systems, 42(2), 656-663.

Henseler, J., \& Wang, H. (2010), Handbook of Partial Least Squares. Springer, Berlin, 691711.

Hulland, J. (1999). Use of partial least squares (PLS) in strategic management research: A review of four recent studies. Strategic Management Journal, 20(2), 195-204. 
Jain, A.K., Malhotra, N.K., \& Guan, C. (2012). Positive and negative affectivity as mediators of volunteerism and service-oriented citizenship behavior and customer loyalty. Psychology and Marketing, 29(12), 1004-1017.

Kamis, A., Koufaris, M., \& Stern, T. (2008). Using an attribute-based decision support system for usercustomized products online: an experimental investigation. MIS Quarterly, 31(1), 159-177.

Katz, K. L., Larson, B. M., \& Larson, R. C. (1991). Prescription for the waiting-in-line blues: Entertain, enlighten, and engage. MIT Sloan Management Review, 32(2), 44-55.

Kim, J., Fiore, A. M., \& Lee, H. H. (2007). Influences of online store perception, shopping enjoyment, and shopping involvement on consumer patronage behavior towards an online retailer. Journal of Retailing and Consumer Services, 14(2), 95-107.

Kowatsch, T., \& Maass, W. (2010). In-store consumer behavior: How mobile recommendation agents influence usage intentions, product purchases, and store preferences. Computers in Human Behavior, 26(4), 697-704.

Koufaris, M., \& Ajit Kambil, P. A. L. (2001). Consumer behavior in web-based commerce: an empirical study. International Journal of Electronic Commerce, 6(2), 115-138.

Lee, H. H., Fiore, A. M., \& Kim, J. (2006). The role of the technology acceptance model in explaining effects of image interactivity technology on consumer responses. International Journal of Retail and Distribution Management, 34(8), 621-644.

Lee, H. J., Fairhurst, A. E., \& Lee, M. Y. (2009). The importance of self-service kiosks in developing consumers' retail patronage intentions. Managing Service Quality: An International Journal, 19(6), 687701.

Lee, H. J. (2015). Consumer-to-store employee and consumer-to-self-service technology (SST) interactions in a retail setting. International Journal of Retail \& Distribution Management, 43(8), 676692. 
Lee, J., Lee, D., Moon, J., \& Park, M. C. (2013). Factors affecting the perceived usability of the mobile web portal services: comparing simplicity with consistency. Information Technology and Management, $14(1), 43-57$.

Lin, J. S. C., \& Hsieh, P. L. (2011). Assessing the self-service technology encounters: development and validation of SSTQUAL scale. Journal of Retailing, 87(2), 194-206.

Maass, W., \& Varshney, U. (2008). Preface to the focus theme section: 'Smart products'. Electronic Markets, 18(3), 211-215.

Meuter, M.L., Ostrom, A.L, Roundtree, R.I., \& Bitner, M.J., (2000). Self-service technologies: Understanding customer satisfaction with technology-based service encounters. Journal of Marketing, 64(3), 50-64.

Nunnally, J. C. (1978). Psychometric theory (2nd ed.). New York: McGraw-Hill.

O'Brien, H. L. (2010). The influence of hedonic and utilitarian motivations on user engagement: The case of online shopping experiences. Interacting with Computers, 22(5), 344-352.

Roggeveen, A., Tsiros, M., \& Grewal, D. (2012). Understanding the co-creation effect: When does collaborating with customers provide a lift to service recovery? Journal of the Academy of Marketing Science, 40(6), 771-790.

Pan, Y., \& Zinkhan, G. M. (2006). Determinants of retail patronage: a meta-analytical perspective. Journal of Retailing, 82(3), 229-243.

Pantano, E., \& Di Pietro, L. (2012). Understanding consumer's acceptance of technology-based innovations in retailing. Journal of Technology Management \& Innovation, 7(4), 1-19.

Pantano, E., Iazzolino, G., \& Migliano, G. (2013). Obsolescence risk in advanced technologies for retailing: a management perspective. Journal of Retailing and Consumer Services, 20(2), 225-233.

Pantano, E. (2014). Innovation drivers in retail industry. International Journal of Information Management, 34(3), 344-350. 
Pantano, E., \& Viassone, M. (2014). Demand pull and technology push perspective in technologybased innovations for the points of sale: The retailer's evaluation. Journal of Retailing and Consumer Services, 21(1), 43-47.

Parasuraman, A., Zeithaml, V. A., \& Berry, L. L. (1985). A conceptual model of service quality and its implications for future research. Journal of Marketing, 41-50.

Puccinelli, N. M., Goodstein, R. C., Grewal, D., Price, R., Raghubir, P., \& Stewart, D. (2009). Customer experience management in retailing: understanding the buying process. Journal of Retailing, 85(1), 1530.

Saarijärvi, H., Mitronen, L., \& Yrjölä, M. (2014). From selling to supporting-Leveraging mobile services in the context of food retailing. Journal of Retailing and Consumer Services, 21(1), 2636.

Samir, S. (2014): The 3 New Realities of Local Retail. Retrievable at: https://www.thinkwithgoogle.com/articles/3-new-realities-of-local retail.html\#?q=mobile\%20

payment.pdf. Last request 01.04.014.

Shamdasani, P., Mukherjee, A., \& Malhotra, N. (2008). Antecedents and consequences of service quality in consumer evaluation of self-service internet technologies. The Service Industries Journal, 28(1), 117-138.

Sivadas, E., \& Baker-Prewitt, J. L. (2000). An examination of the relationship between service quality, customer satisfaction, and store loyalty. International Journal of Retail \& Distribution Management, 28(2), 73-82.

Statista (2016). https://www.statista.com/statistics/257056/smartphone-user-penetration-in-germany/. Last request 21.08.2017.

Ström, R., Vendel, M., \& Bredican, J. (2014). Mobile marketing: A literature review on its value for consumers and retailers. Journal of Retailing and Consumer Services, 21(6), 1001-1012.

Pihlström, M., \& Brush, G. J. (2008). Comparing the perceived value of information and entertainment mobile services. Psychology and Marketing, 25(8), 732-755. 
Sobel, M.E. (1982). Asymptotic confidence intervals for indirect effects in structural equation models. Sociological Methodology, 13, 290-312.

Soper, D.S. (2013). Sobel Test Calculator for the Significance of Mediation [Software]. Retrieved from http://www.danielsoper.com/statcalc, Last request 16.12.2013.

Sun, H., \& Zhang, P. (2008). An exploration of affect factors and their role in user technology acceptance: Mediation and causality. Journal of the American Society for Information Science and Technology, 59(8), 1252-1263.

Venkatesh, V., Morris, M. G., Davis, G. B., \& Davis, F. D. (2003). User acceptance of information technology: Toward a unified view. MIS Quarterly, 425-478.

Wang, C., Harris, J., \& Patterson, P. G. (2012). Customer choice of self-service technology: the roles of situational influences and past experience. Journal of Service Management, 23(1), 54-78.

Warner, R. M. (2012). Applied Statistics: From Bivariate Through Multivariate Techniques: From Bivariate Through Multivariate Techniques. Sage.

Weijters, B., Rangarajan, D., Falk, T., \& Schillewaert, N. (2007). Determinants and outcomes of customers' use of self-service technology in a retail setting. Journal of Service Research, 10(1), 3-21.

Yi, Y., Gong, T., \& Lee, H. (2013). The impact of other customers on customer citizenship behavior. Psychology and Marketing, 30(4), 341-356. 


\title{
3 Why do Customers Use Self-Service Information Technologies in Retail? The Mediating Effect of Perceived Service Quality (Study 2)
}

This paper is published in the Journal of Retailing and Consumer Services, to cite as:

Kallweit, K., Spreer, P., \& Toporowski, W. (2014). Why do customers use self-service information technologies in retail? The mediating effect of perceived service quality. Journal of Retailing and Consumer Services, 21(3), 268-276.

\begin{abstract}
To ensure a high level of service quality (SQ), retailers think about offering self-service information technologies (SSIT) at the point of sale. However, the explanatory value of the SQ for SSIT adoption is barely researched. Thus, the present study examines the mediation effect of SQ within the technology acceptance model. Building on data from a laboratory experiment using a fully functional application for Tablet PCs, the partial least squares approach is applied. The findings reveal that the perceived SQ partially mediates the effect of the attitude towards using on the intention to reuse. Therefore, retailers have to emphasize the service-related value of SSITs.
\end{abstract}




\subsection{Introduction}

The increasing diffusion of information technology is on the brink of revolutionizing the way people shop. This development does not only affect digital distribution channels, but also bricks-and-mortar stores: Retailers progressively substitute or enlarge traditional modes of service delivery by sales clerks through the implementation of technology (Colby \& Parasuraman, 2003; Lee \& Yang, 2013). These self-service technologies (SST) are defined as technological interfaces that enable customers to produce a service independent of direct service employee involvement (Chen, 2005; Meuter, et al., 2000). Examples are self-service check-outs (Dabholkar, et al., 2003; Marzocchi \& Zammit, 2006; Weijters, et al., 2007), express order terminals (Meuter, et al., 2000) and multimedia kiosks (Wang, 2012). Most often they are implemented to cut costs \& raise productivity by turning customers into co-producers of services (Hilton, et al., 2013; Meuter, et al., 2005; Roggeveen, et al., 2012; Weijters, et al., 2007) or simply to keep up with technological advancements (Demirci Orel \& Kara, 2013). Two types of SSTs can be distinguished: transaction-related technologies and customer-service or information-related technologies (Meuter, et al., 2000). Early SSTs especially focused on the first category of "technologyfacilitated transactions" (Meuter, et al., 2000), such as placing an order, scanning or paying. A taxonomy presented by Cunningham et al. (2008) based on the work of Zeithaml and Bitner (2006, p. 402) contains 11 out of 12 types of SSTs that are strictly related to transactions. In recent years, the service quality has become increasingly important as a key differentiator for retailers as sales are initiated by information rather than the simple access to a product via transaction-related technologies due to the transparency of the internet (Grewal, et al., 2004).

\subsubsection{Self-service technologies with focus on information}

Thus, the role of SSTs in retail is also changing: Current approaches are increasingly aimed at delivering information to the user and allow for the provision of customized services instead of executing transactions (Marshall, et al., 2012; Wang, 2012; Hilton, et al., 2013). Examples are mobile shopping assistants (Heijden, 2006; Resatsch, et al., 2008), social media technologies (Marshall, et al., 2012) and information kiosks (Zielke, et al., 2011). Such customer-service or information-related technologies (Meuter, et al., 2000) from the second category of SSTs are referred to as self-service information 
technologies (SSITs). SSITs render customers independent of the availability and know-how of sales clerks and reduce the search cost by pooling all the relevant information available and providing it in a much more customized way (Pantano \& Viassone, 2013). This is especially important in the case of complex products which require explanation and subsequently have a higher buying risk (Chaudhuri, 2000). They are particularly attractive for customers who are looking for a high level of individual control and want to avoid interpersonal interactions to form an opinion without being influenced by sales clerks (Meuter, et al., 2003) or for those who have a low need for personal interaction (Gelderman, et al., 2011), e.g. due to the habit of self-information on the internet. Moreover, waiting times can be reduced for customers who are searching for specific information while sales clerks are engaged in customer talks (Dabholkar, 1994; Meuter, et al., 2000). Therefore, many researchers and retailers try to identify the technology capable of best satisfying customer requests (Pantano, 2010), which is basically a question of technology acceptance. Understanding customer acceptance is highly crucial due to the huge monetary investments and late returns on investment involved in the implementation process (Pantano \& Viassone, 2013).

Such technologies are particularly suitable for retailers with a large selling space and relatively low number of sales clerks. A prominent example is the German do-it-yourself (DIY) retail segment. Since 2009 , the selling space has grown by almost $10 \%$ while the number of employees has remained stable for reasons of cost efficiency (Gemaba, 2013). As a consequence, customers suffer from a lack of service, which negatively affects customer satisfaction and ultimately the economic success of the retailer. Thus, DIY retailers implement SSITs to build up a customer-friendly service landscape and differentiate in terms of shopping experience. Thus, service quality is more important for DIY retailers than ever, especially with regard to the high number of complex products such as lawn-mowers, motor saws or drilling machines.

\subsubsection{Study objective}

The acceptance of SSTs has been broadly researched in the past. Most studies come to the conclusion that the attitude towards using technology has a strong influence on the behavioral intentions. If such a strong relation between predictor and criterion variable exists, Baron and Kenny (1986) recommend the 
analysis of the mediating effects. Thus, the question as to how that strong effect can be explained needs to be evaluated. Because the customer benefit plays a crucial role in technology acceptance and as this benefit consists in a service quality (SQ) improvement in the context of SSITs, one can assume that SQ provides explanatory potential for the relationship between the attitude towards using a technology and the intention to use. The evaluation of SQ is especially important in the context of retail SSITs as the outcome directly redounds upon the evaluation of the retailer (Meuter, et al., 2000; Wang, 2012). Recent studies, for example, have shown the huge relevance of perceived service quality (PSQ) delivered by technology-based self-services, e.g. for retail patronage (Lee \& Yang, 2013; Lee, et al., 2009) and customer satisfaction (Dabholkar \& Spaid, 2012; Demirci Orel \& Kara, 2013). But despite their growing importance in retail, to the best of our knowledge empirical work has not deepened the understanding of the relationship in the context of retail-service technologies yet. As a consequence, retailers are not able to fully understand the acceptance of new technologies without considering the customers' perception of the SQ delivered by SSTs (Lee, et al., 2009; Wang, 2012). To address this point, the study attempts to enlarge the understanding of technology acceptance in the context of retail SSTs by analyzing the mediating effect of PSQ between the attitude towards using a technology and the intention to use it.

The remainder of this paper is organized as follows: The proposed conceptual framework and a literature review on technology acceptance and service quality in retail are presented. Deduced from the relevant literature, specific research propositions are made. Following a description of the methodology, the results are provided. Subsequently, we discuss the most relevant findings and deduce theoretical and managerial implications. The limitations of the study and future research avenues conclude the paper.

\subsection{Conceptual Framework and Hypothesis Development}

The customer acceptance of new technologies is one of the most critical factors given that a lot of innovations do (not) hit the market. In order to gain a deeper understanding of the use of retail SSITs, the relevant literature is presented and the most important influencing factors for consumer acceptance are discussed. Moreover, we embed these findings in service quality research to define the conceptual framework of this study. 


\subsubsection{Acceptance of Self-Service Technologies}

Research on SST acceptance has been conducted in a broad range of different research contexts, using many different research designs and examining a great variety of different technologies. Despite this methodological diversity, the majority of quantitative studies use the technology acceptance model (TAM; Davis, 1989) or related models, such as the theory of reasoned action (TRA; Fishbein and Ajzen, 1975), as a theoretical basis, as demonstrated in a broad overview presented in Table 7.

\begin{tabular}{|c|c|c|c|c|c|c|c|}
\hline Study & SST & $\begin{array}{c}\text { Retail } \\
\text { Context }\end{array}$ & $\begin{array}{l}\text { Focus } \\
\text { on SQ }\end{array}$ & Theory & $\begin{array}{l}\text { Research } \\
\text { Design }\end{array}$ & Analysis & $\mathbf{N}$ \\
\hline $\begin{array}{l}\text { Meuter et al. } \\
(2000)\end{array}$ & diverse & $x$ & $x$ & & $\begin{array}{l}\text { online panel } \\
\text { survey }\end{array}$ & $\begin{array}{l}\text { qualitative/ } \\
\text { quantitative }\end{array}$ & 1,000 \\
\hline $\begin{array}{l}\text { Dabholkar \& } \\
\text { Bagozzi (2002) }\end{array}$ & self-service terminal & $\checkmark$ & $x$ & TAM & $\begin{array}{l}\text { laboratory } \\
\text { experiment }\end{array}$ & quantitative & 392 \\
\hline $\begin{array}{l}\text { Weijters et al. } \\
(2007)\end{array}$ & mobile self-scanning & $\checkmark$ & $x$ & $\begin{array}{l}\text { TAM, } \\
\text { Diffusion } \\
\text { Theory }\end{array}$ & field study & quantitative & 497 \\
\hline $\begin{array}{l}\text { Kowatsch \& } \\
\text { Maass (2010) }\end{array}$ & $\begin{array}{l}\text { mobile } \\
\text { recommendation } \\
\text { agent }\end{array}$ & $\checkmark$ & $x$ & $\begin{array}{l}\text { TAM, } \\
\text { Diffusion } \\
\text { Theory }\end{array}$ & $\begin{array}{l}\text { laboratory } \\
\text { experiment }\end{array}$ & quantitative & 46 \\
\hline Lee et al. (2010) & $\begin{array}{l}\text { self-service } \\
\text { checkout }\end{array}$ & $\checkmark$ & $x$ & & $\begin{array}{l}\text { online } \\
\text { survey }\end{array}$ & quantitative & 285 \\
\hline $\begin{array}{l}\text { Corvello et al. } \\
\text { (2011) }\end{array}$ & $\begin{array}{l}\text { virtual shopping } \\
\text { assistant }\end{array}$ & $\checkmark$ & $x$ & $\begin{array}{l}\text { Adaptive } \\
\text { Structuration } \\
\text { Theory }\end{array}$ & $\begin{array}{l}\text { conceptual } \\
\text { paper }\end{array}$ & & \\
\hline $\begin{array}{l}\text { Zielke et al. } \\
\text { (2011) }\end{array}$ & $\begin{array}{l}\text { interactive terminal } \\
\text { for cooking receipts }\end{array}$ & $\checkmark$ & $x$ & TAM & field study & quantitative & 216 \\
\hline $\begin{array}{l}\text { Marshall et al. } \\
(2012)\end{array}$ & $\begin{array}{l}\text { social media } \\
\text { technologies }\end{array}$ & $\checkmark$ & $\mathrm{x}$ & & $\begin{array}{l}\text { focus } \\
\text { groups }\end{array}$ & qualitative & 35 \\
\hline Wang (2012) & $\begin{array}{l}\text { multimedia kiosk: } \\
\text { payment, ticketing, } \\
\text { downloads }\end{array}$ & $\checkmark$ & $x$ & $\begin{array}{l}\text { Expectation- } \\
\text { Confirmation } \\
\text { Model }\end{array}$ & $\begin{array}{l}\text { online panel } \\
\text { survey }\end{array}$ & quantitative & 424 \\
\hline $\begin{array}{l}\text { Hilton et al. } \\
(2013)\end{array}$ & diverse & $\mathbf{x}$ & $(\checkmark)$ & & $\begin{array}{l}\text { in-depth } \\
\text { interviews }\end{array}$ & qualitative & 24 \\
\hline $\begin{array}{l}\text { Demirci Orel \& } \\
\text { Kara (2013) }\end{array}$ & $\begin{array}{l}\text { self-service } \\
\text { checkout }\end{array}$ & $\checkmark$ & $(\checkmark)$ & & field study & quantitative & 275 \\
\hline $\begin{array}{l}\text { Lee \& Yang } \\
(2013)\end{array}$ & $\begin{array}{l}\text { self-service } \\
\text { checkout }\end{array}$ & $\checkmark$ & $\checkmark$ & TRA & $\begin{array}{l}\text { online panel } \\
\text { survey }\end{array}$ & quantitative & 300 \\
\hline
\end{tabular}

Table 7: Overview of relevant literature on retail SST acceptance 
According to TAM, the acceptance of a technology is reflected in the strength of attitude towards using (ATU) and the intention to use (Davis, et al., 1989), which in turn are fundamentally influenced by the constructs of perceived usefulness (PU) and perceived ease of use (PEOU). PU is defined as "the degree to which a person believes that using a particular system would enhance his or her job performance" (Davis, 1989, p. 320). PEOU in turn is defined by the user's subjective evaluations on how much cognitive effort she or he must expend when using the system (Davis, 1989, p. 320).

TAM is widely understood to be particularly useful to predict the social acceptance and use of technologies while they are still being developed and provide trustworthy estimates for both users that are very familiar and users that have (almost) no experience in using the technology (Davis, 1989). As both is the case in our study, we decided to consult the model as a basis for our research.

Within the last two decades, the TAM has been the object of criticism several times, which we need to address before setting up the conceptual framework of this study. One point for questioning the model is the limitation to PU and PEOU as independent variables. Heijden (2004) claims that this conceptualization makes the TAM inappropriate for hedonic information systems and presents an alternative model. As an important insight from our pre-studies we figured out that the buying process in DIY retail seems to be highly goal-respectively utility-oriented. Thus, we assume that hedonic aspects of SSIT-usage are not particularly crucial in the present research context. Moreover, Benbasat and Barki (2007) criticize that PU has been treated as a "black box" in recent TAM research without investigating what actually makes an IT system useful. Indeed, this point is critical in the SSIT context: It is not the technology itself that constitutes the usefulness for a user but rather the information that is accessed through the technology and that satisfies the user's particular need. Thus, we agree with Dabholkar and Bagozzi (2002), who suggest that PU is not strictly relevant for SSTs that are not owned by the customer. In the present research model, we replace PU by the perceived information quality (PIQ) that refers to the additional value customers associate with the SSIT (Childers, et al., 2001; Weijters, et al., 2007). Studies from SST research suppose that PIQ is mainly influenced by the quality and quantity of information. Yang et al. (2005) conceptualize PIQ as a construct consisting of the adequacy of information (AI, referring to the quantity of information) and the usefulness of content (UC, referring 
to the quality of information). Because the buying decision is based on the quantity and quality of the available information about a product, AI and UC play a crucial role in the evaluation of the SSIT. Therefore, we hypothesize:

\section{H1. The adequacy of information has a positive impact on the attitude towards using the SSIT.}

\section{H2. The usefulness of content has a positive impact on the attitude towards using the SSIT.}

Based on the underlying assumptions of the TAM, PEOU represents the second important acceptance predictor (Davis, 1989). As mentioned above, it concerns the user friendliness or convenience of the retail SSIT. Research has advocated that retailers need to advertise a technology's ease of use to ensure that customers develop a positive attitude towards the system (Dabholkar \& Bagozzi, 2002). Moreover, if customers find a technology easy to use, they consider the self-service as an attractive alternative as it reduces the effort involved in using the service and reduces the risk involved (Shamdasani, et al., 2008). Thus, PEOU is supposed to positively influence the attitude towards using the SSIT.

\section{H3. The perceived ease of use has a positive impact on the attitude towards using the SSIT.}

The customer's attitude towards the use of novel technologies is widely believed to have an impact on the behavioral intention to use a system (Fishbein \& Ajzen, 1975; Curran \& Meuter, 2005). As the participants already got involved with the SSIT during the experiment, the intention to reuse (IR) the system has been used as a dependent variable in this research instead of the intention to use. Thus, we hypothesize:

H4. The attitude towards using the SSIT has a positive impact on the intention to reuse the SSIT.

\subsubsection{Service Quality}

However, some may say that TAM research has reached its saturation point (Benbasat \& Barki, 2007) with regard to the multiplicity of studies. We have identified gaps in the present literature that require further examination. Some studies in a similar context have shown the high relevance of service quality for retail patronage (Lee \& Yang, 2013) and customer satisfaction (Kuo, et al., 2009). But as outlined

in Table 7, SSTs geared towards improvements in retail service quality are still an underrepresented 
research field. Moreover, the previous research specifically called for research to extend the TAM with regard to the relationship between ATU and IR in the context of technology-based self-services (Oghazi, et al., 2012).

The stream of research investigating the concept of PSQ argues that as the customer is in the focal point of service quality, only his perception of quality is critical (Grönroos, 1993; Anitsal \& Paige, 2006). Thus, we consider PSQ instead of SQ in the following. PSQ can be defined as the evaluation of the result of the comparison that customers make between the expectations for a service and the perception of the way the service has been performed (Parasuraman, et al., 1985; Lehtinen \& Lehtinen, 1991). In recent decades, SQ has predominantly been understood as a global measure for a company's offering (Parasuraman, et al., 1988). Nowadays, however, researchers argue that the assessment of SQ should have a narrower focus on every different service offering because of its unique nature (Demirci Orel \& Kara, 2013). Thus, when we consider PSQ in this context we mean the quality perception of the SSIT rather than the total quality perception of the retailer.

Services above the adequate level are considered capable of creating a competitive advantage for a retailer (Zeithaml \& Berry, 1993). In the case of SSITs, the implementation leads to a perception of enhanced service when customers are able to obtain high quality information more conveniently and quickly (Demirci Orel \& Kara, 2013). Bitner (1992) also claimed that PSQ is closely related to ATU. Thus, the positive evaluation of using a technology is a prerequisite for a favorable perception of service quality. Consequently, there might be a positive relationship between ATU and PSQ in the context of SSITs (Dabholkar, 1996). Therefore, it is postulated:

\section{H5. The attitude towards using the SSIT has a positive impact on the perceived service quality.}

Boulding et al. (1993) reveal that there is a positive correlation between PSQ and behavioral intentions. Moreover, PSQ has been considered as a direct antecedent of IR within the technology acceptance paradigm (Shamdasani, et al., 2008). Zeithaml et al. (1996) and Dabholkar (1996) support their findings. Also in a similar research context, PSQ is found to be a predictor of the intention to use an SSIT (Lee, et al., 2013). If customers evaluate the output delivered by a high-quality SSIT, they will intend to use it again. Thus, one can assume as follows: 


\section{H6. The perceived service quality has a positive impact on the intention to reuse the SSIT.}

In the behavioral literature, it is widely presumed that processes that link attitudes towards an object and behavior exist (Snyder \& Ickes, 1985; Sherman \& Fazio, 1983). However, there is little agreement about the concrete way the TAM constructs are related to behavioral intentions (Brady, et al., 2005). Especially the strong relationship between ATU and IR is rarely examined. Baron and Kenny (1986) recommend the introduction of a mediator when such a strong relation between the predictor and criterion variable exist. Further studies examined several mediation effects of external variables within the TAM (BurtonJones \& Hubona, 2006). With regard to the major importance of service quality in the context of retail service technologies, it might be reasonable to analyze the possibility that PSQ intervenes between ATU and IR to gain a deeper understanding of how the effect is produced (Preacher \& Hayes, 2004).

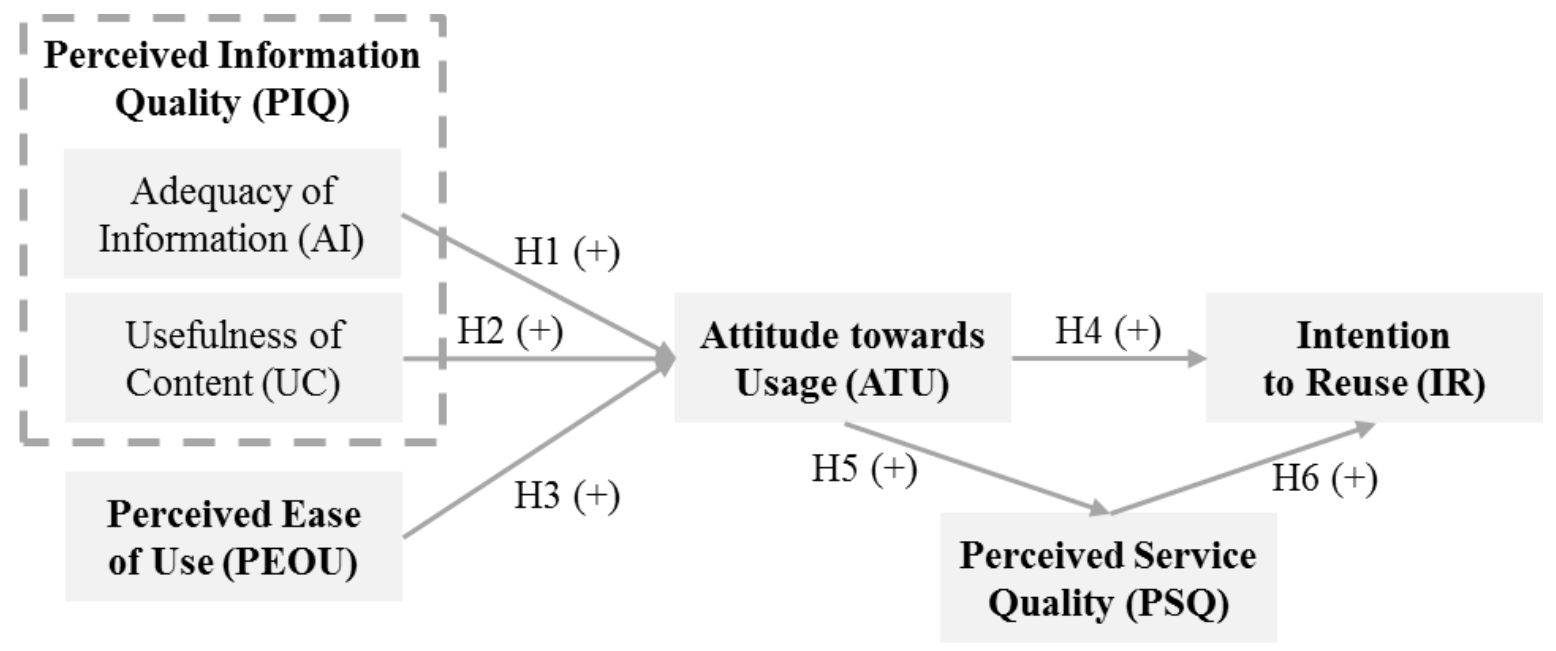

Figure 7: Proposed Model and Hypotheses

\subsection{Methodology}

\subsubsection{Research Setting}

The study is conducted using the context of DIY retail, more precisely the product segment of drilling machines. Drilling machines are among the complex product categories that require in-depth information and explanation and therefore seem to be well-suited to analyze a self-information technology. Building centers and home improvement stores look back on a long history of self-service systems as this was one of the first retail segments to introduce digital point-of-sale media. Furthermore, 
DIY retail is characterized by a high standardization potential for customer questions and a low staff density, which underlines the need for digital advisory systems. Thus, the DIY context is particularly suitable for this research.

\subsubsection{Procedure and Participants}

The study was carried out based on a four-step structure: Firstly, pre-studies were conducted to identify the relevant constructs influencing the acceptance of the SSIT. In expert interviews, sales clerks from DIY retail characterized the most important questions addressed to them by customers and explained the challenge of a low staff density in the stores. These findings were compared with qualitative interviews with DIY customers who complained about the poor reachability of employees. Many of them stated that they use online resources via their smartphone to gather further information about complex products in the store, supporting the choice of the retail segment. Additionally, the way customers purchase drilling machines was observed to support the insights gained in the interviews with behavioral information.

Secondly, a touch-sensitive application for Tablet PCs was developed as a stimulus for the subsequent experiment. By integrating online content such as detailed product information, images, customer reviews and test results, the application was able to find the best-fitting product based on a structured needs assessment, considering criteria such as price range, drilling substrate, weight or frequency of use. Besides the functionality of a product finder, a comparative tool was offered, focusing on the discriminant features of two or more products chosen by the user.

Thirdly, a scenario-based laboratory experiment was conducted as the main study. To imitate a real information process, an artificial shopping environment was created by attaching big posters with motives of drilling machine shelves to the walls. The experiment started with a brief introduction to a concrete buying scenario and an orientation phase before the participants used the application.

Finally, the test subjects answered a structured questionnaire on their assessments of the use of the SSIT as well as individual traits and demographic characteristics. 
1

Pre-Studies: Identification of Relevant Constructs

$\begin{array}{ccc}\text { Expert Interviews } & \text { Interviews with } & \begin{array}{c}\text { Observations of the } \\ \text { with DIY-Sales } \\ \text { Clerks }\end{array} \\ \text { Customers in DIY- } & \text { Retail } & \text { of DIY-Customers }\end{array}$

2 Development of a Touch-Sensitive Ready-to-Use Application

3 Laboratory Experiment in an Artificial Shopping Environment

4

\section{Figure 8: Structure of the Study}

The participants in the laboratory experiment were recruited in the urban center of a medium-sized city in Germany. Consequently, the study was conducted in one of the Western European markets that already has a relatively strong penetration of SST (Wang, 2012). A total of 225 potential DIY shoppers tested the application and answered the questionnaire in spring 2013.

A large proportion of students participated in the experiment. As a consequence, $60 \%$ of the test subjects were between 18 and 25 years of age. Although many of them had a concrete need for tools after leaving the parents' home and showed a high affinity towards the DIY segment, we consider the composition of the sample as a possible limitation. Concerning the gender, with a proportion of $49 \%$ females the sample was representative. Moreover, $83 \%$ already owned a smartphone and $12 \%$ had a Tablet PC.

Table 8 provides an overview of the SSIT functionalities used by the participants in the study. Besides the comparative tool (45\%), the majority of the respondents used the product finder (84\%) to make an adequate decision. Therefore, the most frequently used filter criteria within the product finder were the price range $(69 \%)$, the drilling substrate $(66 \%)$, the reason for use $(64 \%)$ and the customer reviews (45\%). In contrast, battery life (9\%), brand (8\%) and type of drilling machine (e.g. drill hammer, impact drill, cordless drill; 7\%) received much less attention. 


\begin{tabular}{|l|l|}
\hline Functionality & Frequency of usage \\
\hline \hline comparative tool & $45 \%$ \\
\hline product finder (filter) & $84 \%$ \\
\hline price range & $69 \%$ \\
drilling substrate & $66 \%$ \\
reason for usage & $64 \%$ \\
customer reviews & $45 \%$ \\
weight & $16 \%$ \\
frequency of use & $13 \%$ \\
battery life & $9 \%$ \\
brand & $8 \%$ \\
type of drilling machine & $7 \%$ \\
\hline
\end{tabular}

Table 8: Functionalities of the application used in the experiment

\subsubsection{Construct Measurement}

The measures for each construct were adapted from the existing literature. Items were translated and formulated, measuring the constructs in the conceptual model displayed in Figure 7. In some cases, the wording had to be changed slightly due to language differences and to suit the current research context. The researchers independently back-translated the wording to ensure a high translation quality.

For AI and UC, a scale consisting of four and five items borrowed from the work of Yang et al. (2005) was used. PEOU was measured using a four-item scale based on the work of Davis (1989). To measure ATU and IR, scales consisting of four items adapted from Venkatesh, et al. (2003) were used. Finally, PSQ was measured with two items borrowed from Brady and Cronin (2001). All the items were measured using a five-point Likert scale ranging from 1 (meaning "strongly disagree") to 5 (meaning "strongly agree"). Demographic variables such as age, gender, income and profession were also included, as well as individual predispositions such as product experience or technology readiness. 


\subsection{Results}

\subsubsection{Analysis Strategy}

This paper employed the partial least squares (PLS) approach using SmartPLS 2.0 (Ringle, et al., 2005) to estimate the measurement and structural parameters in the structural equation model (SEM). PLS is an iterative combination of principal component analysis and ordinary least squares path analysis. Its purpose is to maximize the prediction quality of endogenous constructs (Yi, et al., 2013). In contrast to covariance-based approaches of SEM, PLS does not require a multivariate normal dataset (Jain, et al., 2012) and it is recommended for small sample sizes. Furthermore, PLS underlines the explorative approach of the study (Götz, et al., 2010, p. 692). Referring to Jarvis et al. (2003), the relations in both the measurement models and the structural model were supposed to be reflective. The standard bootstrapping procedure in the SmartPLS software was used and a robust standard error and $t$-statistic generated. Following the recommendation of Baron and Kenny (1986) to avoid unreliability, the mediation path from ATU via PSQ to IR was also estimated by SEM. As a specialized $t$-test, the Sobel test examines if the postulated mediation effect is significant (Sobel, 1982). This test was calculated with the "Sobel Test Calculator for the Significance of Mediation" (Soper, 2013).

\subsubsection{Measurement Validation}

The internal reliability of the scale items was tested by calculating Cronbach's coefficient alpha. All constructs were proved to have a good level of reliability. All loadings of the constructs tested were greater than 0.7 (Nunally, 1978, p. 245), except for PSQ, which was slightly lower (0.665) due to the small number of measurement items. One item of the UC construct was dropped due to low and insignificant loadings $(\mathrm{SL}=0.21)$ and two items of the AI construct due to limited applicability to the research context. The results of all remaining items are presented in Table 9. Furthermore, the composite reliability was assessed, typically referring to measurements of true reliability using SEM. Composite reliability is supposed to produce better estimates of true reliability than Cronbach's coefficient alpha as it includes the number of indicators used (Chin, 1998; Hair, et al., 2006, p. 777). All constructs achieved values much greater than 0.7 (Hulland, 1999). Moreover, the average variance extracted (AVE) 
was analyzed as an additional measure for evaluating the set of indicators. The AVE should be higher than 0.5 , meaning that at least $50 \%$ of the total variance of all indicators can be explained by the construct (Fornell \& Larcker, 1981). In this study, each construct fulfills this criterion as shown in Table 9.

\begin{tabular}{|c|c|c|c|c|c|c|}
\hline \multirow{3}{*}{$\begin{array}{l}\text { Construct } \\
\begin{array}{l}\text { Adequacy of } \\
\text { Information }\end{array}\end{array}$} & \multirow{2}{*}{$\begin{array}{c}\text { Item } \\
\text { AI1 }\end{array}$} & \multicolumn{2}{|c|}{$\begin{array}{l}\text { Standard } \\
\text { loadings }\end{array}$} & \multirow{2}{*}{$\begin{array}{c}\begin{array}{c}\text { Cronbach's } \\
\text { coefficient } \\
\text { alpha }\end{array} \\
0.739\end{array}$} & \multirow{2}{*}{$\begin{array}{c}\begin{array}{c}\text { Composite } \\
\text { reliability }\end{array} \\
0.847\end{array}$} & \multirow{2}{*}{$\begin{array}{c}\begin{array}{c}\text { Average variance } \\
\text { extracted }\end{array} \\
0.651\end{array}$} \\
\hline & & 0.685 & $(6.517)$ & & & \\
\hline & $\begin{array}{l}\mathrm{AI} 2 \\
\mathrm{AI} 3\end{array}$ & $\begin{array}{l}0.862 \\
0.861\end{array}$ & $\begin{array}{l}(23.612) \\
(21.632)\end{array}$ & & & \\
\hline $\begin{array}{l}\text { Usefulness of } \\
\text { Content }\end{array}$ & $\begin{array}{l}\text { UC1 } \\
\text { UC2 } \\
\text { UC3 }\end{array}$ & $\begin{array}{l}0.792 \\
0.806 \\
0.829\end{array}$ & $\begin{array}{r}(9.191) \\
(10.596) \\
(20.695)\end{array}$ & 0.749 & 0.851 & 0.655 \\
\hline $\begin{array}{l}\text { Perceived Ease of } \\
\text { Use }\end{array}$ & $\begin{array}{l}\text { PEOU1 } \\
\text { PEOU2 } \\
\text { PEOU3 } \\
\text { PEOU4 }\end{array}$ & $\begin{array}{l}0.771 \\
0.826 \\
0.797 \\
0.705\end{array}$ & $\begin{array}{r}(14.095) \\
(18.673) \\
(14.212) \\
(9.213)\end{array}$ & 0.779 & 0.858 & 0.602 \\
\hline $\begin{array}{l}\text { Attitude towards } \\
\text { Usage }\end{array}$ & $\begin{array}{l}\text { ATU1 } \\
\text { ATU2 } \\
\text { ATU3 } \\
\text { ATU4 }\end{array}$ & $\begin{array}{l}0.878 \\
0.861 \\
0.894 \\
0.839\end{array}$ & $\begin{array}{l}(28.075) \\
(25.330) \\
(35.221) \\
(24.012)\end{array}$ & 0.891 & 0.925 & 0.754 \\
\hline $\begin{array}{l}\text { Perceived Service } \\
\text { Quality }\end{array}$ & $\begin{array}{l}\text { PSQ1 } \\
\text { PSQ2 }\end{array}$ & $\begin{array}{l}0.879 \\
0.852\end{array}$ & $\begin{array}{l}(30.260) \\
(19.660)\end{array}$ & 0.665 & 0.856 & 0.749 \\
\hline Intention to Reuse & $\begin{array}{l}\text { IR1 } \\
\text { IR2 } \\
\text { IR3 } \\
\text { IR4 }\end{array}$ & $\begin{array}{l}0.897 \\
0.753 \\
0.849 \\
0.848\end{array}$ & $\begin{array}{l}(39.708) \\
(17.184) \\
(20.356) \\
(24.272)\end{array}$ & 0.858 & 0.904 & 0.703 \\
\hline
\end{tabular}

NOTE: AI = Adequacy of Information; UC = Usefulness of Content; PEOU = Perceived Ease of Use; ATU = Attitude towards Usage; PSQ = Perceived Service Quality; IR = Intention to Reuse.

\section{Table 9: Measure and Items}

Subsequently, the discriminant validity of the measures was assessed and item cross-loadings for all constructs inspected (Chin, 1998). As no item loads were higher on another construct than the construct it is intended to measure, it can be concluded that all constructs exhibit satisfactory discriminant validity and can be deemed unrelated.

Additionally, the average variance detected for each construct exceeds the intercorrelations among the constructs as demanded by Fornell and Larcker (1981) to make sure that a construct shares more variance with its measures than with other model constructs (Chin, 1998). Table 10 provides a detailed summary of all the results regarding the shared variance (SV) and the AVE, showing that the criterion is fulfilled by all constructs. 


\begin{tabular}{|c|c|c|c|c|c|c|}
\hline SV/AVE & ATU & IR & PEOU & $\mathbf{U C}$ & AI & PSQ \\
\hline 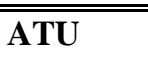 & 0.754 & & & & & \\
\hline IR & 0.639 & 0.703 & & & & \\
\hline PEOU & 0.250 & 0.155 & 0.602 & & & \\
\hline UC & 0.370 & 0.337 & 0.197 & 0.655 & & \\
\hline AI & 0.237 & 0.172 & 0.078 & 0.286 & 0.651 & \\
\hline PSQ & 0.448 & 0.393 & 0.116 & 0.316 & 0.302 & 0.749 \\
\hline
\end{tabular}

Table 10: Shared Variance and Average Variance Extracted

\subsubsection{Hypotheses Tests}

The hypotheses postulate that the AI, UC, and PEOU have a positive influence on the ATU (H1, H2, and H3). Also, the ATU should increase the IR (H4) and the PSQ (H5). Moreover, the IR is influenced by the PSQ (H6). To test the proposed model and establish the significance of parameter estimates, $t$ values using 1,000 bootstrap samples were calculated (Henseler, et al., 2009). As directional hypotheses were postulated, one-tailed significance tests were conducted.

Table 11 presents the path coefficients $\beta$ and $t$-values for the model along with the $\mathrm{R}^{2}$ for ATU, PSQ and IR and indicates the results of the hypothesis test for a level of significance of $0.5 \%$. All postulated hypotheses are confirmed except for $\mathrm{H} 1(\mathrm{AI} \rightarrow \mathrm{ATU})$. The results reveal that the UC $(\beta 1=0.374 ; p<$ $0.01)$ and the PEOU $(\beta 3=0.276 ; p<0.001)$ have a significant effect on the ATU, supporting H2 and H3 whereas AI $(\beta 2=0.209 ; p<$ n.s. $)$ does not exhibit a significant influence on ATU. Consistent with $\mathrm{H} 4$, the effect of the ATU $(\beta 5=0.689 ; p<0.001)$ on the IR is significant and positive. As H5 predicted, the effect of the ATU $(\beta 4=0.669 ; p<0.001)$ on the PSQ is also significant and positive. In addition, the effect of PSQ on IR $(\beta 6=0.166 ; \mathrm{p}<0.01)$ supports H6. 


\begin{tabular}{|c|c|c|c|c|c|}
\hline & & & Standardized & & \\
\hline Hypothesis & Relationship & Direction & Coefficient $(\beta)$ & $t$-value & Result \\
\hline H1 & $\mathrm{AI} \rightarrow \mathrm{ATU}$ & Positive & 0.209 & 1.700 & "Not Supported \\
\hline $\mathrm{H} 2$ & $\mathrm{UC} \rightarrow \mathrm{ATU}$ & Positive & 0.374 & 2.900 & Supported \\
\hline H3 & $\mathrm{PEOU} \rightarrow \mathrm{ATU}$ & Positive & 0.276 & 3.321 & Supported \\
\hline $\mathrm{H} 4$ & $\mathrm{ATU} \rightarrow \mathrm{IR}$ & Positive & 0.689 & 9.357 & Supported \\
\hline H5 & $\mathrm{ATU} \rightarrow \mathrm{PSQ}$ & Positive & 0.669 & 11.452 & Supported \\
\hline H6 & $\mathrm{PSQ} \rightarrow \mathrm{IR}$ & Positive & 0.166 & 2.086 & Supported \\
\hline \multicolumn{6}{|l|}{ Fit } \\
\hline Measures & Endogenous Construct & Model & & & \\
\hline \multirow[t]{3}{*}{$\overline{\mathrm{R}^{2}}$} & $\overline{\mathrm{ATU}}$ & 0.467 & & & \\
\hline & IR & 0.665 & & & \\
\hline & PSQ & 0.448 & & & \\
\hline
\end{tabular}

\section{Table 11: Hypotheses Testing}

The relationship between the ATU and the IR is assumed to be a mediation effect that exists due to the influence of the PSQ, in addition to the direct effect. The results are shown in Table 12.

\begin{tabular}{|ll|}
\hline Direct Effect with no mediator & $\mathbf{0 . 8 0 1}$ \\
Direct Effect with mediator & $\mathbf{0 . 6 8 9}$ \\
\hline \hline ATU $\rightarrow$ PSQ (Beta) & 0.669 \\
PSQ $\rightarrow$ IR (Beta) & 0.166 \\
ATU $\rightarrow$ PSQ (SE) & 0.059 \\
PSQ $\rightarrow$ IR (SE) & 0.080 \\
\hline \hline Sobel test statistic: & $\mathbf{2 . 0 4 6}>\mathbf{1 . 9 6}$ \\
One-tailed probability: & $0.020<0.05$ \\
Two-tailed probability: & $0.041<0.05$ \\
\hline
\end{tabular}

NOTE: SE = Standardized Error

Table 12: Mediation effect of perceived service quality 
By including the PSQ as a mediator, the effect of the ATU on IR is reduced while the effect of the PSQ remains significant. Thus, a partial mediation has been proven (Preacher \& Hayes, 2004). The Sobel test examines a significant effect $(z=2.046, \mathrm{p}<0.01)$ of the postulated mediation (Sobel, 1982).

The model has great explanatory power for the dependent variables: As shown in Table 12, more than $65 \%$ of the variance of the IR is explained by the exogenous factors. Obviously, the integration of the PSQ improves the prediction quality of the TAM. Also, the explanatory power for the PSQ with almost $45 \%$ and for the ATU with more than $46 \%$ is high, suggesting that UC and PEOU are predictors of ATU. As mentioned above, all suggested relationships were confirmed except one (AI $\rightarrow$ ATU). Most of them were shown to be significant on a level of $0.1 \%$ as pictured in Figure 9 .

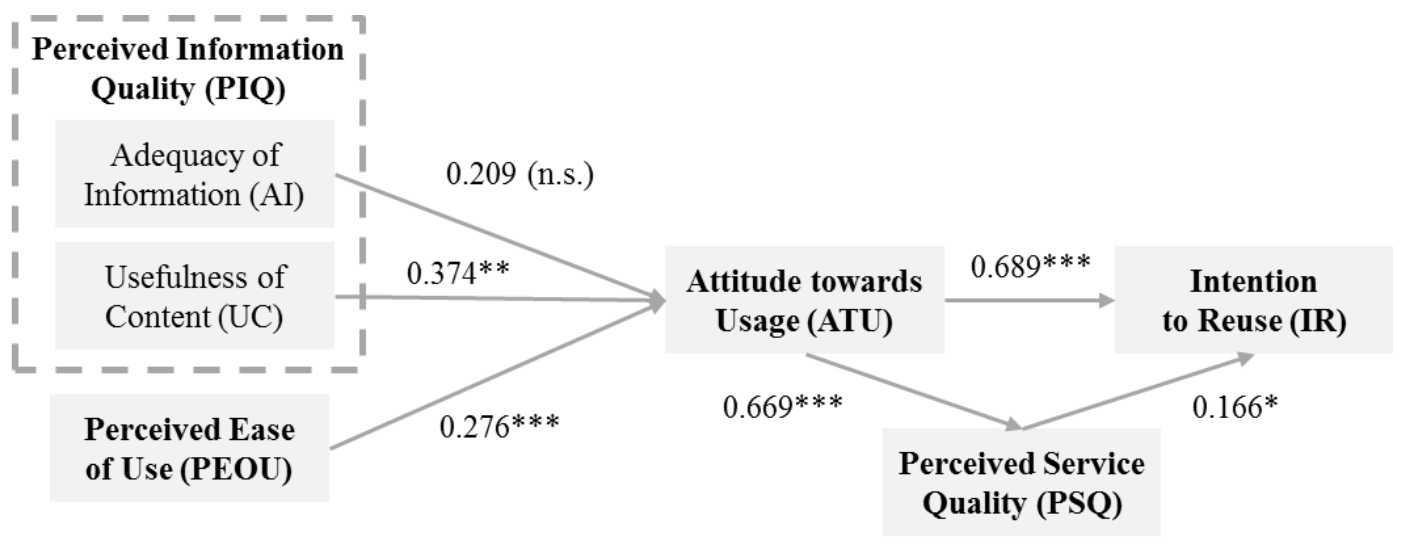

Notes: $* * * p<0.001,{ }^{* *} \mathrm{p}<0.01,{ }^{*} \mathrm{p}<0.05$

Figure 9: Empirical Results

To assess the problem of a possible omitted variable bias, which can occur when a model incorrectly leaves out one or more important causal factors, several control variables (i.e. customer age and gender, customer education, technology readiness, product experience and need for interaction) were included in the structural model. This inclusion did not alter the substantive findings, indicating the absence of an omitted variable bias (Chamberlain, 1979).

\subsection{Discussion}

Despite the fact that a significant amount of research has been conducted in recent years, understanding the customer acceptance of interactive self-service technologies remains a challenge for researchers 
(Venkatesh, 2006). Whereas transaction-related technologies have already been intensively researched, this holds particularly true for customer-service and information-related technologies in retail. Especially the relationship between ATU and IR is rarely examined. To gain a deeper understanding of this relationship, we used a touch-sensitive application for Tablet PCs including a sophisticated product finder and comparison tool developed for the study. By bundling all the product-related information available and displaying them in a highly customized way based on a structured needs assessment, the application supports the customer's solution-oriented information process.

The empirical results provide strong evidence to support the proposed model as almost all of the postulated relations were shown to be highly significant. Consistent with previous research in the field of technology acceptance, PEOU has a positive influence on the ATU. While the UC has a positive impact on the ATU, the effect of AI on ATU is not significant. This suggests that the quality but not the quantity of information is important for the evaluation of an SSIT. However, the influence of the PEOU was weaker. Therefore, the results are in line with other studies from similar research contexts.

Special emphasis has been placed on the effect of the ATU on the IR. Firstly, we confirmed the expected strong relationship between these two constructs. Secondly, it was shown that the PSQ partially mediates the effect between the ATU and IR. Thus, with regard to the findings of Lee and Yang (2013) and Fairhurst and Lee (2009), who found PSQ to have a high relevance for retail patronage and customer satisfaction, we can add that PSQ is also relevant for technology acceptance as it mediates the relationship between the attitude and behavioral intentions.

\subsubsection{Theoretical and Managerial Implications}

SSITs are becoming increasingly relevant for retailers to improve customer satisfaction and create a competitive advantage by offering information-related services. Due to the potential to reduce waiting times, SSITs are especially useful for retail segments with a poor availability of sales clerks and substantial need for information like the DIY branch. Managers who wish to use SSITs should gain a profound understanding of the factors that drive customer acceptance and usage intentions of such technology first. 
The PSQ accounts for the relationship between ATU and IR and serves as a mediator through which the stressor affects the outcome variable. This implies that if the information service delivered by the SSIT is not well evaluated by users, the intention to use the SSIT will decrease again. This supports the assumption that the ATU is related to the evaluation process of the SQ after using the SSIT. Therefore, retailers have to emphasize the service-related value of the SSIT in their point-of-sale communication to support continuous usage.

As a critical element of the TAM the perceived usefulness was replaced by PIQ, taking into account the special characteristics of information-related technologies (Dabholkar \& Bagozzi, 2002). Referring to the aspects of quality and quantity of information and in line with previous research (Yang, et al., 2005) PIQ was represented through the AI and UC. While UC has a strong effect on ATU, AI does not exhibit a significant influence. This can be explained through the use of a product finder that does not display all available but only relevant information selected by the user himself. For retailers, it can be deduced that once the quantity of information is substantial enough to avoid search queries without results, no positive effect on the attitude towards the SSIT can be expected anymore.

Moreover, only a limited number of information is used when making a buying decision. In our study the price, the drilling substrate, the reason for usage or the customer reviews were the most commonly demanded information. To recap, it is not important to provide a high variety of information, but information with a high relevance for the needs of the customer. Therefore, SSITs should be designed with regard to the target audience and their special requirements using a product finder with different filter options and product comparing tools to avoid overstimulation.

Customers consider SSITs as an attractive alternative if it is believed to be easy to use. The high share of smartphone users in the sample (83\%) indicates a high affinity towards technology, which matches the appreciation of the SSIT and the positive evaluation of its ease of use. Thus, the convenience should be advertised by the retailer to increase the willingness for the first use. The influence of PEOU on ATU was weaker than the influence of the content quality. Obviously, the SSIT is mainly evaluated with regard to its problem-solving capacities, not to the cognitive effort involved in its use. So the most important influencing factor for the ongoing usage of such a technology is the real value added. One 
explanation might be that people have learned how to use touchscreen terminals over time. Therefore, it is even more important to employ well-known control elements and gestures. Moreover, we included the perceived enjoyment as a control variable in the model to assess the importance of hedonic aspects with regard to Hejden (2004). As assumed above, hedonic aspects of SSIT-usage are not particularly relevant in the present research-context.

The application used in this study provided both an interactive product finder and a comparative feature. Most users focused on the product finder (84\%) based on their personal needs instead of comparing relevant products directly (45\%). Thus, the design of a digital advisor should be geared towards the practice of sales clerks starting with the assessment of customer needs. Moreover, care should be taken to meet high technical standards regarding up to date content, advanced search algorithms and high quality images.

\subsubsection{Limitations and Further Research}

Although the results and findings contribute to the academic literature, there are certain limitations that require further examination. First of all, the study has a rather explorative character using a scenariobased laboratory experiment as a method of collecting data. Thus, the study should be replicated in a field setting with customers in a real-need situation to confirm the proposed research model and the results. Moreover, the actual behavior rather than the behavioral intention should be analyzed. Although no trade-segment specific constructs were used, the evidence provided in this study is limited to DIY retail. However, many respondents declared that they could imagine using similar SSITs in different retail segments, such as consumer electronics. A self-selection bias cannot be excluded as the test subjects participated in the experiment voluntarily. As the data was obtained near the university campus, the sample contains a high proportion of students and is not fully representative. As a consequence, the data might lack variance in some socio-demographic criteria. Moreover, the development of the application focused on functionality and was aimed at reducing the influence of interface design. As a result, one factor that potentially affects the adoption was eliminated (Meuter, et al., 2000). 
Future research is encouraged to expand the findings of this study across various industries to provide greater generalizability. As the sample used in this study was homogeneous to some extent, further representative studies should analyze the moderating effects of individual characteristics and predispositions such as age, technology anxiety or need for interaction (Lee \& Yang, 2013). Further research should also deepen the insights into the targeted customer groups to improve the usability of the software and the communication in the closer surroundings of the digital system. The experiment was conducted using a Tablet PC as hardware. Although the participants were free to try the application in a mobile manner, almost no test subjects took the Tablet PC with them. This begs the question as to whether the mobility of the system is a relevant influencing factor for usage and adoption. Furthermore, the behavioral intentions of non-users should be compared with the intentions of the SST-users investigated in this research (Proença \& Rodrigues, 2011). The comparison between an SSIT and mobile technology that supports sales clerks could shed some light on the much discussed question as to how important the human is in retailing. 


\subsection{References (Study 2)}

Anitsal, I., \& Paige, R.C. (2006). An exploratory study on consumer perceptions of service quality in technology-based self-service. Services Marketing Quarterly, 27(3), 53-67.

Baron, R.M., \& Kenny, D.A. (1986). The moderator-mediator variable distinction in social psychological research: Conceptual, strategic, and statistical considerations. Journal of Personality and Social Psychology, 51(6), 1173-1182.

Benbasat, I., \& Barki, H. (2007). Quo vadis, TAM. Journal of the Association for Information Systems, 8(4), 211-218.

Bitner, M.J. (1992). Servicescapes: The impact of physical surroundings on customers and employees. Journal of Marketing, 56(2), 57-71.

Boulding, W., Kalra, A., Staelin, R., \& Zeithaml, V.A. (1993). A dynamic process model of service quality: from expectations to behavioral intentions. Journal of Marketing Research, 30(1), 7-27.

Brady, M.K., \& Cronin, J.J. Jr. (2001). Some new thoughts on conceptualizing perceived service quality: a hierarchical approach. Journal of Marketing, 65(3), 34-49.

Brady, M.K., Knight, G.A., Cronin, J.J. Jr., Tomas, G., Hult, M., \& Keillor, B.D. (2005). Removing the contextual lens: a multinational, multi-setting comparison of service evaluation models. Journal of Retailing, 81(3), 215-230.

Burton-Jones, A., \& Hubona, G. (2006). The mediation of external variables in the technology acceptance model. Information \& Management, 43(6), 706-717.

Chamberlain, G. (1979). Heterogeneity, omitted variable bias, and duration dependence, Harvard Institute of Economic Research, Cambridge.

Chaudhuri, A. (2000). A macro analysis of the relationship of product involvement and information search: The role of risk. Journal of Marketing Theory and Practice, 8(1), 1-15. 
Chen, K.-J. (2005). Technology-based service and customer satisfaction in developing countries international. Journal of Management, 22(2), 307-318.

Childers, T.L., Carr, C.L., Peck, J., \& Carson, S. (2001). Hedonic and utilitarian motivations for online retail shopping behavior. Journal of Retailing, 77(4), 511-535.

Chin, W. W. (1998). The partial least squares approach to structural equation modeling. Modern methods for business research, 295(2), 295-336.

Colby, C.L., \& Parasuraman, A. (2003). Technology Still Matters Never mind the doomsayers. Eservices are alive, well, and positioned for growth. Marketing Management, 12(4), 28-33.

Corvello, V., Pantano, E., \& Tavernise, A. (2011). The Design of an Advanced Virtual Shopping Assistant for Improving Consumer Experience, in: Pantano, E., Timmermans, H. (Eds.), Advanced Technologies Management for Retailing, 70-86.

Curran, J.M., \& Meuter, M.L. (2005). Self-service technology adoption: comparing three technologies. Journal of Services Marketing, 19(2), 103-113.

Cunningham, L.F., Young, C.E., \& Gerlach, J.H. (2008). Consumer views of self-service technologies. Service Industries Journal, 28(6), 719-732.

Dabholkar, P.A. (1994). Technology-Based Service Delivery: A Classification Scheme for Developing Marketing Strategies, in: Swartz, T.A., Bowen, D.A., Brown, S.W. (Eds.), Advances in Services Marketing and Management (Vol. 3). Emerald, Greenwich, 241-271.

Dabholkar, P.A. (1996). Consumer evaluations of new technology-based self-service options: an investigation of alternative models of service quality. International Journal of Research in Marketing, $13(1), 29-51$.

Dabholkar, P.A., \& Bagozzi, R.P. (2002). An attitudinal model of technology-based self-service: Moderating effects of consumer traits and situational factors. Journal of the Academy of Marketing Science, 30(3), 184-201. 
Dabholkar, P.A., Bobbitt, L.M., \& Lee, E.-J. (2003). Understanding consumer motivation and behavior related to self-scanning in retailing: Implications for strategy and research on technology-based selfservice. International Journal of Service Industry Management, 14(1), 59-95.

Dabholkar, P.A., \& Spaid, B.I. (2012). Service failure and recovery in using technology-based selfservice: effects on user attributions and satisfaction. The Service Industries Journal, 32(9), 1415-1432.

Davis, F.D. (1989). Perceived usefulness, perceived ease of use, and user acceptance of information technology. MIS Quarterly, 13(3), 319-340.

Davis, F.D., Bagozzi, R.P., \& Warshaw, P.R. (1989). User acceptance of computer technology: A comparison of two theoretical models. Management Science, 35(8), 982-1004.

Demirci Orel, F., \& Kara, A. (2013). Supermarket self-checkout service quality, customer satisfaction, and loyalty: Empirical evidence from an emerging market. Journal of Retailing and Consumer Services (in press), http://dx.doi.org/10.1016/j.jretconser.2013.07.002.

Fishbein, M., \& Ajzen, I. (1975). Belief, attitude, intention, and behavior: An introduction to theory and research, Addison-Wesley, Reading.

Fornell, C., \& Larcker, D.F. (1981). Evaluating structural equation models with unobservable variables and measurement errors. Journal of Marketing Research, 18(1), 39-50.

Gelderman, C.J., Ghijsen, P.W.T., \& van Diemen, R. (2011). Choosing self-service technologies or interpersonal services - The impact of situational factors and technology-related attitudes. Journal of Retailing and Consumer Services, 18(5), 414-421.

Gemaba - Gesellschaft für Stuktur- und Betriebsanalyse (2013). Baumarkt-Strukturuntersuchung 2013. Retrieved from http://www.gemaba.de/Baumarkte2013.pdf, Last request 16.12.2013.

Götz, O., Liehr-Gobbers, K., \& Krafft, M. (2010). Evaluation of structural equation models using the partial least squares (PLS) approach, in: Vinzi, V.E., Chin, W.W., Henseler, J., Wang, H. (Eds.), Handbook of Partial Least Squares. Springer, Berlin, 691-711. 
Grewal, D., Iyer, G.R., \& Levy, M. (2004). Internet retailing: enablers, limiters and market consequences. Journal of Business Research, 57(7), 703-713.

Grönroos, C. (1993). Quality Comes to Service, in: Scheuing, E.E., Christopher, W.F. (Eds.), Service Quality Handbook. American Management Association, New York, 17-24.

Hair, J.F., Black, W.C., Babin, B.J., Anderson, R.E., \& Tatham, R.L. (2006). Multivariate data analysis, sixth ed. Prentice-Hall, Upper Saddle River.

Heijden, H.v.d. (2004). User acceptance of hedonic information systems. MIS Quarterly, 28(4), 695704.

Heijden, H.v.d. (2006). Mobile decision support for in-store purchase decisions. Decision Support Systems, 42(2), 656-663.

Henseler, J., Ringle, C.M., \& Sinkovics, R.R. (2009). The use of partial least squares path modeling in international marketing, in: Sinkovics, R.R., Ghauri, P.N. (Eds.), Advances in international marketing (Vol. 20). Emerald, Bingley, 277-319.

Hilton, T., Hughes, T., Little, E., \& Marandi, E. (2013). Adopting self-service technology to do more with less. Journal of Services Marketing, 27(1), 3-12.

Hulland, J. (1999). Use of partial least squares (PLS) in strategic management research: A review of four recent studies. Strategic Management Journal, 20(2), 195-204.

Jain, A.K., Malhotra, N.K., \& Guan, C. (2012). Positive and negative affectivity as mediators of volunteerism and service-oriented citizenship behavior and customer loyalty. Psychology \& Marketing, 29(12), 1004-1017.

Jarvis, C., MacKenzie, S.B., \& Podsakoff, P.M. (2003). A Critical Review of Construct Indicators and Measurement Model Misspecification in Marketing and Consumer Research. Journal of Consumer Research, 30(2), 199-218. 
Kowatsch, T., \& Maass, W. (2010). In-store consumer behavior: How mobile recommendation agents influence usage intentions, product purchases, and store preferences. Computers in Human Behavior, 26(4), 697-704.

Kuo, Y.F., Wu, C.M., \& Deng, W.J. (2009). The relationships among service quality, perceived value, customer satisfaction, and post-purchase intention in mobile value-added services. Computers in Human Behavior, 25(4), 887-896.

Lee, H.-J., Cho, H.J., Xu, W., \& Fairhurst, A. (2010). The influence of consumer traits and demographics on intention to use retail self-service checkouts. Marketing Intelligence \& Planning, 28(1), 46-58.

Lee, H.J., Fairhurst, A., \& Cho, H.J. (2013). Gender differences in consumer evaluations of service quality: self-service kiosks in retail. The Service Industries Journal, 33(2), 248-265.

Lee, H.J., Fairhurst, A.E., \& Lee, M.Y. (2009). The importance of self-service kiosks in developing consumers' retail patronage intentions. Managing Service Quality, 19(6), 687-701.

Lee, H.J., \& Yang, K. (2013). Interpersonal service quality, self-service technology (SST) service quality, and retail patronage. Journal of Retailing and Consumer Services, 20(1), 51-57.

Lehtinen, U., \& Lehtinen, J.R. (1991). Two approaches to service quality dimensions. Service Industries Journal, 11(3), 287-303.

Marshall, G.W., Moncrief, W.C., Rudd, J.M., \& Lee, N. (2012). Revolution in Sales: The Impact of Social Media and Related Technology on the Selling Environment. Journal of Personal Selling and Sales Management, 32(3), 349-363.

Marzocchi, G.L., \& Zammit, A. (2006). Self-scanning technologies in retail: determinants of adoption. The Service Industries Journal, 26(6), 651-669.

Meuter, M.L., Bitner, M.J., Ostrom, A.L., \& Brown, S.W. (2005). Choosing among alternative service delivery modes: An investigation of customer trial of self-service technologies. Journal of Marketing, $69(2), 61-83$. 
Meuter, M.L., Ostrom, A.L, Roundtree, R.I., \& Bitner, M.J. (2000). Self-service technologies: Understanding customer satisfaction with technology-based service encounters. Journal of Marketing, 64(3), 50-64.

Meuter, M.L., Ostrom, A.L., Bitner, M.J., \& Roundtree, R. (2003). The influence of technology anxiety on consumer use and experiences with self-service technologies. Journal of Business Research, 56(11), 899-906.

Nunnally, J.C. (1978). Psychometric theory, second ed. McGraw-Hill, New York.

Oghazi, P., Mostaghel, R., Hultman, M., \& Parida, V. (2012). Antecedents of Technology-Based SelfService Acceptance: A Proposed Model. Services Marketing Quarterly, 33(3), 195-210.

Pantano, E. (2010). New technologies and retailing: Trends and directions. Journal of Retailing and Consumer Services, 17(3), 171-172.

Pantano, E., \& Viassone, M. (2014). Demand pull and technology push perspective in technology-based innovations for the points of sale: The retailers evaluation. Journal of Retailing and Consumer Services, 21(1), 43-47.

Parasuraman, A., Zeithaml, V.A., \& Berry, L.L. (1985). A conceptual model of service quality and its implications for future research. Journal of Marketing, 49(4), 41-50.

Parasuraman, A., Zeithaml, V.A., \& Berry, L.L. (1988). Servqual. Journal of Retailing, 64 (1), 12-40.

Preacher, K.J., \& Hayes, A.F. (2004). SPSS and SAS procedures for estimating indirect effects in simple mediation models. Behavior Research Methods, Instruments, \& Computers, 36(4), 717-731.

Proença, J.F., \& Rodrigues, M.A. (2011). A comparison of users and non-users of banking self-service technology in Portugal. Managing Service Quality, 21(2), 192-210.

Resatsch, F., Sandner, U., Leimeister, J.U., \& Krcmar, H. (2008). Do point of sale RFID-based information services make a difference? Analyzing consumer perceptions for designing smart product information services in retail business. Electronic Markets, 18(3), 216-231. 
Ringle, C.M., Wende, S., \& Will, A. (2005). SmartPLS 2.0 (beta). Retrieved from www.smartpls.de, Last request 16.12.2013.

Roggeveen, A., Tsiros, M., \& Grewal, D. (2012). Understanding the co-creation effect: When does collaborating with customers provide a lift to service recovery. Journal of the Academy of Marketing Science, 40(6), 771-790.

Shamdasani, P., Mukherjee, A., \& Malhotra, N. (2008). Antecedents and consequences of service quality in consumer evaluation of self-service internet technologies. Service Industries Journal, 28(1), $117-138$.

Sherman, S.J., \& Fazio, R.H. (1983). Parallels between attitudes and traits as predictors of behavior. Journal of Personality, 51(3), 308-345.

Sobel, M.E. (1982). Asymptotic confidence intervals for indirect effects in structural equation models. Sociological Methodology, 13, 290-312.

Soper, D.S. (2013). Sobel Test Calculator for the Significance of Mediation [Software]. Retrieved from http://www.danielsoper.com/statcalc, Last request 16.12.2013.

Snyder, M., \& Ickes, W. (1985). Personality and social behavior, in Lindzey, G., Aronson, E. (Eds.). Handbook of social psychology (Vol. 2). Random House, New York, 883-947.

Venkatesh, V. (2006). Where to go from here? Thoughts on future directions for research on individuallevel technology adoption with a focus on decision making. Decision Sciences, 37(4), 497-518.

Venkatesh, V., Morris, M.G., Davis, G.B., \& Davis, F.D. (2003). User acceptance of information technology: Toward a unified view. MIS Quarterly, 27(3), 425-478.

Wang, M.C.-H. (2012). Determinants and consequences of consumer satisfaction with self-service technology in a retail setting. Managing Service Quality, 22(2), 128-144.

Weijters, B., Rangarajan, D., Falk, T., \& Schillewaert, N. (2007). Determinants and outcomes of customers' use of self-service technology in a retail setting. Journal of Service Research, 10(1), 3-21. 
Yang, Z., Cai, C., Zhou, Z., \& Zhou, N. (2005). Development and validation of an instrument to measure user perceived service quality of information presenting web portals. Information and Management, 42(4), 575-589.

Yi, Y., Gong, T., \& Lee, H. (2013). The impact of other customers on customer citizenship behavior. Psychology \& Marketing, 30(4), 341-356.

Zeithaml, V.A., \& Berry, L.L. (1993). The nature and determinants of customer expectations of service. Journal of the Academy of Marketing Science, 21(1), 1-12.

Zeithaml, V.A., Berry, L.L., \& Parasuraman, A. (1996). The behavioral consequences of service quality. Journal of Marketing, 60(2), 31-46.

Zeithaml, V.A., \& Bitner, M.J. (2006). Services marketing: Integrating customer focus across the firm, fourth ed. McGraw-Hill, New York.

Zielke, S., Toporowski, W., \& Kniza, B. (2011). Customer acceptance of a new interactive information terminal in grocery retailing, in: Pantano, E., Timmermans, H. (Eds.), Advanced technologies management for retailing. Business Science Reference, Hershey, 289-305. 


\title{
4 Exploring Customer Segments based on the Acceptance of Self-Service Technologies in Retailing (Study 3)
}

[with Philipp Spreer]

\begin{abstract}
Technology acceptance is one of the key factors in the successful implementation and usage of service technologies. However, technologies will neither provide the same benefit nor be used by all users and therefore need to address the specific needs of the target group. While previous studies on technology acceptance barely differentiated between users, this paper explores user segments based on technology acceptance constructs - a novel approach. Building on data from a laboratory study using a retail selfservice technology prototype, a cluster analysis is employed, the results of which are two distinct segments which provide the basis for a meaningful customer approach.
\end{abstract}




\subsection{Introduction}

Information technologies are increasingly shaping the face of modern retail businesses: Not only do brick-and-mortar retailers add e-commerce to their distribution system, also the in-store shopping experience is increasingly enhanced by digital approaches such as self-service technologies (SSTs). Examples are information kiosks (Zielke, et al., 2011), interactive service systems (Kallweit, et al,. 2014), and mobile sales assistants (Spreer \& Gutknecht, 2015). Due to the potential of combining digital and traditional channels, not to mention the opportunity to provide a higher level of service without a need for further personnel, retailers are very keen to bring SSTs to their stores (Pantano \& Viassone, 2014). However, a comprehensive penetration of such in-store technologies has not occurred yet. This might be due to the fact that, firstly, large monetary investments are required for the implementation (Pantano \& Viassone, 2014); secondly, prominent success stories are sparse as only a small number of retailers have solid experience in the operation of SSTs (Wang, 2012); and thirdly, there is still a significant amount of uncertainty with regard to customer acceptance (Lee \& Yang, 2013).

Although extensive research has been carried out on the acceptance of retail technologies in general and SSTs in particular, the existing literature comes up with heterogeneous findings on the drivers of customer acceptance and the relationships among constructs (e.g., Dabholkar \& Bagozzi, 2002; Simon \& Usunier, 2007). As a consequence, researchers question the generalizability of these models across differing contexts (e.g., Burton-Jones \& Hubona, 2005; Sun \& Zhang, 2006; Venkatesh et al., 2012). One suitable approach to address this criticism is to focus more intensively on different groups of users, following the assumption that a technology will not provide the same benefit to all users. While some users consider technologies supporting the in-store decision process to be helpful and convenient (Maity \& Dass, 2014), others only exhibit a low level of acceptance regarding technology as an alternative to personal contact with an employee (Dabholkar et al., 2003; Lee, 2015). Particularly, SSTs are considered attractive for people who appreciate a high level of individual control and have a low need for personal interaction with a salesperson when making a buying decision (Meuter et al., 2000; Gelderman et al., 2011). Such large differences in the assessment of technology may be explained by very specific servicerelated customer needs and a wide range of buying behaviours. It therefore becomes imperative for firms 
to develop new ways to understand and manage the heterogeneity in their customers' usage of the SSTs in order to deliver the highest possible benefit to the users and to ensure a high level of acceptance (Bolton \& Saxena-Iyer, 2009).

As differences among customers, their needs and technology usage behaviours seem to exist (Lee et al., 2010), general statements on technology acceptance are probably inadmissible (Neslin \& Shankar, 2009). Burton-Jones and Hubona (2005) clearly point out that explanatory models without the consideration of these differences are incomplete and inaccurate predictors of usage behaviour. While the analysis of user characteristics as mediating or moderating effects are limited by nature to explaining single relationships between constructs, segmentation approaches provide the opportunity to identify group differences in a broader setting. Hence and building on the work of Legris et al. (2003) and Devolder et al. (2012), the present paper proposes to build segments in order to take such large differences in technology acceptance into account.

To the best of the authors' knowledge, no study has examined technology acceptance as a basis for segmentation to date. Some studies came up with meaningful segments based on psychographic variables such as involvement (e.g., McKechnie et al., 2006; Teichert et al., 2008). However, psychographic drivers of acceptance are hardly changeable. Hence, the interesting question is not how changes in psychographic factors influence the acceptance, but rather how the level of acceptance differs between people with different psychographic profiles. This research is the first to combine technology acceptance and customer segmentation and thereby contributes to the present literature by (1) demonstrating that meaningful customer segments can be built on the basis of technology acceptance, (2) describing these segments with regard to both technology-related and psychographic criteria, and (3) deducing targeting strategies for an effective customer orientation of SSTs. By showing that distinct and meaningful segments can be established on technology acceptance behaviour, an alternative way of executing technology acceptance studies is proposed that takes the user heterogeneity into account. This provides a more nuanced and differentiated understanding of the user's behaviour.

From a practical standpoint the study addresses the problem that traditional acceptance studies tend to level existing attitudinal and behavioural differences when user segments are not taken into account. 
This may lead to rather general and imprecise customer approach and might explain the failure of some projects in practice (Zhu et al., 2013). Only technologies that are implemented according to the needs of the specific target group will generate a relevant benefit and be used continuously. Based on the description of distinctive user clusters, the study also deduces important managerial implications for the conceptualization and implementation of SSTs.

The remainder of this paper is organized as follows: First, the relevant literature on SST acceptance is presented Concerning the methodology, the research setting and the results of a series of pre-studies are highlighted, followed by a description of the sampling and the measurement instruments. Then, the findings from a cluster analysis are outlined and discussed. Implications for research and practice, limitations of the study and issues for further research conclude the paper.

\subsection{Literature Review}

A systematic literature review in the most influential scientific databases (e.g. EbscoHost, ACM, Science Direct, Econbiz, Emerald, JSTOR, EconStor, IEEE, OLC SSG) is obligatory to obtain a consistent overview of the extant body of research regarding the adoption of service technology in retail. Every possible combination of a predefined group of common search terms regarding technology adoption (e.g. "acceptance") with a group of common search terms regarding the relevant technologies (e.g. "self-service technology") served as search queries. It was deliberately refrained from applying a range of publication for the literature analysis in order to totally capture this rather new research area. All relevant studies were classified and prepared for further analysis. Publications dealing with retailing as a context received particular attention.

\subsubsection{Technology Acceptance Research}

Technology acceptance is a label for a research agenda into the antecedents to the acceptance of new technologies on an individual level, particularly rooted in information systems, psychology, and sociology (Venkatesh et al., 2003). Starting with the now classic technology acceptance model (TAM) by Fred Davis (1986) to study technology usage at work, a large stream of research has developed over time to study the use of various technologies in different settings (e.g. Venkatesh \& Davis, 2000; 
Venkatesh et al., 2007; Losch \& Schulz, 2010; Lawry \& Choi, 2013). To date, TAM is among the most widely accepted frameworks to understand individuals' adoption of new technologies (King \& He, 2006).

TAM is mainly influenced by the theory of reasoned action (Ajzen \& Fishbein, 1980; Bagozzi et al., 1992) and social cognitive theory (Bandura, 1986). According to the initial TAM, two core factors determine the adoption of a technology: Perceived usefulness and perceived ease of use. Perceived usefulness describes "the degree to which a person thinks that using a particular system would enhance his or her job performance" (Davis, 1989, p. 320), and ease of use "the degree to which a person believes that using a particular system would be free of effort". The TAM has proven to be a salient model to predict potential technology usage by measuring user's beliefs after they are exposed to the system (Yang \& Yoo, 2004). Its simplicity, robustness and high explanatory power are likely core reasons for its prominence in various disciplines (Turner et al., 2010; King \& He, 2006; Yousafzai et al., 2007).

At the same time, TAM's simplicity also constitutes a weakness and evoked both criticism for too narrowly focusing on few utilitarian constructs (Bagozzi, 2007) and the notion of the high inherent robustness of the model (King \& He, 2006). As a consequence and to augment the explanatory value of the predictor variables, the model underwent refinements (e.g. by adding additional constructs) by numerous authors (e.g., Venkatesh \& Davis, 2000; Venkatesh et al., 2007; Venkatesh \& Bala, 2008), or it was adapted to specific contexts (e.g. Giannopoulos, 2004; Lee \& Lehto, 2013; Osswald et al., 2012). Prominent examples of TAM extensions are TAM2 (Venkatesh \& Davis, 2000) or TAM3 (Venkatesh \& Bala, 2008).

Venkatesh et al. (2003) synthesized eight theories and acceptance models and proposed a comprehensive 'unified theory of acceptance and use of technology' (UTAUT) that follows a broader holistic approach than TAM. UTAUT received initial empirical evidence in organizational settings. Venkatesh et al. (2012) adapted UTAUT to consumer settings and termed this model UTAUT2.

Various studies have raised criticism of the application of acceptance models in studying retail technologies without adjustments (Bolton \& Saxena-Iyer, 2009; Neslin \& Shankar, 2009; Pantano, 2010). The pitfall of the most frequently applied general approach is that it ignores the heterogeneity 
among the customers who face a technology. Hence, Lee et al. (2005) argue that describing potential technology users "as a homogeneous population may be inaccurate and inappropriate" (Lee et al., 2005). Thus, according to Bruner II and Kumar (2005), building actionable segments is a promising way to increase the prognostic value of technology acceptance research respectively to identify "consumers who might be more inclined to adopt new devices" (Bruner II \& Kumar, 2005).

\subsubsection{Customer Segmentation}

Customer segmentation is a well-known marketing instrument, which is widely used in practice and analysed in a research context (Kim et al., 2006). Particularly when developing new products, services and service technologies, their characteristics have to fit the individual needs of the potential customer groups (Neslin \& Shankar, 2009). Therefore, a well thought-out segmentation is helpful for retailers to serve their customers effectively and to fulfil their needs appropriately. Consequently, as depicted in Table 13, several customer segmentations have been conducted in a retail context in the past, examining mainly psychographic variables.

\begin{tabular}{|c|c|c|c|c|c|c|}
\hline & \multicolumn{2}{|c|}{ Retail context } & \multirow{2}{*}{$\begin{array}{l}\text { SST under } \\
\text { consideration }\end{array}$} & \multirow{2}{*}{$\begin{array}{l}\text { Customer } \\
\text { segmentati } \\
\text { on }\end{array}$} & \multicolumn{2}{|c|}{ Examined variables } \\
\hline & traditional & Online & & & $\begin{array}{l}\text { technology- } \\
\text { related }\end{array}$ & psychographic \\
\hline $\begin{array}{l}\begin{array}{l}\text { Browning } \\
(1985)\end{array} \\
\text { \& }\end{array}$ & $\checkmark$ & - & - & $\checkmark$ & - & $\checkmark$ \\
\hline Lockshin et al. (1997) & $\checkmark$ & - & - & $\checkmark$ & - & $\checkmark$ \\
\hline $\begin{array}{l}\text { Dabholkar \& Bagozzi } \\
(2002)\end{array}$ & $(\checkmark)$ & - & self-service terminal & - & $\checkmark$ & $\checkmark$ \\
\hline Weijters et al. (2007) & $\checkmark$ & - & mobile self-scanning & - & $\checkmark$ & $\checkmark$ \\
\hline Konuş et al. (2008) & $\checkmark$ & $\checkmark$ & - & $\checkmark$ & - & $\checkmark$ \\
\hline Lee et al. (2010) & $\checkmark$ & - & self-service checkout & - & (ひ) & $\checkmark$ \\
\hline $\begin{array}{l}\text { Kowatsch \& Maass } \\
(2010)\end{array}$ & $\checkmark$ & - & $\begin{array}{l}\text { mobile } \\
\text { recommendation agent }\end{array}$ & - & $\checkmark$ & $\checkmark$ \\
\hline Devolder et al. (2012) & - & - & electronic patient record & $\checkmark$ & $\checkmark$ & $\checkmark$ \\
\hline Wang (2012) & $\checkmark$ & - & multimedia kiosk & - & $\checkmark$ & $\checkmark$ \\
\hline Kallweit et al. (2014) & $\checkmark$ & - & $\begin{array}{l}\text { self-service information } \\
\text { technology }\end{array}$ & - & $\checkmark$ & $\checkmark$ \\
\hline Present paper & $\checkmark$ & - & $\begin{array}{l}\text { self-service information } \\
\text { technology }\end{array}$ & $\checkmark$ & $\checkmark$ & $\checkmark$ \\
\hline
\end{tabular}

Table 13: Prior research overview on customer segmentation and technology acceptance

However, and as mentioned above, segmentation on the basis of widely stable psychographic criteria appears muss less promising than to analyse how the level of acceptance differs between people with 
different psychographic profiles. When carrying out a segmentation, Ketchen and Shook (1996) suggest that variables based on an in-depth theory should be applied as key constructs. This paper combines these standpoints and attempts to present a customer segmentation based on technology acceptance constructs (from TAM and UTAUT).

Despite the fact that this approach is novel and has not been pursued empirically yet, the general idea of segmenting customers with regard to their technology usage behaviour has already received some attention. In his well-known diffusion theory, Rogers (2010) suggested that the adoption of products and technologies can be segmented into identifiable groups. He proposed a seminal categorization including the segments innovators, early adopters, early majority, late majority, and laggards.

\subsection{Model Development}

Segmentation starts with the identification of relevant segmentation variables. We apply a theory driven approach to identify these variables. Drawing upon prior technology acceptance research, particularly TAM and its extensions as well as UTAUT2 while taking into account prior research on SST, we generated a list of segmentation variables. Building on a multitude of theories allows to best capture the heterogeneous nature of technology users. However, when studying novel technologies such as SST in retailing, not all of the original constructs can serve as segmentation variables. This section explains the development of the model and necessary adjustments of established theories.

UTAUT and UTAUT2 have been developed for applications where users already had first experiences with a technology or already owned it. The purpose of this study mainly focuses on consumer's reactions to a very new technology - here: self-service technologies at the point of sale. Thus, not all of UTAUT2's and TAM's determinants might be relevant, and the uniqueness of the technology requires the incorporation of additional factors. For example, the price value of a technology is unlikely to play a substantial role on SST usage, as consumers usually are not aware (and typically don't care) about the price of a SST. Likewise, habit and social influences are unlikely to be existent for a novel SST where neither a person, nor its peers, have any form of prior experience with and knowledge about. However, 
performance and effort expectancies, as well as hedonic motivations are relevant technology acceptance factors (e.g., as covered in TAM3 and UTAUT2).

Dabholkar and Bagozzi (2002) argue that PU is irrelevant for users who do not own the device as the usefulness of a technology does not lie in the device itself but in the information displayed on it. More explicitly, Benbasat and Barki (2007) questioned the true insightfulness of PU: "the knowledge that 'usefulness is useful' has, in fact, provided little in terms of actionable research and hence a paucity of recommendations to direct design and practice (p. 213)." Indeed, not the SST itself constitutes the usefulness for a customer but rather the information that is accessed through the technology satisfies the customer's particular need. Hence, the usefulness dimension is operationalized differently to TAM: Instead of PU, the perceived information quality (PIQ) is applied. PIQ refers to the additional value customers associate with the SSIT (Childers et al., 2002; Weijters et al., 2007). Yang et al. (2005) conceptualize PIQ as a construct consisting of the adequacy of information (AI, referring to the quantity of information) and the usefulness of content (UC, referring to the quality of information).

Some authors included further constructs such as privacy concerns (Rauschnabel \& Ro, 2016) or hedonic benefits (Dabholkar \& Bagozzi, 2002; Venkatesh \& Bala, 2008) in the model. Hedonic benefits are conceptualized in TAM as perceived enjoyment (PE), defined as the extent to which the activity of using a technology "is perceived to be enjoyable in its own right" (Davis et al., 1992, p. 1113). For the purpose of this research, it is built on the basic premise of TAM and its extensions by incorporating utilitarian and hedonic benefits.

Moreover, variations of the TAM, including the perceived service quality (PSQ), are of particular interest in the context of retail SSTs (Dabholkar, 1996; Weijters et al., 2007) as PSQ becomes an increasingly critical factor in developing or maintaining a competitive advantage for bricks-and-mortar retailers and constitutes the key benefit of service technologies (Kallweit et al., 2014). PSQ develops from the comparison between the expectation of a service and the perception of the way the service has been performed (Parasuraman et al., 1985). 
The total of all context-specific adaptions of the original TAM are illustrated in Figure 10. These technology acceptance constructs are important for the context of this study and therefore serve as a basis for the following segmentation.

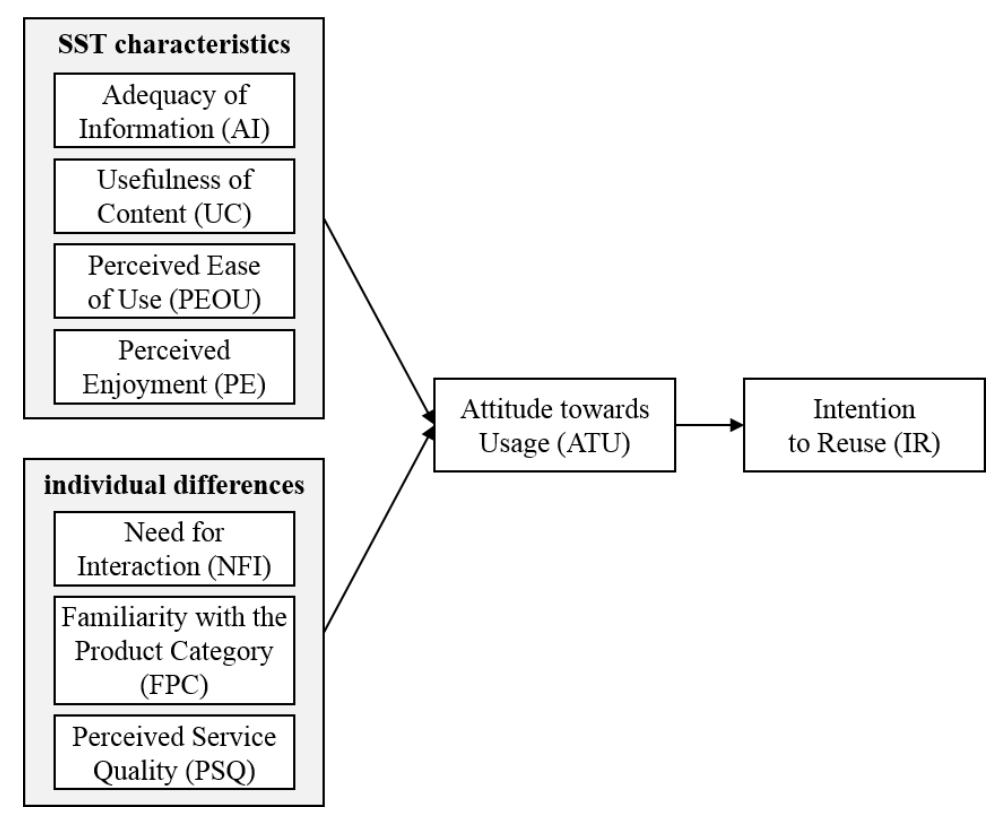

Figure 10: Underlying acceptance model for the segmentation

\subsection{Research Methodology}

\subsubsection{Research setting and prestudy}

For the empirical analysis, a retail sector that was particularly convenient for the implementation of interactive information systems was sought. The following criteria were identified as relevant: Firstly, the sector should have a high standardization potential regarding the questions salespeople are confronted with (e.g. Which product satisfies my needs best? What are technological characteristics of a specific product? How do specific products differ?) Secondly, the sector should exhibit a relevant proportion of complex and not self-explanatory product categories, which makes customers look for an aggregated source of information. And thirdly, customers should be highly heterogeneous in terms of information and buying behaviour because this leads to the assumption that the assessment of SSTs also differs significantly, which constitutes one of the prerequisites for a meaningful segmentation on the basis of technology acceptance. 
The choice fell on do-it-yourself retailing (DIY), which best meets the above criteria (Davidson et al., 2002; Reutterer et al., 2006). Customer questions are highly standardizable, many product categories such as drilling machines are not self-explanatory and customers (e.g. gardeners, decorators, hobby modellers, professional craftsmen) differ significantly in terms of information and buying behaviour. Moreover, the sector is characterized by a low staff density at the point of sale, which leads to the poor reachability of the employees and enhances the benefit of SSTs. In the past, the selling spaces in European DIY retailing grew continuously while the number of salespeople remained stable (gemaba, 2016). This trend strengthened the need for technology-based service-delivery options. Hence, DIY retailing represents a good context for the present research setting.

The empirical work started with a series of pre-studies to verify the relevance of the constructs identified in the literature review. In expert interviews, employees from DIY markets described a typical sales conversation, including the most frequently asked questions. Using data from unstructured open-ended interviews $(n=5)$, these insights were compared with the customers' perspective to understand the information process in DIY retailing. Special emphasis was paid to constructs that possibly explain the usage of the technology. It became obvious that the familiarity with the product category (FPC) influences the information behaviour. Moreover, differences in the need for interaction (NFI) seemed to shape the information process as well. Additionally, the information gathered in the pre-studies was enriched by behavioural observations of people buying drilling machines, which served as the exemplary product category used for this study.

Then, software for a touch-sensitive SST was developed as a stimulus for the subsequent main study (see Appendix 1). The application enabled customers to retrieve information such as product details, high resolution images, customer reviews, and test results without asking an employee. Moreover, it identified the best-fitting product based on a structured needs assessment and offered the possibility of comparing two or more products directly. In addition, a product filter system including attributes such as the price, the surface to be treated, the intended purpose, customer reviews, the weight, the frequency of use, the battery capacity, and the brand was implemented to offer quick access to product information for customers with a very clear idea of their needs. These functionalities referred to the most relevant 
customer demands raised in the prestudy. The present study builds on a laboratory design in order to have full control over external disturbances. Thus, an artificial shopping environment was created in the room where the data collection took place. The participants were asked to immerse themselves in a concrete shopping scenario, which consists in the need to buy a drill machine in order to fix a curtain rod to a concrete wall. This procedure aimed to reduce the cognitive effort involved in assessing the benefit of the SST and increasing the generalizability of the results. Then, the test subjects were given a brief introduction into using the technology. Afterwards, they were allowed to orientate themselves before using the application in a similar manner to how they would in a store. Following the completion of the task in the scenario, the participants answered a structured online questionnaire regarding their evaluation of the use of the SST.

\subsubsection{Sampling}

A total of 229 potential DIY shoppers was recruited for the study. The data was collected in the centre of a medium-sized German city. Thus, the study was conducted in a market with a comparatively strong penetration of SSTs (Wang, 2012), which had a positive impact on the willingness to participate in the study. $48.5 \%$ of the participants were female. As a high proportion of students participated, $62.0 \%$ of the participants were between 18 and 25 years of age. It was decided to continue the analysis with this relatively heterogeneous sample in terms of age for three reasons: Firstly, King and $\mathrm{He}$ (2006) show that there are no great differences in the construct relationships across different categories of participants in 88 TAM studies: Professionals, students and general users produced very similar results. Secondly, Swinyard and Smith (2003) concluded that technology users tend to be younger and more educated than non-users which is expressed through the sample. And thirdly, the young sample represents the potential users of the SST fairly well as it has a high affinity to technology and a significant need for tools such as drills, having left the parental home.

Before analysing the segments based on the characteristics of the SST users, several descriptive analyses were conducted to obtain an overview of the dataset. $83.8 \%$ of the participants used the product filtering function, whereas only $20.0 \%$ made use of the option to compare two or more products directly. It became apparent that the price $(69.4 \%)$, the surface to be treated $(66.4 \%)$ and the intended purpose 
(e.g., drilling and screwing; $64.2 \%$ ) were the most frequently used filter criteria. Customer reviews also played an important role (45.0\%), while criteria such as the weight, frequency of use, battery capacity, and brand were only rarely applied. Regarding the future use of SSTs, $81.2 \%$ of the participants stated that they would use a similar system at the next convenient opportunity.

\subsubsection{Measurement instruments}

Based on the insights from the literature review and the prestudies, a questionnaire consisting of 33 items was developed (see Appendix 2) to measure the TAM constructs. The items were deduced from previously published multi-item scales based on the work of Davis (1989; PEOU), Dabholkar (1996; PE and 1992; NFI), Yang et al. (2005; AI and UC), Venkatesh et al. (2003; ATU and ITU), Brady and Cronin (2001; PSQ), and Raju (1977; FPC). All items were supposed to be reflective and measured on a five-point Likert scale, ranging from "strongly disagree" (1) to "strongly agree" (5). An initial draft of the questionnaire was compiled in English based on the established constructs before it was translated into the local language (German). Occasionally, the formulations had to be changed slightly in order to suit the current research context and accommodate linguistic peculiarities. Two researchers backtranslated the wording independently to ensure a high-quality translation.

The internal reliability of the scale items was tested by calculating Cronbach's coefficient alpha. The results are presented in Table 14. All constructs were proved to have a good level of reliability. All loadings of the constructs tested were greater than 0.7 (Nunally, 1978), except for PSQ, which was slightly lower (0.665) due to the small number of measurement items. One item of the UC construct was dropped due to low and insignificant loadings ( $\mathrm{SL}=0.21$ ). Another item was added to the FPC construct to improve the applicability to the research context. 


\begin{tabular}{|c|c|c|c|}
\hline Construct & Items & Standardized Loadings & Cronbach's Alpha \\
\hline \multirow[t]{4}{*}{ Perceived Ease of Use } & PEOU1 & .77 & .78 \\
\hline & PEOU2 & .83 & \\
\hline & PEOU3 & .80 & \\
\hline & PEOU4 & .71 & \\
\hline \multirow[t]{4}{*}{ Perceived Enjoyment } & PE1 & .84 & .82 \\
\hline & PE2 & .85 & \\
\hline & PE3 & .73 & \\
\hline & PE4 & .79 & \\
\hline \multirow[t]{5}{*}{ Adequacy of Information } & AI1 & .57 & .76 \\
\hline & $\mathrm{AI} 2$ & .63 & \\
\hline & $\mathrm{AI} 3$ & .80 & \\
\hline & $\mathrm{AI} 4$ & .75 & \\
\hline & AI5 & .81 & \\
\hline \multirow[t]{3}{*}{ Usefulness of Content } & $\mathrm{UC1}$ & .79 & .75 \\
\hline & $\mathrm{UC2}$ & .81 & \\
\hline & UC3 & .83 & \\
\hline \multirow[t]{4}{*}{ Attitude towards Usage } & ATU1 & .88 & .89 \\
\hline & ATU2 & .86 & \\
\hline & ATU3 & .89 & \\
\hline & ATU4 & .84 & \\
\hline \multirow[t]{2}{*}{ Perceived Service Quality } & PSQ1 & .88 & .66 \\
\hline & PSQ2 & .85 & \\
\hline \multirow[t]{4}{*}{ Intention to Use } & ITU1 & .90 & .86 \\
\hline & ITU2 & .75 & \\
\hline & ITU3 & .85 & \\
\hline & ITU4 & .85 & \\
\hline \multirow[t]{4}{*}{ Familiarity with the Product Category } & FPC1 & .92 & .89 \\
\hline & FPC2 & .89 & \\
\hline & FPC3 & .83 & \\
\hline & FPC4 & .83 & \\
\hline \multirow[t]{3}{*}{ Need for Interaction } & NFI1 & .79 & .80 \\
\hline & NFI2 & .83 & \\
\hline & NFI3 & .89 & \\
\hline
\end{tabular}

Table 14: Constructs, loadings and scale reliabilities 


\subsection{Results}

A review of the existing literature did not reveal a prior instance in which a sample was segmented based on technology acceptance. The present study provides a segmentation approach using the process outlined in Figure 11. Building on attitudinal and behavioural aspects of technology acceptance, a threestep approach was applied as recommended by Singh (1990) using the statistic software SPSS.

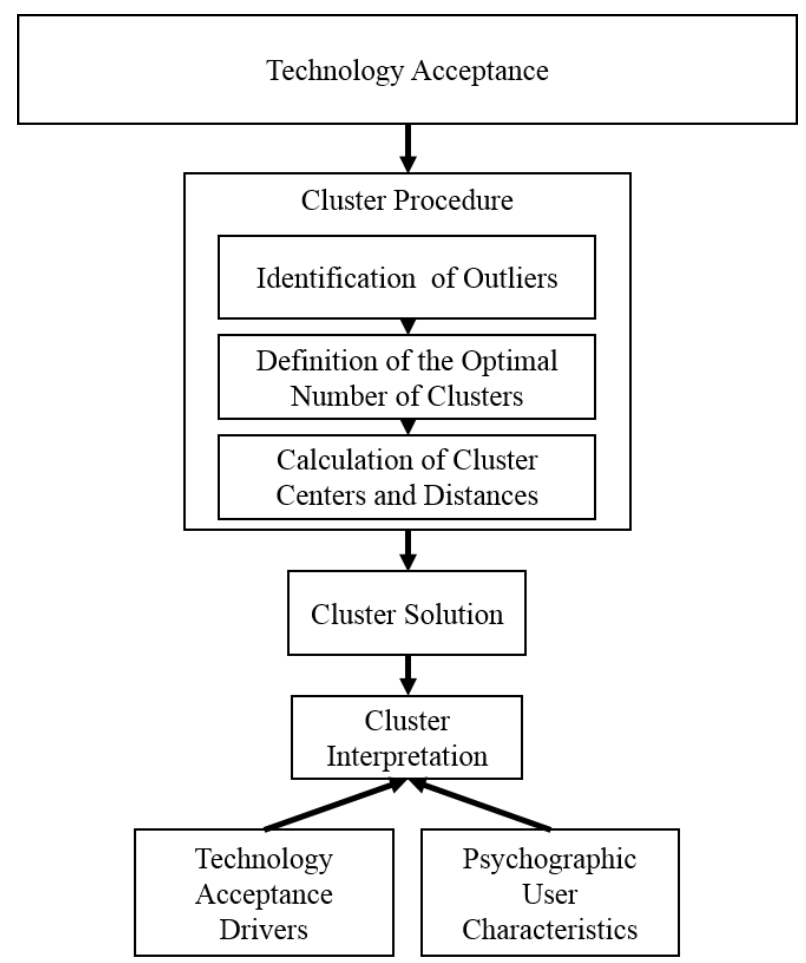

Figure 11: Segmentation procedure model

The first step was to identify outliers using the single-linkage procedure, which tends to fuse extreme values at the end of the clustering process due to its so-called chaining phenomenon (Griffiths et al., 1984). One case was found that did not fit any of the clusters. It removed from the data set.

As a second step, a hierarchical cluster analysis based on the factor scores was conducted using Ward's algorithm, which has proved to be very effective in finding the optimal number of clusters when outliers are removed (Punj \& Stewart, 1983). A screeplot (Appendix 4) indicated that two clusters are convenient for the data. Additionally, the Mojena stopping rule was calculated (Mojena, 1977), which also supported the finding that a two-cluster solution is most suited to the data (Appendix 5). The classification split the sample into clusters comprising 137 and 92 cases respectively (Table 15). Some researchers criticize the calculation of a cluster analysis based on factor scores, claiming that it implies 
a loss of information and leads to less accurate segments (Ketchen \& Shook, 1996). To address this criticism, the suggestions of Ketchen \& Shook (1996) was followed and cluster analyses calculated for both the factor scores and the raw items. The results display a high degree of similarity. Due to the large number of raw items, these clusters were difficult to interpret. Hence, the factor-cluster approach was followed, which is characterized by a clearly comprehensible outcome due to the use of well-established constructs, the meanings of which were clearly defined in extant studies (Frochot \& Morrison, 2001).

\begin{tabular}{lll}
\hline & $\begin{array}{ll}\text { Cluster 1 } \\
(\mathrm{n}=137 ; 59.8 \%)\end{array}$ & $\begin{array}{l}\text { Cluster 2 } \\
(\mathrm{n}=92 ; 4.2 \%)\end{array}$ \\
\hline Technology Acceptance & mean & mean \\
\hline Attitude towards Usage & 4.3 & 3.3 \\
Perceived Service Quality & 4.0 & 2.9 \\
Intention to Use & 4.2 & 3.1 \\
Perceived Ease of Use & 4.4 & 3.9 \\
Perceived Enjoyment & 3.7 & 3.2 \\
Usefulness of Content & 4.2 & 3.6 \\
Adequacy of Information & 3.8 & 3.1 \\
\hline Psychographic User Characteristics & mean & 3.4 \\
\hline Familiarity with the Product Category & 2.7 & mean \\
\hline
\end{tabular}

\section{Table 15: Cluster centres and user characteristics of the end solution}

In a third step, a non-hierarchical cluster analysis using k-means was conducted to obtain the final cluster solution. The mean values from the preceding hierarchical analysis were used as initial cluster centres and distances were calculated using the simple Euclidean distance. The iteratively calculated end solution of the cluster centres and the other profile characteristics for the two clusters are shown in Table 
15. A graphical representation of the mean values of the constructs in each cluster can be found in Appendix 6.

The one-way analysis of variance (ANOVA) shown in Table 16 indicates which dimension of technology acceptance contributes the most to the explanation of the generated clusters: The F-values and the statistical significance are evidence of how well the respective factor distinguishes between groups (Hair et al., 2013). The factors ATU, PSQ, and ITU display by far the highest F-statistics and appropriate mean square errors, which suggests that they are the most suitable for distinguishing between the clusters. The technology acceptance drivers AI, UC, PEOU, PE, NFI, and FPC exhibit smaller F-values. Nevertheless, all of them are proved to be significant on a level of $1 \%$.

\begin{tabular}{llllll}
\hline Factor & Mean & Mean Square & Mean Square & \\
& Difference & Cluster & Error & F & Sign. \\
& & & & & \\
\hline \hline Attitude towards Usage & 1.01 & 56.31 & .30 & 189.56 & $.000^{* * *}$ \\
Perceived Service Quality & 1.22 & 82.06 & .45 & 183.70 & $.000^{* * *}$ \\
Intention to Use & 1.07 & 62.68 & .36 & 173.37 & $.000^{* * *}$ \\
Adequacy of Information & .74 & 3.24 & .27 & 113.45 & $.000^{* * *}$ \\
Usefulness of Content & .66 & 33.68 & .30 & 8.99 & $.000^{* * *}$ \\
Perceived Ease of Use & .54 & 15.90 & .33 & 47.83 & $.000^{* * *}$ \\
Perceived Enjoyment & .53 & 15.39 & .41 & 37.66 & $.000^{* * *}$ \\
Need for Interaction & -.57 & 17.71 & .63 & 28.19 & $.000^{* * * *}$ \\
Familiarity with the Product & -.63 & 21.64 & .90 & 23.93 & $.000^{* * *}$ \\
Category & & & & & \\
\hline NOTE: *** $<<.001$ & & & & & \\
\hline
\end{tabular}

Table 16: Results of the ANOVA

On the basis of these analysis findings the segments may be labelled:

1) Self-service enthusiasts, comprising $59.8 \%$ of the sample, represent those users who have an exceptionally positive attitude toward using the SST and also have a high perception of the delivered service quality. Therefore, they have a strong intention to use the technology again. 
The expected output of the SST, respectively AI, UC, PEOU and PE, is evaluated better compared to the other cluster. Moreover, the cluster is characterized by people with a lesser familiarity with the product category and a lesser need for interaction with a salesperson.

2) Self-service casuals, comprising $40.2 \%$ of the sample, represent those users who have a much less positive attitude towards the SST and a low perception of the service quality compared to the first cluster. Accordingly, the usage intention is also limited. AI, UC, PEOU and PE are only rated on average in this cluster. At the same time, users from this segment exhibit a high familiarity with the product category and greater need for personal interaction.

\subsection{General Discussion}

\subsubsection{Conclusion}

The cluster analysis came up with two distinctive segments. The details are summarized in Table 17. The first cluster evidently stands out due to a higher level of technology acceptance in general. Particularly, perceptible differences can be found concerning ATU (cluster $1=4.3$; cluster $2=3.3$ ) and ITU (cluster $1=4.2$; cluster $2=3.1$ ). Both are assessed better by the first segment, which is thus more likely to use the SST again. Furthermore, in the case of the self-service enthusiasts, the SST provides a higher level of PSQ than the self-service casuals (cluster $1=4.0$; cluster $2=2.9$ ). Obviously, self-service enthusiasts are more likely to adopt SSTs as they perceive relative advantages compared to the traditional way of gathering information (Rogers, 2010).

Moreover, the PEOU (cluster $1=4.4$; cluster $2=3.9$ ) and PE (cluster $1=3.7$; cluster $2=3.2$ ) is rated more highly by self-service enthusiasts who face a buying decision. The same applies to the evaluation of the information quality consisting of AI and UC provided by the SST. It was found that self-service casuals did not recognize the benefit of information provided by the SST for their individual buying decision to the same degree (AI cluster $1=3.8$; AI cluster $2=3.1$ and UC cluster $1=4.2$; UC cluster 2 $=3.6$ ). 


\section{Cluster 1}

self-service enthusiasts self-service casuals

$(n=137 ; 59.8 \%) \quad(n=92 ; 4.2 \%)$

\begin{tabular}{lcl}
\hline \hline Technology Acceptance & & \\
\hline Attitude towards Usage & $(+)$ & $(-)$ \\
Perceived Service Quality & $(+)$ & $(-)$ \\
Intention to Use & $(+)$ & $(-)$ \\
Perceived Ease of Use & $(+)$ & $(-)$ \\
Perceived Enjoyment & $(+)$ & $(-)$ \\
Usefulness of Content & $(+)$ & $(-)$ \\
Adequacy of Information & $(+)$ & $(-)$ \\
\hline
\end{tabular}

Psychographic characteristics and usage behaviour

\begin{tabular}{lll}
\hline Familiarity with the Product Category & $(-)$ & $(+)$ \\
Need for Interaction & $(-)$ & $(+)$ \\
Product comparison tool usage & $(-)$ & $(+)$ \\
Price filter usage & $(+)$ & $(-)$ \\
Ability to make a buying decision & $(+)$ & $(-)$
\end{tabular}

NOTE: (+) higher value compared to the other cluster; (-) lower value compared to the other cluster

Table 17: Summary of the segmentation results

Regarding the psychographic characteristics, the findings reveal that customers from the first cluster are characterized by a low familiarity and limited knowledge of the product category compared to the selfservice casuals (FPC cluster $1=2.7$; FPC Cluster $2=3.4$ ). At the same time the need for interaction with a salesperson is considerably higher in the self-service enthusiast segment (NFI cluster $1=3.4$; cluster $2=4.0$ ). This can be explained as follows: Customers need information to identify a suitable product and make a well-founded buying decision (Berry et al., 2010). The necessary product information can be acquired from two different sources: Firstly, prior knowledge, which refers to experiences from former buying decisions and examinations with similar products stored in the memory (Srinivasan \& 
Agrawal, 1988). People who believe they have a high level of knowledge of the relevant product category such as the self-service casuals also believe that they have enough information in their internal memory and that additional information will not create any additional value. And secondly, external searches, such as point-of-sale media and service technologies (Chaney, 2000). People without considerable prior knowledge, such as the self-service enthusiasts, especially tend to minimize the level of perceived risk involved in the buying process by collecting external information (Bennett \& Harrell, 1975). Therefore, the findings are in line with the work of Schmidt and Spreng (1996), who demonstrate that additional information offers greater value to customers with a low level of product knowledge and a high degree of uncertainty. However, it is not surprising that the PSQ, ATU and the ITU are assessed better by self-service enthusiasts. Members of this cluster have a greater need for general information and therefore, by providing a set of relevant products, the SST seems to be more helpful for making a well-founded product choice. In turn, members of the self-service casuals segment are more familiar with the product category and have a greater need for personal interaction with a salesperson to receive answers to very specific requests.

With regard to the SST usage behaviour, the price filter seems to be more relevant for the self-service enthusiasts segment (cluster $1=72.3 \%$; cluster $2=65.2 \%$ ) whereas the product comparison tool is used more often by self-service casuals (cluster $1=12.4 \%$; cluster $2=28.3 \%$ ). Hence, the usage of filter applications within the two clusters indicates a different relevance of information. Self-service enthusiasts seem to make a product choice based on the price rather than on quality features. Overall, 93.4\% of them stated that they were able to make a buying decision for one of the products offered in the virtual shelf after using the SST compared to the self-service casuals with only $59.8 \%$.

\subsubsection{Implications for Research and Practice}

Retailers providing self-service technologies must effectively segment potential users in order to increase the fit between to benefits of the technology with the needs of the user segment with the highest adoption likeliness. Especially in the introduction period, it appears crucial to identify prospective adopters. This study demonstrates the viability of identifying distinctive consumer segments. By showing that distinct and meaningful customer segments can be established based on technology 
acceptance behaviour, it confirms the assumption that a technology does not fit the needs of all users to the same degree.

This study deepens the current understanding of technology acceptance by conducting an in-depth segmentation study based on TAM constructs and proposes an alternative way of carrying out technology acceptance studies that takes the heterogeneous user behaviour into account. The investigation came up with two clearly separated clusters. A significant proportion of present research from other context such as banking technologies also employs a similar dichotomy in empirical investigation (e.g. Gilly \& Zeithaml, 1985; Gerrard \& Cunningham, 2003; Akinci et al., 2004). The stability of the cluster solution is especially remarkable as the sample used in the empirical analysis was proportionally homogenous in terms of demographic characteristics. Consequently, the results are in line with the findings of Lee et al. (2010), who discovered that demographic factors only have an indirect effect on the acceptance of SSTs. Moreover, the findings of McKenna et al. (2013) were supported who showed that individual adoption constructs are linked to technology-based service offers. The findings on the present study can serve as the basis for developing marketing strategies to target the segments in a differentiated manner.

Furthermore, the results are relevant since prior research indicated that the usefulness of a technology does not lie in the system itself, but in the output delivered by the SST (Dabholkar \& Bagozzi, 2002). The value of the output in turn depends on the specific context of use and personal characteristics of the user. In the analysis, strong evidence for a self-service enthusiasts segment is found that consists of customers who have a high level of SST acceptance along with a positive service quality perception. The members of this segment benefit the most from the information provided by the technology due to their limited knowledge about the product category and a resulting need for information to make a wellfounded buying decision. Hence, these customers are highly relevant as the target group for technologybased self-service providing a basic set of information crucial for their product choice. Retailers are recommended to provide a great depth of information to ensure meaningful search results for every representable user request which is in line with Ahn et al. (2007). Moreover, only highly specific information should be displayed as output to reduce complexity (e.g. one concrete product 
recommendation instead of ten products matching the applied filter criteria). Altogether, it seems reasonable to organize access to the information in a similar way to a sales conversation, e.g. by starting with an indirect needs assessment by asking for the usage intentions of the product.

Unlike the first segment, self-service casuals are less convinced about the service delivered by the SST. The values across all factors of acceptance are considerably lower compared to self-service enthusiasts while the need for personal interaction and the level of product knowledge are higher. As the highly specific needs of those customers cannot be standardized and satisfied adequately through the use of an interactive information system, salespeople should not be replaced by technology. Hence, the SST should be implemented permeably and serve as a digital interface between customer and salesperson, e.g., by including a "call a salesperson" button. Salespeople might use a portable version of the SST as a support system in sales consultations in order to enrich their didactic competence and flexibility through a technology's depth of information (Spreer \& Gutknecht, 2015). Thus, SSTs can be seen as a supplementary tool that relieves salespeople of repetitive tasks and enables them to focus on more complex customer requests.

\subsubsection{Limitations and further research directions}

As discussed above, the findings of the present study contribute to the academic literature and provide concrete managerial implications. However, as in any empirical research, there are possible contentual or methodological limitations that require further consideration.

The replication of the present study in a field environment is recommended to confirm the proposed segmentation. Moreover, as the continuous usage of technology is absolutely crucial for retailers, further research should examine the actual behaviour in addition to the behavioural intention. Therefore, on should conduct longitudinal studies which analyse possible dynamic effects between the clusters that might occur when the technology-related user characteristics change over time. This addresses the general idea of Rogers diffusion theory (2010) that adoption takes place over time and should not be perceived a stable construct. Moreover, the relevance of the portability and size of the device screen in question (kiosk terminal vs. Tablet PC vs. Smartphone) needs to be taken under consideration to identify 
the most proper technological basis for SSTs. Finally, the importance of salespeople for successful selling has already been underlined. The comparison between SST and mobile technologies supporting salespeople could shed some light on the question as to how important face-to-face interaction is in retailing. 


\subsection{References (Study 3)}

Ahn, T., Ryu, S., \& Han, I. (2007). The impact of Web quality and playfulness on user acceptance of online retailing. Information \& Management, 44(3), 263-275.

Ajzen, I. (1991). The theory of planned behaviour. Organizational Behaviour and Human Decision Processes, 50(2), 179-211.

Akinci, S., Aksoy, S., \& Atilgan, E. (2004). Adoption of internet banking among sophisticated consumer segments in an advanced developing country. International Journal of Bank Marketing, 22(3), 212-232.

Bandura, A. (1986). Social Foundations of Thought and Action: A Social Cognitive Theory. Upper Saddle River, NJ: Prentice Hall.

Benbasat, I., \& Barki, H. (2007). Quo vadis TAM?. Journal of the Association for Information Systems, 8(4), 211-218.

Bennett, P. D., \& Harrell, G. D. (1975). The role of confidence in understanding and predicting buyers' attitudes and purchase intentions. Journal of Consumer Research, 2(2), 110-117.

Berry, L. L., Bolton, R. N., Bridges, C. H., Meyer, J., Parasuraman, A., \& Seiders, K. (2010). Opportunities for innovation in the delivery of interactive retail services. Journal of Interactive Marketing, 24(2), 155-167.

Bolton, R., \& Saxena-Iyer, S. (2009). Interactive services: a framework, synthesis and research directions. Journal of Interactive Marketing, 23(1), 91-104.

Brady, M. K., \& Cronin, J. J. Jr. (2001). Some new thoughts on conceptualizing perceived service quality: a hierarchical approach. Journal of Marketing, 65(3), 34-49.

Browning, J. M., \& Zabriskie, N. B. (1985). Do-it yourself consumer: Segmentation insights for retailers. Journal of Consumer Marketing, 2(3), 5-15.

Bruner II, G. C., \& Kumar, A. (2005). Explaining consumer acceptance of handheld Internet devices. Journal of Business Research, 58(5), 553-558. 
Burton-Jones, A., \& Hubona, G. S. (2005). Individual differences and usage behavior: revisiting a technology acceptance model assumption. ACM Sigmis Database, 36(2), 58-77.

Chaney, I. M. (2000). External search effort for wine. International Journal of Wine Marketing, 12(2), $5-21$.

Dabholkar, P. A. (1992). Role of affect and need for interaction in on-site service encounters. Advances in Consumer Research, 19(1), 563-569.

Dabholkar, P. A. (1996). Consumer evaluations of new technology-based self-service options: An investigation of alternative models of service quality. International Journal of Research in Marketing, 13(1), 29-51.

Dabholkar, P. A., \& Bagozzi, R. P. (2002). An attitudinal model of technology-based self-service: Moderating effects of consumer traits and situational factors. Journal of the Academy of Marketing Science, 30(3), 184-201.

Dabholkar, P. A., Bobbitt, L. M., \& Lee, E.-J. (2003). Understanding consumer motivation and behaviour related to self-scanning in retailing: Implications for strategy and research on technologybased self-service. International Journal of Service Industry Management, 14(1), 59-95.

Davidson, W. R., Bates, A. D., \& Bass, S. J. (2002). The retail life cycle. Retailing: The Evolution and Development of Retailing, 55(6), 89-96.

Davis, F. D. (1986). A Technology Acceptance Model for Empirically Testing New End-User Information Systems: Theory and Results, Massachusetts Institute of Technology.

Davis, F. D. (1989). Perceived usefulness, perceived ease of use, and user acceptance of information technology. MIS Quarterly, 13(3), 319-334.

Davis, F. D., Bagozzi, R. P., \& Warshaw, P. R. (1989). User acceptance of computer technology: a comparison of two theoretical models. Management Science, 35(8), 982-1004.

Davis, F. D., Bagozzi, R. P., \& Warshaw, P. R. (1992). Extrinsic and intrinsic motivation to use computers in the workplace. Journal of Applied Social Psychology, 22(14), 1111-1132. 
Devolder, P., Pynoo, B., Sijnave, B., Voet, T., \& Duyck, P. (2012). Framework for user acceptance: Clustering for fine-grained results. Information \& Management, 49(5), 233-239.

Frochot, I., \& Morrison, A. M. (2001). Benefit segmentation: A review of its applications to travel and tourism research. Journal of Travel \& Tourism Marketing, 9(4), 21-45.

Gelderman, C. J., Ghijsen, P. W. T., \& van Diemen, R. (2011). Choosing self-service technologies or interpersonal service - The impact of situational factors and technology-related attitudes. Journal of Retailing and Consumer Services, 18(5), 414-421.

gemaba (2016). 34. Baumarkt-Strukturuntersuchung der Gemaba. Available at http://www.gemaba.de/ StrukturWebsite2016.pdf, Last request 16.12.2013.

Gerrard, P., \& Barton Cunningham, J. (2003). The diffusion of internet banking among Singapore consumers. International Journal of Bank Marketing, 21(1), 16-28.

Gilly, M. C., \& Zeithaml, V. A. (1985). The elderly consumer and adoption of technologies. Journal of Consumer Research, 12(3), 353-357.

Griffiths, A., Robinson, L. A., \& Willett, P. (1984). Hierarchic agglomerative clustering methods for automatic document classification. Journal of Documentation, 40(3), 175-205.

Hair, J. F. Black, W. C., Babin, B. J., \& Anderson, R. E. (2013). Multivariate data analysis (7th ed.), Pearson: Essex.

Kallweit, K., Spreer, P., \& Toporowski, W. (2014). Why do Customers Use Self-Service Information Technologies in Retail? The Mediating Effect of Perceived Service Quality. Journal of Retailing and Consumer Services, 21(3), 268-276.

Ketchen, D. J., \& Shook, C. L. (1996). The application of cluster analysis in strategic management research: an analysis and critique. Strategic Management Journal, 17(6), 441-458. 
Kim, S. Y., Jung, T. S., Suh, E. H., \& Hwang, H. S. (2006). Customer segmentation and strategy development based on customer lifetime value: A case study. Expert systems with applications, 31(1), $101-107$.

King, W. R., \& He, J. (2006). A meta-analysis of the technology acceptance model. Information \& Management, 43(6), 740-755.

Konuş, U., Verhoef, P. C., \& Neslin, S. A. (2008). Multichannel shopper segments and their covariates. Journal of Retailing, 84(4), 398-413.

Kowatsch, T., \& Maass, W. (2010). In-store consumer behaviour: How mobile recommendation agents influence usage intentions, product purchases, and store preferences. Computers in Human Behavior, 26(4), 697-704

Lawry, C. A., \& Choi, L. (2013). The Omnichannel Luxury Retail Experience: Building Mobile Trust and Technology Acceptance of Quick Response (QR) Codes. Marketing ZFP - Journal of Research and Management, 35(2), 144-154.

Lee, E. J., Kwon, K. N., \& Schumann, D. W. (2005). Segmenting the non-adopter category in the diffusion of internet banking. International Journal of Bank Marketing, 23(5), 414-437.

Lee, H. J. (2015). Consumer-to-store employee and consumer-to-self-service technology (SST) interactions in a retail setting. International Journal of Retail \& Distribution Management, 43(8), 676692.

Lee, H. J., Cho, H. J., Xu, W., \& Fairhurst, A. (2010). The influence of consumer traits and demographics on intention to use retail self-service checkouts. Marketing Intelligence \& Planning, 28(1), 46-58.

Lee, H. J., \& Yang, K. (2013). Interpersonal service quality, self-service technology (SST) service quality, and retail patronage. Journal of Retailing and Consumer Services, 20(1), 51-57.

Legris, P., Ingham, J., \& Collerette, P. (2003). Why do people use information technology? A critical review of the technology acceptance model. Information \& Management, 40(3), 191-204. 
Losch, N., \& Schulz, S. (2010). Akzeptanz und Reaktanz von mobilen Diensten. Marketing ZFP Journal of Research and Management, 32(4), 235-258.

Maity, M., \& Dass, M. (2014). Consumer Decision-Making across Modern and Traditional Channels: E-Commerce, M-Commerce, In-Store. Decision Support Systems, 61(1), 34-46.

McKechnie, S., Winklhofer, H., \& Ennew, C. (2006). Applying the technology acceptance model to the online retailing of financial services. International Journal of Retail \& Distribution Management, 34(4/5), 388-410.

McKenna, B., Tuunanen, T., \& Gardner, L. (2013). Consumers' adoption of information services. Information \& Management, 50(5), 248-257.

Meuter, M. L., Ostrom, A. L., Roundtree, R. I., \& Bitner, M. J. (2000). Self-service technologies: understanding customer satisfaction with technology-based service encounters. Journal of Marketing, 64(3), 50-64.

Mojena, R. (1977). Hierarchical grouping methods and stopping rules: an evaluation. The Computer Journal, 20(4), 359-363.

Neslin, S. A., \& Shankar, V. (2009). Key issues in multichannel customer management: current knowledge and future directions. Journal of Interactive Marketing, 23(3), 70-81.

Nunnally, J. C. (1978). Psychometric theory, New York: McGraw-Hill.

Pantano, E., \& Migliarese, P. (2014). Exploiting consumer-employee-retailer interactions in technology-enriched retail environments through a relational lens. Journal of Retailing and Consumer Services, 21(6), 958-965.

Pantano, E., \& Viassone, M. (2014). Demand pull and technology push perspective in technology-based innovations for the points of sale: The retailers evaluation. Journal of Retailing and Consumer Services, 21(1), 43-47.

Parasuraman, A., Zeithaml, V. A., \& Berry, L. L. (1985). A conceptual model of service quality and its implications for future research. Journal of Marketing, 49(4), 41-52. 
Punj, G., \& Stewart, D. W. (1983). Cluster analysis in marketing research: review and suggestions for application. Journal of Marketing Research, 20(2), 134-148.

Raju, P. S. (1977). Product familiarity, brand name and price influences on product evaluation. Advances in Consumer Research, 4(1), 64-71.

Reutterer, T., Mild, A., Natter, M., \& Taudes, A. (2006). A dynamic segmentation approach for targeting and customizing direct marketing campaigns. Journal of Interactive Marketing, 20(3/4), 43-57.

Rogers, E. M. (2010). Diffusion of innovations (4th ed.), New York: The Free Press.

Schmidt, J. B., \& Spreng, R. A. (1996). A proposed model of external consumer information search. Journal of the Academy of Marketing Science, 24(3), 246-256.

Shamdasani, P., Mukherjee, A., \& Malhotra, N. (2008). Antecedents and consequences of service quality in consumer evaluation of self-service internet technologies. The Service Industries Journal, 28(1), 117-138.

Simon, F., \& Usunier, J. C. (2007). Cognitive, demographic, and situational determinants of service customer preference for personnel-in-contact over self-service technology. International Journal of Research in Marketing, 24(2), 163-173.

Singh, J. (1990). A typology of consumer dissatisfaction response styles. Journal of Retailing, 66(1), 57-99.

Spreer, P., \& Gutknecht, K. (2015). Technologieakzeptanz von Verkäufern als Herausforderung. Marketing Review St. Gallen, 32(6), 30-37.

Srinivasan, N., \& Agrawal, J. (1988). The relationship between prior knowledge and external search. Advances in Consumer Research, 15(1), 27-31.

Sun, H., \& Zhang, P. (2006). The role of moderating factors in user technology acceptance. International Journal of Human-Computer Studies, 64(2), 53-78. 
Swinyard, W. R., \& Smith, S. M. (2003). Why people (don't) shop online: A lifestyle study of the internet consumer. Psychology \& Marketing, 20(7), 567-597.

Teichert, T., Shehu, E., \& von Wartburg, I. (2008). Customer segmentation revisited: The case of the airline industry. Transportation Research Part A: Policy and Practice, 42(1), 227-242.

Venkatesh, V., \& Bala, H. (2008). Technology acceptance model 3 and a research agenda on interventions. Decision Sciences, 39(2), 273-315.

Venkatesh, V., \& Davis, F. D. (2000). A theoretical extension of the technology acceptance model: Four longitudinal field studies. Management Science, 46(2), 186-204.

Venkatesh, V., Morris, M. G., Davis, G. B., \& Davis, F. D. (2003). User acceptance of information technology: Toward a unified view. MIS Quarterly, 27(3), 425-478.

Venkatesh, V., Thong, J. Y., \& Xu, X. (2012). Consumer acceptance and use of information technology: extending the unified theory of acceptance and use of technology. MIS Quarterly, 36(1), 157-178.

Wang, M. C. H. (2012). Determinants and consequences of consumer satisfaction with self-service technology in a retail setting. Managing Service Quality, 22(2), 128-144.

Weijters, B., Rangarajan, D., Falk, T., \& Schillewaert, N. (2007). Determinants and outcomes of customers' use of self-service technology in a retail setting. Journal of Service Research, 10(1), 3-21.

Yang, H. D., \& Yoo, Y. (2004). It's all about attitude: revisiting the technology acceptance model. Decision Support Systems, 38(1), 19-31.

Yang, Z., Cai, C., Zhou, Z., \& Zhou, N. (2005). Development and validation of an instrument to measure user perceived service quality of information presenting web portals. Information \& Management, 42(4), 575-589.

Yousafzai, S. Y., Foxall, G. R., \& Pallister, J. G. (2007). Technology acceptance: a meta-analysis of the TAM: Part 2. Journal of Modelling in Management, 2(3), 281-304. 
Zhu, Z., Nakata, C., Sivakumar, K., \& Grewal, D. (2013). Fix it or leave it? Customer recovery from self-service technology failures. Journal of Retailing, 89(1), 15-29.

Zielke, S., Toporowski, W., \& Kniza, B. (2011). Customer acceptance of a new interactive information terminal in grocery retailing. In Pantano, E. \& Timmermans, H. (Eds.). Advanced technologies management for retailing, Hershey: IGI Global, 289-305. 


\section{Appendix}

Appendix 1: Screenshots from the software application

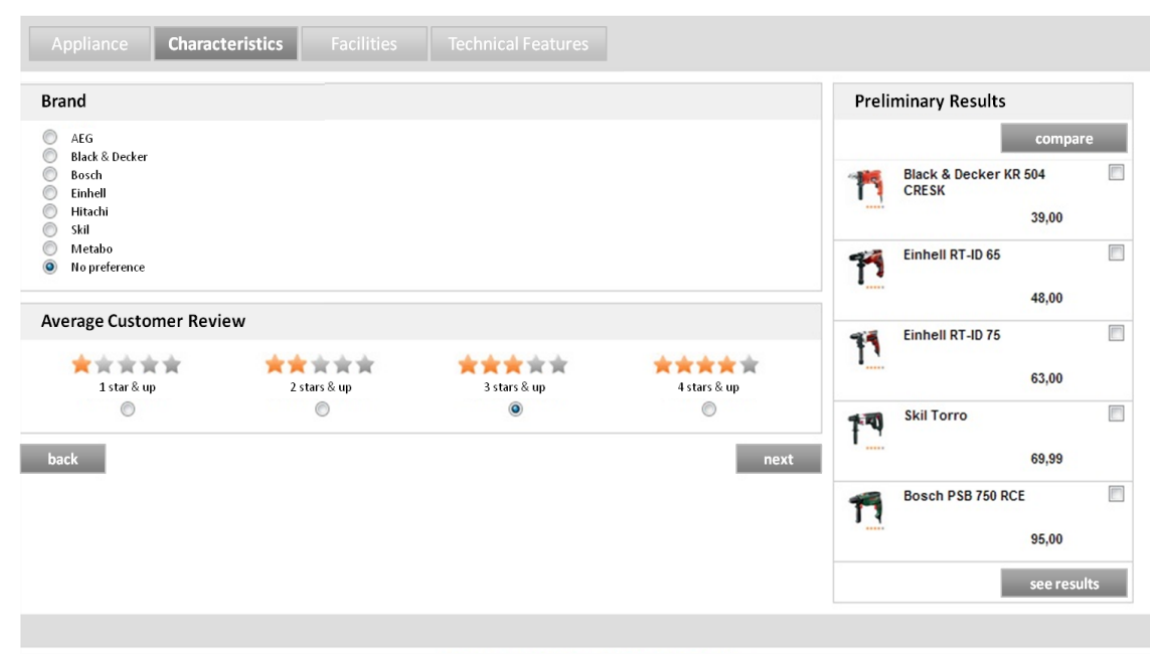

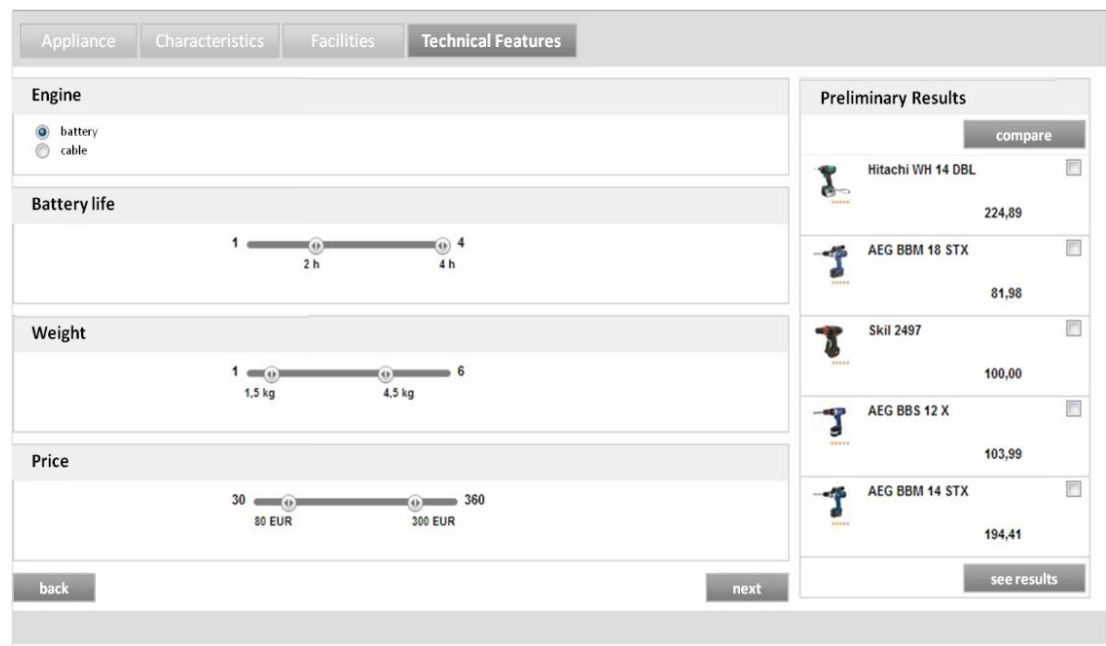

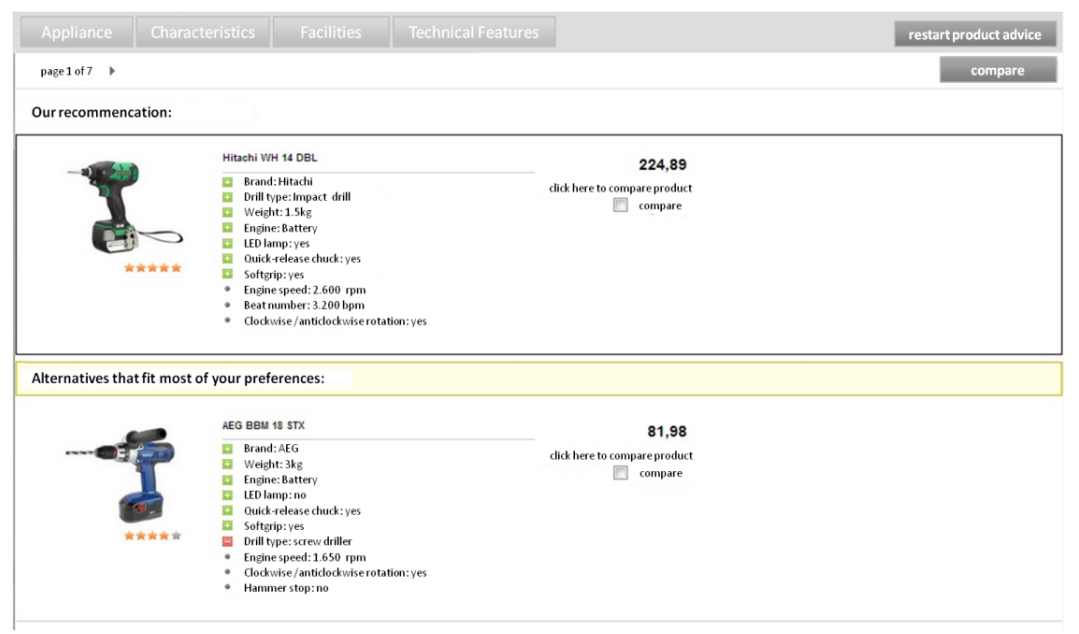


Appendix 2: Construct measurement scales

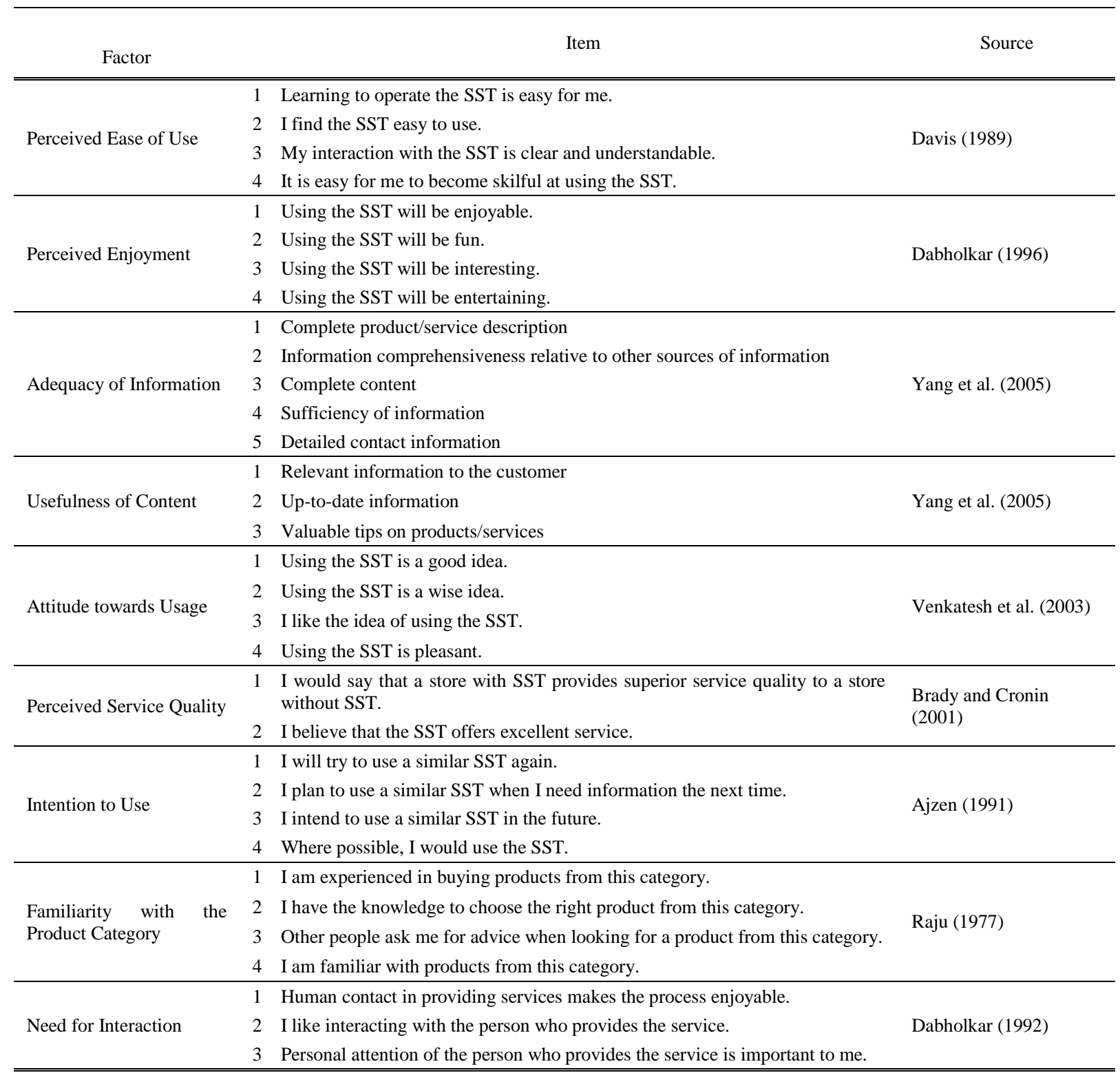


Appendix 3: Dendrogram for the identification of the number of clusters

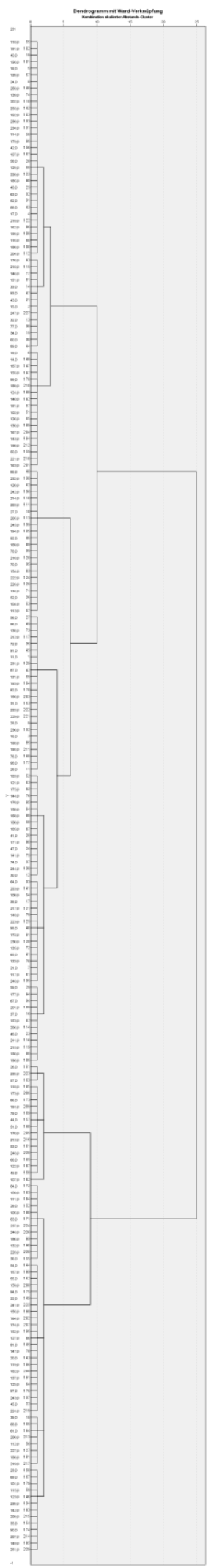


Appendix 4: Screeplot for the identification of the number of clusters

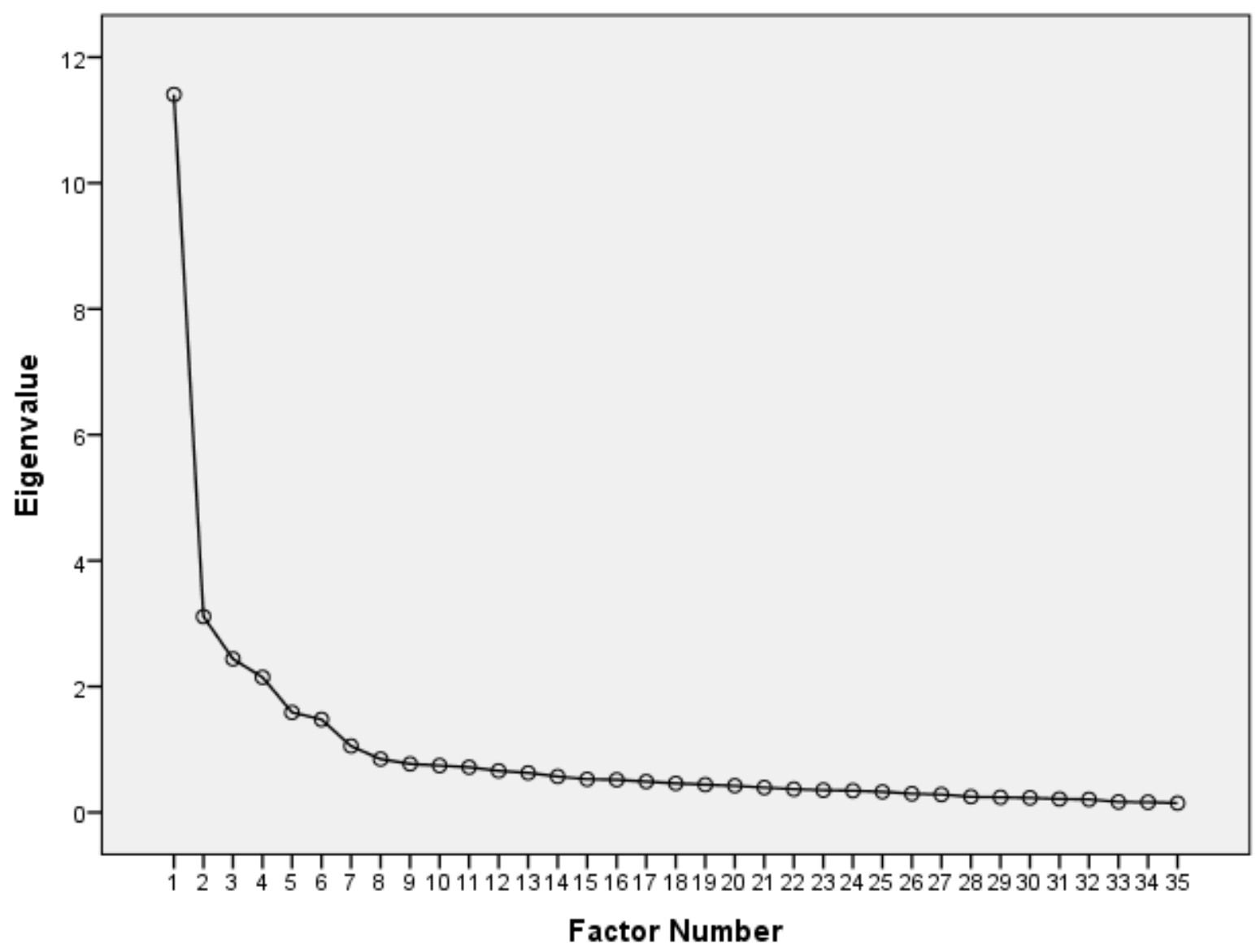

Appendix 5: Application of the Mojena stopping rule

\begin{tabular}{ccrr}
\hline \multirow{2}{*}{ Number of Fusions } & Number of Clusters & Fusion Coefficient $\mathrm{a}_{i}$ & Standardized Fusion Coefficient $\tilde{\mathrm{a}}_{i}$ \\
\hline \hline & 9 & 34.094 & -2.525 \\
2 & 8 & 83.548 & -2.182 \\
3 & 7 & 143.283 & -1.768 \\
4 & 6 & 23.500 & -1.163 \\
5 & 5 & 325.020 & -.507 \\
6 & 4 & 488.886 & .629 \\
7 & 3 & 723.831 & 2.258 \\
$\mathbf{8}$ & $\mathbf{2}$ & $\mathbf{1 1 5 6 . 3 8 8}$ & $\mathbf{5 . 2 5 7}$ \\
\hline
\end{tabular}

The standardized fusion coefficient exceeds the critical threshold of 2.75 in a two-cluster-solution (5.257). Consequently, the results support the findings of the analysis of the dendrogram and the screeplot. 
Appendix 6: Graphic representation of the clusters' mean values

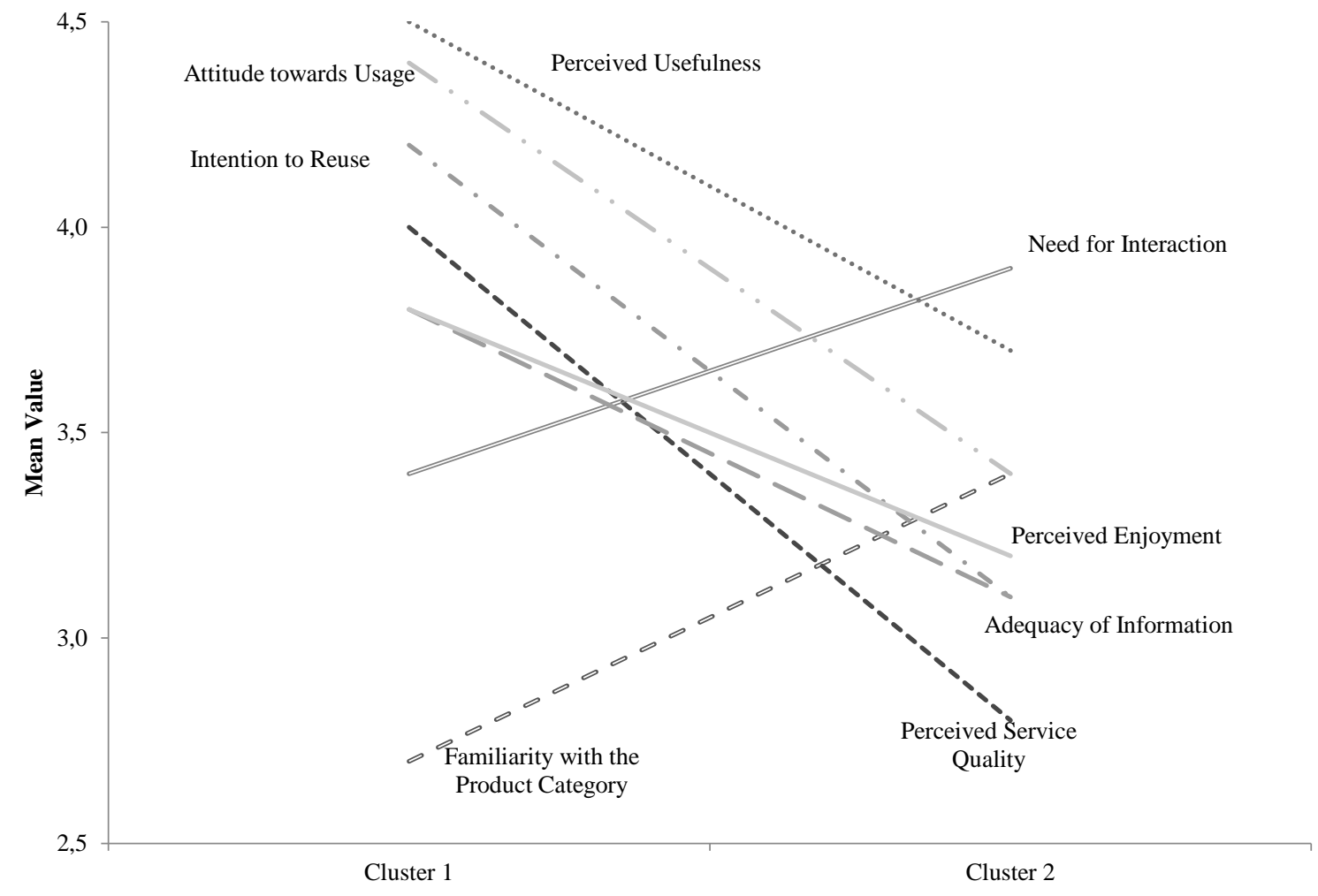




\section{General Conclusion}

\subsection{Research and Practical Implications}

This thesis aimed to address unanswered challenges in research to address the presented challenges of mobile services in the retail environment concerning (1) the analysis of the drivers of mobile service acceptance at the PoS (2) the relationship between acceptance and behavioral intention (3) and the exploration of different segments based on their acceptance of mobile services.

As one of the thesis objectives was to deepen the understanding of mobile service acceptance in-store the relation between the driver of acceptance as well as the behavioral intention based on the technology acceptance model by Davis (1989) was examined. The findings of Papers 1 and 2 add to the understanding of the mobile service acceptance at the point of sale for searching and evaluating products. The findings of studies 1 and 2 affirms that utilitarian benefits are important driver of the mobile service acceptance. As, the value creation using the mobile service offers useful information to the customer to support the customer's path to purchase.

To gain a deeper understanding of the utilitarian aspect within the technology acceptance model respectively, the perceived usefulness study 2 focused on the value of information and the influence on the acceptance. It was found that the quality as well as the quantity have a significant relevance to the evaluation of mobile service. Moreover, the results demonstrate that the quality is more important than the quantity. As retailers try to increase their presence on mobile devices via Apps the risk of choice and information overload increases significantly for shoppers (Shankar et al. 2016). Thus, the results are highly relevant to the information design delivered by a mobile service. This gives an answer to marketers thinking about how to optimize their mobile app design (Shankar et al., 2017).

As the hedonic aspect of a technology is reflected in the ease of use as another driver of technology acceptance, enjoying the usage of the mobile device as a kind of shopping assistant seems to also be relevant. Unexpectedly, this only holds true for study 1 but not for study 2. Perhaps, this can be explained by the different retail sectors. Whereas study 1 deals with consumer electronics which has a strong relation to hedonistic aspects by itself (Chuang and $\mathrm{Li}, 2016$ ) study 2 investigates mobile services in the 
context of do-it-yourself retailing. More precisely, the study is conducted using the product segment of drilling machines, which are used to achieve a defined goal for example to complete a DIY project.

Furthermore, both studies show the basic prerequisite for the ease of use regarding user acceptance. Concerning this matter, the overall user experience should be the first priority and should keep to the usual standards known for good usability. It can be assumed, that the product type has an influence on the driver of acceptance.

The relationship between acceptance and behavioral intention has hardly been examined. This thesis contributes to research by analyzing mediation effects between technology acceptance and behavioral intention. By offering a value-added service through the mobile device of the customer, the retailer can enhance the customer`s in-store experience with positive consequences for the retailer. This is confirmed by the results of study 1 and 2, which demonstrate that perceived service quality as well as the intention to patronage a retail store is also relevant for technology acceptance as it mediates the relationship between the attitude and behavioral intentions. This is highly important for the retailer because the risk of losing the customer during his customer journey to the competition is much lower as if the customer is looking for websites from other (online) retailers.

In the previous section we learned how users interact with a mobile technology at the point of sale and which drivers influence the acceptance. Study 3 has identified different segments based on the customer acceptance of mobile services. The results show that a group of users consider mobile services supporting the in-store decision process to be helpful and convenient (Maity \& Dass, 2014). From a practical point of view, it is important for retailers to know their target group and address the segment with the highest adoption likelihood. Especially in the introduction period, it appears crucial to identify prospective adopters. Therefore, the early involvement of users in the development process to ensure that the technology meets the customer's requirements and offers a real value.

\subsection{Limitations and Further Research}

This thesis has built a foundation to understanding how people react to mobile services. Moreover, we are better able to explain why some users are more likely to use it than others. Retailers can now create incentives and improve their mobile service technologies. Nevertheless, this may not hold true for all 
retailers in the same way. Such mobile services as described in this thesis are well suited for retail segments characterized by a high standardization potential for customer questions and a low staff density with a large sales area at the same time. Thus, the acceptance in other retail segments (e.g. perfume store or small boutiques) can deviate from the sectors presented here and is worth further examination.

A number of limitations and suggestions of how to address them in future studies have been discussed in each study. This chapter provides some inspiration for new areas of research that arise from this dissertation as a whole.

First, we want to address two special properties of the considered technology: the mobility and the ownership of the system. Unlike other in-store technologies, such as self-service terminals or checkout counters, mobile services can be used anywhere in the store. This begs the question to whether or not the mobility of the system is a relevant influencing factor for usage and adoption (Rauschnabel \& Ro, 2016). Particularly for the product search and evaluation, the direct proximity to the product seems to be very important. For instance, features like scanning a product or using augmented reality (Spreer \& Kallweit, 2014) make the search easier and convenient. Therefore, further research should investigate the role of mobility within the technology acceptance model.

Additionally, most of the research in the field of in-store technology has focused on systems owned by the retailer (Pantano \& Viassone, 2014). This thesis conducted mobile services, which are running on the customer's device and offer a service independent of time and place as well as a high ability of personalization (Ström et al., 2014). The customer's smartphone is a very private property and most of owners have an extremely close relationship with their phone. A study found that $61 \%$ of people check their phones 5 minutes after waking up (Genter, 2016). This may turn to more trust in the technology and could be another important driver of acceptance.

Surprisingly, little attention has been given to the relationship between acceptance and behavioral intention. As demonstrated in the thesis, acceptance by the customer has positive consequences for the evaluation of the retailer. Since the investigations of the studies presented before refer only to the behavioral intention, the investigation should be repeated in a field setting with customers in a real-need situation to confirm the proposed research model and the results. Regarding this, the effect of the mobile 
service usage on some of the key store dimensions, e.g. number of visits, purchase frequency, value of the shopping cart or customer satisfaction over an extended period of time, would be of great interest. 


\subsection{References (General Conclusion)}

Chuang, C. W. Li, H. C., \& Li, S. T. (2016). Hedonic Analysis for Consumer Electronics Using Online Product Reviews, 2016 5th IIAI International Congress on Advanced Applied Informatics (IIAI-AAI), Kumamoto, 2016, 609-614.

Davis, F.D. (1989). Perceived usefulness, perceived ease of use, and user acceptance of information technology. MIS Quarterly, 13(3), 319-340.

Gentner, A. (2016). Deloitte Global Mobile Consumer Survey 2016, https://www2.deloitte.com/de/de/pages/technology-media-and-telecommunications/articles/globalmobile-consumer-survey-2016.html, Last request 21.08.2017.

Maity, M., \& Dass, M. (2014). Consumer Decision-Making across Modern and Traditional Channels: E-Commerce, M-Commerce, In-Store. Decision Support Systems, 61(1), 34-46.

Pantano, E., \& Viassone, M. (2014). Demand pull and technology push perspective in technology based innovations for the points of sale: The retailer's evaluation. Journal of Retailing and Consumer Services, 21(1), 43-47.

Rauschnabel, P. A., \& Ro, Y. K. (2016). Augmented reality smart glasses: An investigation of technology acceptance drivers. International Journal of Technology Marketing, 11(2), 123-148.

Spreer, P., \& Kallweit, K. (2014): Augmented Reality in Retail: Assessing the Acceptance and the Potential for Multimedia Product Presentation at the PoS. Transactions on Marketing Research, 1(1), 20-25.

Shankar, V., Kleijnen, M., Ramanathan, S., Rizley, R., Holland, S., \& Morrissey, S. (2016). Mobile shopper marketing: Key issues, current insights, and future research avenues. Journal of Interactive Marketing, 34(C), 37-48.

Ström, R., Vendel, M., \& Bredican, J. (2014). Mobile marketing: A literature review on its value for consumers and retailers. Journal of Retailing and Consumer Services, 21(6), 1001-1012. 


\section{Versicherung}

Promotionsstudiengang „Wirtschaftswissenschaften“"

Ich versichere,

1. dass ich die eingereichte Dissertation

\section{"RETAIL INNOVATIONS - THE USER ACCEPTANCE OF MOBILE SERVICE TECHNOLOGIES AND THE EFFECT ON RETAILER“}

selbstständig angefertigt habe und nicht die Hilfe Dritter in einer dem Prüfungsrecht und wissenschaftlicher Redlichkeit widersprechenden Weise in Anspruch genommen habe,

2. dass ich das Prüfungsrecht einschließlich der wissenschaftlichen Redlichkeit - hierzu gehört die strikte Beachtung des Zitiergebots, so dass die Übernahme fremden Gedankenguts in der Dissertation deutlich gekennzeichnet ist - beachtet habe,

3. dass beim vorliegenden Promotionsverfahren kein Vermittler gegen Entgelt eingeschaltet worden ist sowie im Zusammenhang mit dem Promotionsverfahren und seiner Vorbereitung - kein Entgelt gezahlt oder entgeltgleiche Leistungen erbracht worden sind - keine Dienste unentgeltlich in Anspruch genommen wurden, die dem Sinn und Zweck eines Prüfungsverfahrens widersprechen

4. dass ich eine entsprechende Promotion nicht anderweitig beantragt und hierbei die eingereichte Dissertation oder Teile daraus vorgelegt habe.

Mir ist bekannt, dass Unwahrheiten hinsichtlich der vorstehenden Versicherung die Zulassung zur Promotionsprüfung ausschließen und im Falle eines späteren Bekanntwerdens die Promotionsprüfung für ungültig erklärt werden oder der Doktorgrad aberkannt werden kann.

Göttingen, 28. September 2017

\section{Katrin Kallweit}




\section{Curriculum Vitae}

\section{Professional Experience}

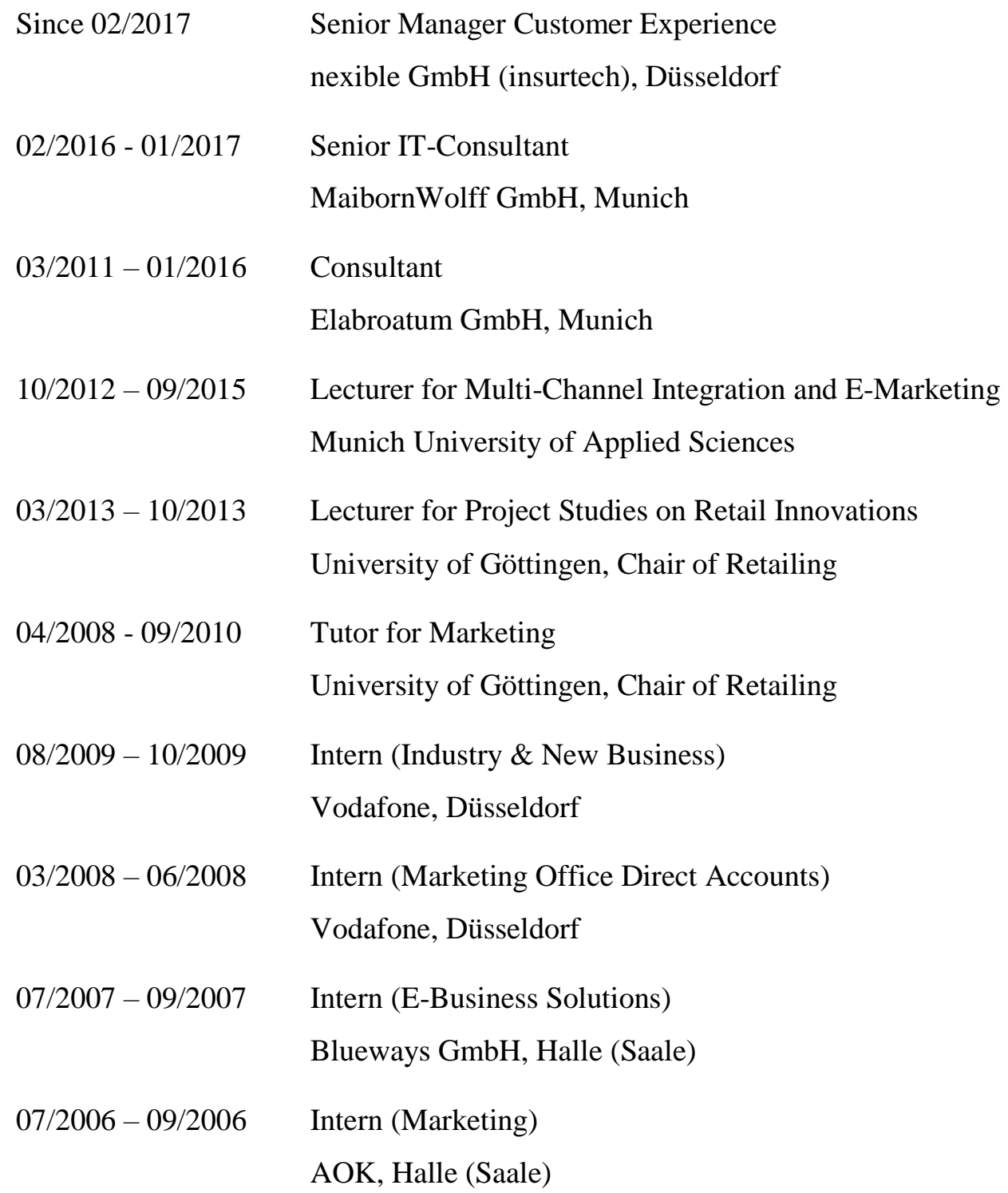

\section{Education}

since $03 / 2011$

since $03 / 2011$

$10 / 2008-11 / 2010$

$10 / 2005-09 / 2008$
Ph.D. student at University of Göttingen, Chair of Retailing (Göttingen)

Göttingen Graduate School of Social Sciences (Göttingen)

Master's Degree in Marketing and Channel Management at University of Göttingen (Göttingen)

Bachelor's Degree in Marketing and Business Informatics at the University of Applied Sciences (Merseburg) 


\section{Publications}

Spreer, P./Kallweit, K. (2015): Differentiation through Service Excellence: The Role of Self-Service Information Technology in Retail, in: Successful Technological Integration for Competitive Advantage in Retail Settings.

Kallweit, K. (2014): Mobile Services im Handel, in: Innovationen im Handel (Hrsg. Funk, D./Gutknecht, K./ Stumpf, J.), 244-268.

Kallweit, K./Spreer, W./ Toporowski , W. (2014): Why do Customers Use Self-Service Information Technologies in Retail? The Mediating Effect of Perceived Service Quality, Journal of Retailing and Consumer Services, 21(3), 268-276.

Spreer, P./Kallweit, K. (2014): Augmented Reality in Retail: Assessing the Acceptance and the Potential for Multimedia Product Presentation at the PoS, Transactions on Marketing Research, 1(1), 20-25.

Mues, S./Wrede, J./Kallweit, K./Stumpf, J. (2013): Multichannel und lebendiger Marktplatz, German Council Magazin, 17(4), 46-48.

Spreer, P./Kallweit, K./Gutknecht, K./ Toporowski, W. (2012): Augmented Retailing. Digital erweiterte Realität im stationären Handel, in: Marketing Review St Gallen, 4(5), 28-32.

Spreer, P./Kallweit, K./Gutknecht, K. (2012): Improving the In-Store Customer Information Process using Mobile Augmented Reality, in: Proceedings of the 11th International Conference on Research in Advertising (ICORIA), June 28-30 2012.

Spreer, P./Kallweit, K./Gutknecht, K. (2012): Improving the In-Store Customer Information Process using Mobile Augmented Reality, in: The Changing Roles of Advertising, European Advertising Academy, Stockholm, 4045.

\section{Review Activities}

International Journal of Retail \& Distribution Management Journal of Retailing and Consumer Services 